\title{
Output Hysteresis and Optimal Monetary Policy*
}

\author{
Vaishali Garga $^{\dagger} \quad$ Sanjay R. Singh ${ }^{\ddagger}$
}

August 2019

\begin{abstract}
We analyze the implications for monetary policy when deficient aggregate demand can cause a permanent loss in potential output, a phenomenon termed as output hysteresis. In the model, incomplete stabilization of a temporary shortfall in demand reduces the return to innovation, thus reducing TFP growth and generating a permanent loss in output. Using a purely quadratic approximation to welfare under endogenous growth, we derive normative implications for monetary policy. Away from the zero lower bound (ZLB), optimal commitment policy sets interest rates to eliminate output hysteresis. A strict inflation targeting rule implements the optimal policy. However, when the nominal interest rate is constrained at the ZLB, strict inflation targeting is sub-optimal and admits output hysteresis. A new policy rule that targets output hysteresis returns the output to the pre-shock trend and approximates the welfare gains under optimal commitment policy. A central bank unable to commit to future policy actions suffers from hysteresis bias: it does not offset past losses in potential output.
\end{abstract}

*FIRST DRAFT: OCTOBER 2016. We owe invaluable debt to Gauti Eggertsson for continuous advice and extensive comments on various versions of this paper. We thank Alexei Abrahams, Francesco Bianchi, James Cloyne, Òscar Jordà, David Glancy, Mark Gertler, Violeta Gutkowski, David Hémous, Peter Howitt, Peter Karadi, Todd Keister, Mrityunjay Kothari, Pascal Michaillat, Neil Mehrotra, Matthias Paustian, Carl Walsh, David Weil, and several seminar participants at Boston Fed, Brown, Federal Reserve Board, Cleveland Fed, Rutgers, Reserve Bank of India, UC Davis, UC Santa Cruz, CEF Fordham, ECB 2017 workshop on Monetary policy in non-standard times, Fifth ECB/CBRT conference, Mid-West Macro 2017, North American Summer Meeting of the Econometric Society 2017 and SED 2018 for helpful comments and suggestions. The views expressed herein are those of the authors and do not indicate concurrence by the Federal Reserve Bank of Boston, the principals of the Board of Governors, or the Federal Reserve System. All errors are our own.

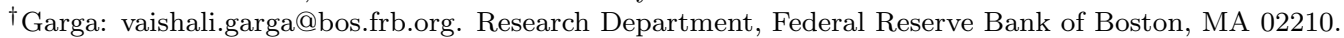

¥Singh: sjrsingh@ucdavis.edu. Department of Economics, University of California at Davis, Davis, CA 95616. 


\section{Introduction}

"... a portion of the relatively weak productivity growth ... may be the result of the recession itself. ... In particular, investment in research and development has been relatively weak... Federal Reserve actions to strengthen the recovery may not only help bring our economy back to its productive potential, but it may also support the growth of productivity and living standards over the longer run."

Janet L. Yellen, Former Chair of the Board of Governors of the Federal Reserve System

In the aftermath of the Great Recession, the US economy has experienced its slowest post-recession recovery since World War II. Ten years in, real GDP is still approximately $15 \%$ below the pre-recession trend (Figure 1). Similar trajectories have been observed in other OECD countries as well (see Martin, Munyan and Wilson 2015). One of the primary drivers of this output shortfall has been slow productivity growth (Hall 2016, Stock and Watson 2016), the source of which has been a subject of extensive debate. Fernald (2014a) and Cette, Fernald and Mojon (2016) show that total factor productivity (TFP) growth started slowing in 2004, three years before the recession started. Thus, they say slowed growth following the recession may not have been due to the recession itself. On the other hand, Decker, Haltiwanger, Jarmin and Miranda (2014) show that the recession accelerated the slowdown in startup entry, which is a significant channel for productivity growth. Similarly, investment in research and development (R\&D), considered to be another important contributor to TFP growth, fell considerably during the recent recession. These facts underscore Chairwoman Yellen's concerns as cited above. ${ }^{1}$

Figure 1: Real GDP

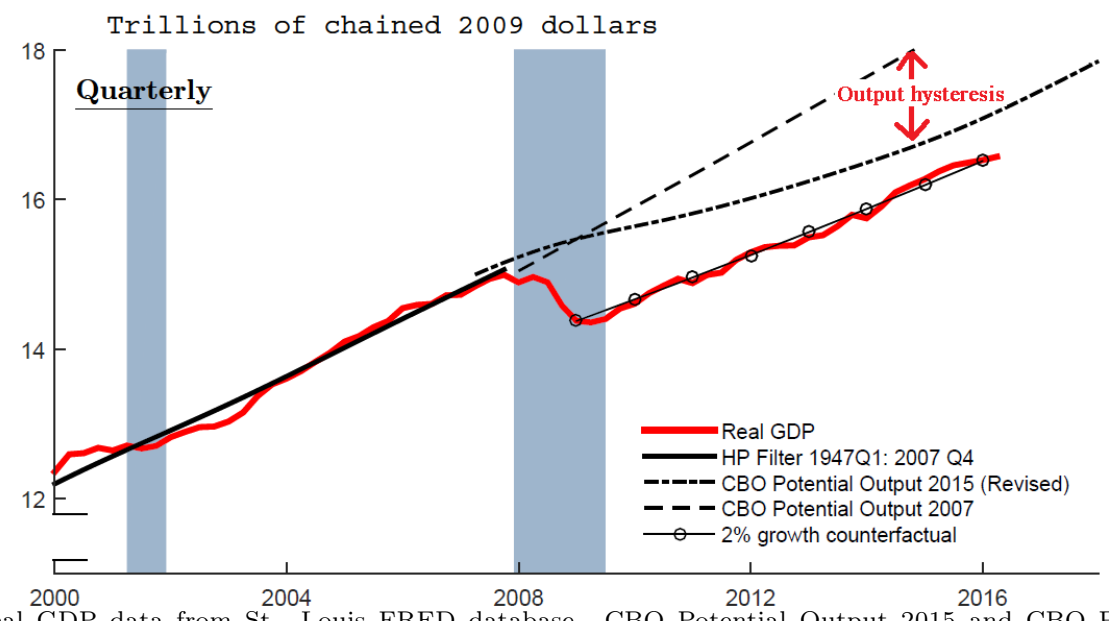

Note: Quarterly Real GDP data from St. Louis FRED database. CBO Potential Output 2015 and CBO Potential Output 2007 estimates are taken from the Congressional Budget Office February 2016 releases. The trend line until 2007Q4 is estimated on quarterly data from 1947 Q1: 2007 Q4 using Hodrick-Prescott filter with a smoothing parameter of 1600 . The solid black line with circles is constructed using $2 \%$ annual growth rate starting from 2009. The shaded areas represent the recessions dated by NBER.

The standard theoretical treatment of monetary policy is largely silent on the interaction of monetary

\footnotetext{
${ }^{1}$ More recently, Yellen (2016) remarked, "Are there circumstances in which changes in aggregate demand can have an appreciable, persistent effect on aggregate supply? Prior to the Great Recession, most economists would probably have answered this question with a qualified "no." ... This conclusion deserves to be reconsidered in light of the failure of the level of economic activity to return to its pre-recession trend in most advanced economies. This post-crisis experience suggests that changes in aggregate demand may have an appreciable, persistent effect on aggregate supply-that is, on potential output." (October 14, 2016)
} 
policy with the productive potential of the economy. ${ }^{2}$ In this paper, we construct a model in which there is such an interaction. We embed a model of Schumpeterian growth along the lines of Aghion and Howitt (1992) and Grossman and Helpman (1991) in a new Keynesian (NK) setting. A contraction in aggregate demand reduces the incentives for firms to invest in $R \& D$, resulting in lower innovation. This leads to an endogenous slowdown in TFP growth, which accumulates into a persistent output gap. Thus, following a recession unemployment returns to its natural rate while output remains below its pre-recession trend. In this framework, monetary policy can affect the long-run potential output of the economy. This is in contrast to the traditional NK models which do not incorporate endogenous productivity and thus incorrectly predict a recovery of output to its pre-recession trend.

Using this framework, we ask whether it is optimal for monetary policy to engineer a recovery back to the pre-recession trend. Optimal policy analysis is the focus and main contribution of this paper. In order to analyze normative implications for the conduct of monetary policy, we derive a closed-form expression for the linear-quadratic approximation of the representative agent's lifetime utility function. This expression generalizes the approximation derived by Benigno and Woodford (2004) to the endogenous growth environment and nests the exogenous growth as a special case. In particular, we decompose the stabilization objectives of the social planner into three key market distortions: a wage inflation gap, a labor efficiency gap and a productivity growth rate gap. Of these, the productivity growth rate gap is novel to the endogenous growth framework and provides an additional rationale for stabilization of short-run fluctuations.

We use this framework to study an economy hit with temporary demand shortfalls. While our quadratic approximation is general, we focus the discussion on liquidity demand and monetary policy shocks because the model exhibits divine coincidence under these shocks. This implies that monetary policy can completely undo these shocks and maintain the economy at the first-best level. An implication of this property is that while the natural rate of interest, $r$-star, is exogenous, the level of potential output becomes an endogenous object. Hence, these shocks allow us to tractably study monetary policy with endogenous growth. In this environment, we define output hysteresis as the gap between the output and its initial deterministic trend. We obtain the following three sets of results.

First, away from the zero lower bound (ZLB), an optimizing policy-maker with ability to commit to future policy actions (optimal commitment policy) sets interest rates to offset the permanent output gap. A standard textbook prescription of strict inflation targeting rule implements the optimal policy. If the central bank strictly targets inflation and the nominal interest rate is away from the ZLB, there is no output hysteresis. Although strict inflation targeting implements optimal policy away from the ZLB, it is unable to stabilize aggregate demand when the ZLB becomes a binding constraint. As a result, a strict inflation targeting rule admit output hysteresis after a ZLB episode. On the other hand, there exist policy rules which, if credibly communicated to the public, could prevent output hysteresis following recessions induced

\footnotetext{
${ }^{2}$ There is a recent synchronous literature that explores these interactions, including Anzoategui et al. (2019), Bianchi, Kung and Morales (2019) and Benigno and Fornaro (2018). Ours is the first paper to analyze the interaction of optimal monetary policy at the ZLB, aggregate demand and endogenous growth. We discuss this at length in the related literature section.
} 
by shortage of aggregate demand, whether or not the ZLB is binding. A new rule where the central bank targets zero output hysteresis emerges in the endogenous growth framework. The central bank commits to keeping interest rates lower until output is back at the initial trend. This hysteresis targeting rule rule signals ex-ante commitment by the central bank to running a high-pressure economy in the future when there is no slack in employment. Thus, we find that output hysteresis is contingent on the monetary policy specification of the central bank.

While the hysteresis targeting rule can eliminate output hysteresis, it raises the question of whether it is desirable to run a high-pressure economy using this rule. Our second set of results speak to this. At the ZLB, the optimal policy response is to credibly commit to keeping future interest rates low in order to incentivize recovery close to the pre-recession trend. A zero output-hysteresis targeting policy rule eliminates all the persistent effects resulting from constrained monetary policy, thereby closely replicating the welfare gains achieved under optimal policy for a feasible range of parameters. This rule has the relative advantage in ease of communicating the central bank's policy stance to the public, unlike optimal policy rules studied in the literature.

Third, and importantly, we uncover a new dynamic inconsistency problem. A policy-maker unable to commit to future policy actions (discretionary policy) does not find in its interest to undo permanent output gaps, following a ZLB period. This means that it is sub-optimal ex post for policy to be redesigned in order to offset the existing output hysteresis. We label this as the hysteresis bias of a discretionary policymaker. It complements our first finding that hysteresis is a consequence of a central bank's policy constraints, in particular, its inability to credibly commit to future policy actions, and not of inept or irrational behavior on part of the central bankers.

On the technical front, the hysteresis bias result may be surprising to scholars of business cycles given that we operate in an environment with an endogenous state variable (level of productivity) influenced by policy levers. Because of linearity assumption in production functions in a broad-class of endogenous growth models (see Jones 2005 for details), past losses in productivity do not affect the allocation of resources between investment and consumption, and are bygones from the policy maker's perspective. Lack of credible monetary policy tools results in permanent output shortfalls. This long-run consequence of policy constraints provides a reason for policy makers to pursue aggressive stabilization policy through implementable rules during times of severe demand shortfalls.

The rest of the paper paper is organized as follows. We begin with a brief review of the related literature. Section 2 proposes a production economy with nominal wage rigidities augmented with endogenous growth. Section 3 discusses the main theoretical results under liquidity demand shocks. A purely quadratic approximation of household's utility function allows us to decompose objectives of the policy-maker into key market distortions/wedges. In Section 4, we provide brief discussion on optimal policy under discount rate shocks and supply shocks. We also summarize findings from a quantitative medium scale model that illustrate the potency of monetary policy in offsetting output hysteresis. An extended discussion on the 
quantitative model including estimated structural impulse responses is relegated to the appendix to keep the paper focused on the optimal monetary policy analysis. Section 5 concludes.

\section{Related Literature}

Our paper is closely related to the recent work of Anzoategui, Comin, Gertler and Martinez (2019), Benigno and Fornaro (2018), Bianchi, Kung and Morales (2019), Garcia-Macia (2015), Guerron-Quintana and Jinnai (2019), Moran and Queraltó (2018) and Queralto (2019) who integrate endogenous growth into a business cycle framework. Among these papers, our framework is most similar to that of Benigno and Fornaro (2018), who identify the possibility of an economy entering a phase of persistent liquidity trap and low TFP growth due to pessimistic expectations. While the model is closest to the one by Benigno and Fornaro (2018), our paper should be seen as complementary. We complement their elegant analysis by studying optimal monetary policy in response to shocks to fundamentals while Benigno and Fornaro (2018) study the possibility that the economy is trapped in the zero lower bound equilibrium. ${ }^{3}$ To our knowledge, ours is the first paper to analyze the desirability of permanent output gaps in the presence of severe demand shocks, particularly relevant once the ZLB is binding. The analytical result on hysteresis bias is new to the literature and has important implications for central bank policy. ${ }^{4}$

Moran and Queraltó (2018) provide empirical evidence in support of the mechanism that monetary policy shocks affect R\&D investment, which in turn affects TFP growth. In a related work, Jordà, Singh and Taylor (2019) using panel data for seventeen advanced countries over 1890-2015, provide causal evidence of persistent effects of monetary policy. ${ }^{5}$ Moran and Queraltó (2018) also build a quantitative endogenous growth model with nominal rigidities and emphasize the importance of ZLB constraint on TFP. Our work complements their analysis by characterizing optimal policy at and away from the ZLB under endogenous growth. Our result on hysteresis bias emphasizes that lack of commitment tools at the disposal of the central bank can lead to persistent drop in output.

We contribute to the optimal monetary policy literature by providing an analytically tractable generalization of the textbook optimal policy problem with nominal rigidities (Woodford 2003, Benigno and Woodford 2004). Recently, a number of papers have explored the implications for optimal monetary policy in a hysteresis-prone environment. Blanchard (2018) provides a detailed survey of the empirical and theoretical advancements in the hysteresis literature. Here we only highlight the papers that relate closest to

\footnotetext{
${ }^{3}$ Our framework cannot rule out stagnation traps of Benigno and Fornaro (2018) without making further assumptions. For example, one can construct fiscal strategies following Benhabib, Schmitt-Grohe \& Uribe (2002) that rule out such traps for a given monetary policy rule. Our analysis implicitly assumes that there exists an equilibrium selection device that allows us to focus on the fundamentals-driven equilibrium.

${ }^{4}$ Stadler (1990) and Fatas (2000) are also important precursors to our paper and this recent literature.

${ }^{5}$ In appendix G.1, we identify quantitatively similar effects of monetary policy shocks on R\&D at the firm-level in Compustat, monthly number of business incorporations from Survey of Current Business, quarterly establishments births from National Private Sector Business Employment Dynamics data, utilization-adjusted TFP series from (Fernald, 2014b) using various external instruments with Jordà (2005) local projections techniques. To keep our discussion focused on optimal monetary policy analysis, we relegate discussion of those results and their robustness to the appendix. Meier and Reinelt (2019) also find that monetary policy shocks affect aggregate TFP. They provide quantitative assessment in support of a misallocation channel through markup dispersion.
} 
ours from optimal policy perspective. Acharya, Bengui, Dogra and Wee (2018) conduct policy analysis in environment with permanent skill-loss from temporary unemployment at the ZLB. Galí (2016) solves for optimal policy in an insider-outsider model of labor markets (Blanchard and Summers, 1986). Erceg and Levin (2014) evaluate monetary policy rules in an environment where workers may exit the labor force, to reconcile the lower labor force participation rates in the economy. We complement these analyses by allowing contractions in demand to negatively affect long-term supply via endogenous productivity growth. Because of the linearity assumption in the production function of endogenous growth model, our setup is analytically tractable. Annicchiarico and Pelloni (2016) study Ramsey policy and Ikeda and Kurozumi (2014) study the use of simple operational rules in an endogenous TFP growth setting away from the ZLB.

We also contribute to the literature on stabilization policy, where DeLong and Summers (2012) and Fatás and Summers (2015) argue that these permanent deviations can be avoided using appropriate policy tools. These two papers focus on fiscal policy as the appropriate mechanism to counteract the permanent negative effects, while our analysis carves out a role for monetary policy as suggested by Yellen (2016) recently. Our theoretical analysis uncovers an implementable policy rule for the central bank that approximates welfare gains achieved under optimal policy. On fiscal policy, we show in Appendix F that investment tax credits are expansionary and in related work, it has been shown that debt-financed fiscal policy can be self-financing in hysteresis-prone environments (see Eggertsson, Mehrotra, Singh and Summers (2016)). However, our focus in the main text is on monetary policy.

Finally, our paper adds to the Hansen/Summers/Gordon secular stagnation literature. While our model can not generate permanent recessions (as in Eggertsson and Mehrotra 2015, Guerrieri and Lorenzoni 2017) due to the representative agent setup, it formalizes how demand-side and supply-side secular stagnation ideas are related. These papers instead employ a permanent shock to the borrowing limit, and hence to the natural interest rate $r$-star. As a result, output is permanently depressed. In our setting, a temporary shock to $r$-star propagates through a slowdown in TFP growth to generate a permanent effect on the level of output. Our paper formalizes that secular stagnation may be a consequence of policy constraints.

\section{A New Keynesian Model with Endogenous Growth}

We integrate a textbook model of endogenous growth into a new Keynesian (NK) environment. Households set nominal wages in staggered contracts following Calvo (1983). ${ }^{6}$ On the production side, we use a discrete time version of the Schumpeterian growth model of Aghion and Howitt (1992), following Aghion and Howitt (2008, Ch. 4). There is a continuum of intermediate goods, each of which is produced by a sector-specific monopolist. Growth results from innovations that raise the productivity in the economy by improving the quality of products. These innovations are undertaken by profit-maximizing entrepreneurs in every sector, who spend final output in research. We delegate the monetary authority with the task of mitigating the

\footnotetext{
${ }^{6}$ Our results do not depend on assuming this specific form of nominal rigidity. Results apply with a quadratic adjustment costs or menu cost frictions that generate money non-neutrality.
} 
effects of nominal rigidities, while fiscal policy is responsible for offsetting the distortions associated with imperfect competition.

There are six main actors in our model - households, wage unions, firms, entrepreneurs, fiscal authority and the central bank - described below.

\subsection{Households \& Wage Setting}

\subsubsection{Households}

There is a continuum of monopolistically competitive households (indexed on the unit interval), each of which supplies a differentiated labor service to the production sector. As is standard, we assume perfect risk sharing within the household. Household derives utility from consuming a final consumption good, disutility from supplying labor and utility from holding a risk-free bond.

$$
\mathbb{E}_{t} \Sigma_{s=0}^{\infty} \beta^{j}\left[\log \left(C_{t+s}\right)-\frac{\omega}{1+\nu} \int_{0}^{1} L_{t+s}(j)^{1+\nu} d j+\xi_{t} \frac{B_{t+1}}{P_{t}}\right]
$$

where $\nu>0$ is the inverse Frisch elasticity of labor supply, $\omega>0$ is a parameter that pins down the steady-state level of hours and the discount factor $\beta$ satisfies $0<\beta<1$.

We use this particular specification of the utility function augmented with taste for holding risk-free bonds in order to introduce the liquidity demand shock $\xi_{t}$. Fisher (2015) models this shock as a micro-foundation for the risk-premia shock considered by Smets and Wouters (2007). The primary reason for our preference for this shock, as we proof shortly in Proposition 2, is that $\xi_{t}$ allows us to maintain divine coincidence (Blanchard and Galí, 2007). ${ }^{7}$ That is, a monetary policy authority following optimal policy rule does not face a trade-off in stabilizing fluctuations in output and inflation arising from such shocks. This shock is an example of purely intertemporal shock considered by Eggertsson (2008) and we think is a desirable ingredient in order to generalize the study of monetary policy to an environment with endogenous TFP growth.

Labor income $W_{t} L_{t}$ is subsidized at a fixed rate $\tau^{w}$. Households own an equal share of all firms, and thus receive $\Gamma_{t}$ dividends from profits, and pay taxes $\tau^{b}$ on their incomes from riskfree bonds. Finally, each household receives a lump-sum government transfer $T_{t}$. Household's budget constraint in period $t$ states that consumption expenditure plus asset accumulation must equal disposable income.

$$
P_{t} C_{t}+B_{t+1}=\left(1-\tau^{b}\right) B_{t}\left(1+i_{t}\right)+\left(1+\tau^{w}\right) W_{t} L_{t}+\Gamma_{t}+T_{t}
$$

Utility maximization delivers the first order condition linking the inter-temporal consumption smoothing

\footnotetext{
${ }^{7}$ We assume that the household cannot issue any risk-free debt $B_{t+1}$. Anzoategui et al. (2019) also use the same specification for the demand shock because this shock induces a co-movement in investment and consumption. This is also a relevant feature for our setting. This shock also has a standard interpretation of a shock to the money in the utility function if the central bank paid interest on reserves. In Section 4, we show the results for standard preference shocks to the household's utility as employed in Eggertsson (2008). Alternately, we could have introduced these shocks through the budget constraint of the household. Amano and Shukayev (2012) show that such shocks are important ingredients for building models with binding ZLB. We prefer introducing them as shocks to the "wealth in the utility" function. Intrinsic desirability for wealth is not unconventional. See for instance Michaillat and Saez (2014) for more references.
} 
to the marginal utility of holding the riskfree bond

$$
1=\beta \mathbb{E}_{t}\left[\frac{C_{t+1}^{-1}}{C_{t}^{-1}}\left(1+i_{t}\right) \frac{P_{t}}{P_{t+1}}\left(1-\tau^{b}\right)\right]+\xi_{t} C_{t}
$$

The stochastic discount factor by which financial markets discount nominal income in period $t+1$ is given by:

$$
Q_{t, t+1}=\beta \frac{C_{t+1}^{-1}}{C_{t}^{-1}} \frac{P_{t}}{P_{t+1}}
$$

The household does not choose hours directly. Rather each type of worker is represented by a wage union who sets wages on a staggered basis. Consequently the household supplies labor at the posted wages as demanded by firms.

\subsubsection{Wage Setting}

Wage setting follows the modeling of Erceg, Henderson and Levin (2000). Perfectly competitive labor agencies combine $j$ type labor services into a homogeneous labor composite $L_{t}$ according to a Dixit-Stiglitz aggregator:

$$
L_{t}=\left[\int_{0}^{1} L_{t}(j)^{\frac{1}{1+\lambda_{w, t}}} d j\right]^{1+\lambda_{w, t}}
$$

where $\lambda_{w, t}>0$ is the (time-varying) nominal wage markup. Labor unions representing workers of type $j$ set wages (with indexation) on a staggered basis following Calvo (1983), taking as given the demand for their specific labor input:

$$
L_{t}(j)=\left(\frac{W_{t}(j)}{W_{t}}\right)^{-\frac{1+\lambda_{w, t}}{\lambda_{w, t}}} L_{t}, \quad \text { where } W_{t}=\left[\int_{0}^{1} W_{t}(j)^{\frac{-1}{\lambda_{w, t}}} d j\right]^{-\lambda_{w, t}}
$$

In particular, with probability $1-\theta_{w}$, the type- $j$ union is allowed to re-optimize its wage contract and it chooses $W_{t}^{*}$ to minimize the dis-utility of working for laborer of type $j$, taking into account the probability that it will not get to reset wage in the future. If a union is not allowed to optimize its wage rate, it indexes wage to steady state wage inflation $\bar{\Pi}^{w}$. Workers supply whatever labor is demanded at the posted wage. The first order condition for this problem is given by:

$$
\mathbb{E}_{t} \sum_{s=t}^{\infty}\left(\beta \theta_{w}\right)^{s-t} C_{s}^{-1}\left[\frac{W_{t}^{*}(j)\left(\bar{\Pi}^{w}\right)^{s-t}}{P_{s}}-\left(1+\lambda_{w, t}\right) \omega L_{s}^{\nu}(j) C_{s}\right] L_{s}(j)=0
$$

By the law of large numbers, the probability of resetting the nominal wage corresponds to the fraction of types who actually change their wage. Consequently, the nominal wage evolves according to:

$$
W_{t}^{\frac{-1}{\lambda w, t}}=\left(1-\theta_{w}\right) W_{t}^{* \frac{-1}{\lambda_{w, t}}}+\theta_{w}\left(W_{t-1} \bar{\Pi}^{w}\right)^{\frac{-1}{\lambda_{w}, t}}
$$




\section{$2.2 \quad$ Firms}

\subsubsection{Final Good producer}

Households consume the final good, which is produced by perfectly competitive firms. These firms use identical production technology employing a homogeneous labor composite supplied by the wage union and a CES composite of intermediate goods weighted by their productivity: ${ }^{8}$

$$
Y_{t}^{G}=M_{t}^{1-\alpha} L_{t}^{1-\alpha} \int_{0}^{1} A_{i t}^{1-\alpha} x_{i t}^{\alpha} d i
$$

where each $x_{i t}$ is the flow of intermediate product $i$ used at time $t$, the productivity parameter, $A_{i t}$ reflects the quality of that product and $M_{t}$ is the stationary (aggregate) productivity shock.

The firms choose $L_{t}$ and $\left\{x_{i t}\right\}_{i \in[0,1]}$ to maximize profits, taking as given both the wage index $W_{t}$ and the prices of the intermediate goods $\left\{p_{i t}\right\}_{i \in[0,1]}$. The inverse demands for labor composite and intermediate good $i$ are given by the following first-order conditions:

$$
\begin{aligned}
& \frac{W_{t}}{P_{t}}=(1-\alpha) M_{t}^{1-\alpha} L_{t}^{-\alpha} \int_{0}^{1} A_{i t}^{1-\alpha} x_{i t}^{\alpha} d i \\
& \frac{p_{i t}}{P_{t}}=\alpha M_{t}^{1-\alpha} L_{t}^{1-\alpha} A_{i t}^{1-\alpha} x_{i t}^{\alpha-1}
\end{aligned}
$$

\subsubsection{Intermediate goods producer}

There is a continuum of intermediate products indexed by $i \in[0,1]$, each of which is produced by an indexspecific monopolist. The monopolist uses one unit of final good to produce one unit of her own good. As a result, every monopolist faces a marginal cost of $P_{t}$. Each intermediate monopolist sets prices flexibly to maximize her firm's profits, taking as given the final sector's demand for its product. In particular, she solves

$$
\max _{p_{i t}}\left(1-\tau^{p}\right) p_{i t} x_{i t}-P_{t} x_{i t} \quad \text { s.t. } \quad \text { inverse demand in eq } 6
$$

where $\tau^{p}$ is a sales tax/subsidy imposed on the monopoly price. Further, we assume that there is a competitive fringe in every sector who can produce the intermediate good with quality $\frac{A_{i t}}{\gamma}$, where $\gamma>1$ is the step-size of innovation and captures the quality distance between the frontier and laggard firms within a sector. As a result, the intermediate monopolist cannot charge a price higher than $p_{i t}=\gamma^{1-\alpha} P_{t}$. In equilibrium, the monopolist charges a price given by:

$$
p_{i t}=\zeta P_{t} \equiv \min \left(\gamma^{1-\alpha}, \frac{1}{\left(1-\tau^{p}\right) \alpha}\right) P_{t}
$$

\footnotetext{
${ }^{8}$ We denote gross output by $Y_{t}^{G}$, to keep it distinct from $Y_{t}$ (defined shortly after), which we refer to as the GDP analog of our model.
} 
The linearity in the use of rival goods in the final goods' production function is an important ingredient here. It makes an intermediate firm's profits linear in the labor demanded by the final good's firm and it's own productivity. ${ }^{9}$ Higher own productivity enables the firm to capture a larger share of the demand for the final good. Profits are given by

$$
\begin{aligned}
\Gamma_{t}\left(A_{i t}\right) & =\chi^{m} P_{t} M_{t} L_{t} A_{i t} \\
\text { where } \chi^{m} & =(\zeta-1)\left(\frac{\alpha}{\zeta}\right)^{\frac{1}{1-\alpha}}
\end{aligned}
$$

\subsubsection{Entrepreneurs}

There is a single entrepreneur in each sector who invests $R D\left(z_{i t}\right) A_{i t}$ of final good in research and development in period $t$, where $R D^{\prime}>0, R D^{\prime \prime}>0 .{ }^{10}$ The dependence on productivity $A_{i t}$ is assumed for stationarity. With probability $z_{i t}$, she is successful in making a process improvement. The productivity in sector $i$ goes up by a factor of $\gamma>1$ (step size of innovation) and she gets the monopoly rights (patent) over production of the intermediate good in the following period. If she fails to innovate, the incumbent monopolist continues to produce with productivity $A_{i t}$ until replaced by a successful entrant. Hence,

$$
A_{i t+1}=\left\{\begin{array}{l}
\gamma A_{i t} \text { with probability } z_{i t} \\
A_{i t} \text { otherwise }
\end{array}\right.
$$

The cost of research is increasing in the innovation intensity chosen by the entrepreneur and the existing level of technology in the intermediate goods' sector in which the entrepreneur operates. Specifically, we assume that $R D\left(z_{i t}\right)=\delta z_{i t}^{\varrho}$, where $\delta>0$ and and $\varrho>1$ is the inverse elasticity of innovation intensity to $\mathrm{R} \& \mathrm{D}$ expenses. $\tau^{r}$ is a research subsidy provided by the government to the entrepreneur. The entrepreneur in every sector chooses $z_{i t}$ to maximize her expected discounted profits (from the patent):

$$
\max _{z_{i t} \in[0,1]}\left\{z_{i t} \mathbb{E}_{t} Q_{t, t+1} V_{t+1}\left(\gamma A_{i t}\right)-\left(1-\tau^{r}\right) P_{t} R D\left(z_{i t}\right) A_{i t}\right\}
$$

where value of the patent is given by:

$$
V_{t}=\Gamma_{t}+\left(1-z_{i t}\right) \mathbb{E}_{t} Q_{t, t+1} V_{t+1}
$$

The value function is linear in productivity due to the linearity in the production function (see appendix A).

\footnotetext{
${ }^{9}$ This linear dependence on productivity is central to endogenous growth models. Jones (2005, Sec 6.2) formalizes this argument as "any model of sustained exponential growth requires that a particular differential equation is linear in some sense".

${ }^{10}$ We follow Aghion, Akcigit and Howitt (2014) in this discrete time analog of their classic Schumpeterian model, but extend it to allow for a more general innovation production function that allows decreasing returns to R\&D. Benigno and Fornaro (2018) use a similar model but with $R D^{\prime \prime}=0$. Assuming $R D^{\prime \prime}>0$ introduces decreasing returns to innovation, which is a feature stressed regularly in the innovation literature. As we will argue in Section 6 , this curvature is a crucial parameter that regulates the quantitative implications of several endogenous growth models.
} 
Writing the normalized value function as $\tilde{V}_{i t} \equiv \frac{V_{i t}}{P_{t} A_{i t}}$ and focusing on the symmetric equilibrium, we solve for interior solution (where $z_{t}>0$ ):

$$
\varrho z_{t}^{\varrho-1}=\beta \mathbb{E}_{t}\left(\frac{C_{t+1}}{C_{t}}\right)^{-1} \frac{\gamma \tilde{V}_{t+1}}{\left(1-\tau_{t}^{r}\right) \delta}
$$

According to equation (12), the entrepreneur chooses innovation intensity so that the discounted marginal revenue of an additional unit of innovation intensity is equal to the marginal cost of this unit. Increase in demand for final good increases the value of obtaining the patent. This is because of the market size effect - for a given cross-sectional distribution of productivities, increase in demand for final good requires higher quantities of intermediate goods to fulfill that demand. Since a monopolist's profits are increasing in the quality of its product, she can capture higher share of the increased market with a successful innovation.

\section{$2.3 \quad$ Aggregation \& market clearing}

The aggregate behavior of the economy depends on the aggregate (which also corresponds to the average in this case) productivity index defined as:

$$
A_{t}=\int_{0}^{1} A_{i t} d i
$$

Because of the linear production function, we can aggregate the firm-level variables to form aggregate composites. Specifically $R D_{t}=\int R D_{i t} d i$ is the total $\mathrm{R} \& \mathrm{D}$ expenditure and $X_{t}=\int X_{i t} d i$ is the aggregate intermediate good produced in the economy. We can rewrite the aggregate output and nominal wage purely in the form of aggregates:

$$
\begin{aligned}
Y_{t}^{G} & =\left(\frac{\alpha}{\zeta}\right)^{\frac{\alpha}{1-\alpha}} M_{t} L_{t} A_{t} \\
W_{t} & =(1-\alpha)\left(\frac{\alpha}{\zeta}\right)^{\frac{\alpha}{1-\alpha}} M_{t} A_{t} P_{t}
\end{aligned}
$$

The growth rate of output in the economy is equal to the growth rate of aggregate productivity:

$$
g_{t+1}=\frac{A_{t+1}-A_{t}}{A_{t}}
$$

In any period, innovations occur in $z_{t}$ sectors and $1-z_{t}$ sectors use previous period's production technology. Aggregating across all the sectors, we get the following equation governing the dynamics of aggregate productivity:

$$
A_{t+1}=\int_{0}^{1}\left[z_{t} \gamma A_{i t}+\left(1-z_{t}\right) A_{i t}\right] d i=A_{t}+z_{t}(\gamma-1) A_{t}
$$

This means that the growth rate of the economy in period $t+1$ is determined in period $t$ and equals the 
number of innovating sectors times the step-size of innovation:

$$
g_{t+1}=z_{t}(\gamma-1)
$$

The number of innovating sectors $z_{t}$ may be interpreted as new entrants since the incumbents do not undertake $R \& D$ investment in our model. The final output produced in the economy is used for consumption, research and production of intermediate goods:

$$
Y_{t}^{G}=C_{t}+R D_{t}+X_{t}
$$

Henceforth, we define $Y_{t}^{G}-X_{t}=\left(1-\frac{\alpha}{\zeta}\right) Y_{t}^{G} \equiv Y_{t}$ as GDP.

\section{$2.4 \quad$ Fiscal \& monetary policy}

To close the model, we assume net zero supply of risk-free bonds: ${ }^{11}$

$$
B_{t}=0
$$

The government's budget is balanced every period, so total lump-sum transfers are equal to intermediategood, labor and research taxes.

$$
P_{t} T_{t}=\tau^{p} \int_{0}^{1} p_{i t} x_{i t} d i+\tau^{r} P_{t} R D_{t}+\tau^{w} \int_{0}^{1} W_{t}(h) L_{t}(h) d h
$$

An independent central bank follows a Taylor rule in setting the nominal interest rate in the economy:

$$
1+i_{t}=\max \left(1,\left(1+i_{s s}\right)\left(\frac{\Pi_{W, t}}{\bar{\Pi}_{W}}\right)^{\phi_{\pi}}\left(\frac{L_{t}}{\bar{L}}\right)^{\phi_{y}} \varepsilon_{t}^{i}\right) ; \quad \phi_{\pi}>1, \phi_{y} \geq 0
$$

The nominal interest rate is set in order to target deviations of wage inflation and employment at respective steady state targets, as long as the implied nominal interest rate is non-negative. $\varepsilon_{t}^{i}$ is defined as a monetary policy shock. ${ }^{12}$

\footnotetext{
${ }^{11}$ We do not allow government debt to offset the increased demand for liquidity to keep the analysis focused on optimal monetary policy. In a recent work, Del Negro, Eggertsson, Ferrero and Kiyotaki (2017) assess the importance of government liquidity facilities during the Great Recession in stabilizing the economy. Similar analysis under endogenous growth and sticky prices following the quantitative model of Guerron-Quintana and Jinnai (2019) is left for future work.

${ }^{12}$ From equation 14, we wish to emphasize that this rule is analogous to the Taylor rule used to represent monetary policy response in an exogenous growth model. Once we normalize $Y_{t}$ by level of productivity $A_{t}$, there is a one to one mapping between employment and normalized output. In the presence of liquidity demand and monetary policy shocks, a rule targeting employment or normalized output are identical.
} 


\subsection{Equilibrium}

We formally define the competitive equilibrium of the economy in appendix A. In order to arrive at a stationary system of equations, we normalize the equilibrium equations by dividing the non-stationary variables such as consumption, output, real wage by the level of productivity. We define $c_{t}=\frac{C_{t}}{A_{t}}$ as the normalized (productivity adjusted) consumption and so forth. This allows us to solve for the steady state.

We find the steady state by imposing restrictions on the parameters such that the steady state satisfies a) $z \in(0,1)$, b) consumption is non-negative and c) nominal interest rates are non-negative. ${ }^{13}$ In appendix $\mathrm{B}$, we analytically characterize the existence and uniqueness of the steady state by imposing additional assumptions on the nature of wage rigidity and the duration of patents granted to the monopolist.

\section{Steady State Efficiency}

Because of the presence of research externalities and monopoly distortions, the private sector equilibrium is inefficient. We define the efficient steady state as the one in which the welfare of the representative household is maximized subject to the production technology of consumption good (eq 14), the law of motion of aggregate productivity (eq 17), and the economy's resource constraint (eq 19) for a given initial productivity. The complete system of equations is provided in appendix D.

Proposition 1 states that the steady state of the competitive equilibrium allocation is inefficient. This is due to the presence of three static distortions in our setup: (i) monopoly power in each intermediate goods sector, (ii) monopolistic competition in the labor market and (iii) inter-temporal research externalities. Whereas the first two distortions are common in the business cycle literature, the third distortion is specific to the endogenous growth literature. The entrepreneur is unable to reap all the benefits of her technology advancement because she gets replaced with positive probability by a new entrant (surplus appropriability effect). This makes her under invest in $\mathrm{R} \& \mathrm{D}$. On the other hand, an entrant replaces the incumbent to profit from the full step size of innovation $\gamma$ rather than the incremental gain in knowledge $\gamma-1$. This business stealing effect (Aghion and Howitt, 1992) incentivizes the entrepreneur to over-invest in R\&D. As a result of these two opposing forces, private investment in research can be higher or lower than the first-best.

We assume that the fiscal authority has access to lump-sum taxes, and so the first best allocation in the steady state can be implemented by a set of constant taxes elaborated in the following proposition:

Proposition 1 (Steady State Efficiency). Assuming the policy maker has access to non-distortionary lumpsum taxes, the steady state of the competitive equilibrium can be made efficient using the following three taxes:

a) sales subsidy $\tau^{p}=1-\frac{1}{\alpha}$

b) labor $\operatorname{tax} \tau^{w}=\frac{1-\lambda_{w}}{\lambda_{w}}$, and

c) research tax $\tau^{r}=1-\left[\left(\frac{\gamma *^{*}(1-\alpha) \alpha^{\frac{\alpha}{1-\alpha}}}{1-\beta\left(1-z^{*}\right)}\right)\left(\frac{1-\beta}{(\gamma-1) c^{*}}\right)\right]$, where terms with $*$ denote the efficient steady state

\footnotetext{
${ }^{13}$ In our numerical simulations, we verify that innovation probability is bounded $z_{t} \in(0,1)$.
} 
values.

Proof. See appendix E

It is commonly argued in the endogenous growth literature that the private sector under invests in $R \& D$ (Jones and Williams 1998), and therefore growth rate is higher in the efficient steady state. These distortions would imply that in the absence of relevant fiscal instruments, monetary policy could affect the growth rate of output in the long-run. We follow the monetary economics literature and suppose that the average productivity growth rate is optimal and independent of monetary policy. As shown by Woodford (2003) and Benigno and Woodford (2004), the linear-quadratic approximation to the social welfare function around the non-stochastic efficient variables is justified if there are no distortions under price stability. In the parlance of the literature, there are no permanent differences between the efficient and natural rate of interest. The idea is to disassociate the welfare losses from fluctuations in growth rate from those arising from suboptimal growth solely due to monopoly distortions and research externalities. We make the following assumption:

Assumption 1. The fiscal authority provides the set of constant subsidies described in Proposition 1 such that the competitive equilibrium is efficient in the steady state.

The crucial difference to note from the earlier monetary economics literature is that monetary policy in our setting has a bearing on the long-run level of output even though we do not allow monetary policy to influence the steady state distortions. We log-linearize the competitive equilibrium around the efficientsteady state and define the following approximate equilibrium: ${ }^{14}$

Definition 2.1 (Approximate Equilibrium). The approximate competitive equilibrium in this economy with endogenous growth is defined as a sequence of variables $\left\{\hat{\pi}_{t}^{w}, \hat{c}_{t}, \hat{y}_{t}, \hat{g}_{t+1}, \hat{i}_{t}, \hat{L}_{t}, \hat{w}_{t}, \hat{\pi}_{t}, \hat{V}_{t}\right\}$ which satisfy the following equations, for a given sequence of exogenous shocks $\left\{\hat{\xi}_{t}, \hat{M}_{t}, \hat{\epsilon}_{t}^{i}, \hat{\lambda}_{w t}\right\} \cdot{ }^{15}$

Aggregate Demand:

$$
-\left(\mathbb{E}_{t} \hat{c}_{t+1}-\hat{c}_{t}+\hat{g}_{t+1}\right)+\hat{i}_{t}-\mathbb{E}_{t} \hat{\pi}_{t+1}+\hat{\xi}_{t}=0
$$

Endogenous Growth equations:

$$
\begin{aligned}
& (\varrho-1) \eta_{g} \hat{g}_{t+1}=-\left(\mathbb{E}_{t} \hat{c}_{t+1}-\hat{c}_{t}+\hat{g}_{t+1}\right)+\mathbb{E}_{t} \hat{V}_{t+1} \\
& \hat{V}_{t}=\eta_{y} \hat{y}_{t}-\eta_{z} \hat{g}_{t+1}-\eta_{q}\left(\mathbb{E}_{t} \hat{c}_{t+1}-\hat{c}_{t}+\hat{g}_{t+1}\right)+\eta_{q} \mathbb{E}_{t} \hat{V}_{t+1}
\end{aligned}
$$

\footnotetext{
${ }^{14}$ In the appendix, we show the necessary condition for local determinacy for the model with perfect wage rigidity and single period patent granted to the monopolist. This derivation generalizes the local determinacy condition derived by Benigno and Fornaro (2018) to include diminishing returns to R\&D investment. However, a closed form representation of determinacy is not possible in our benchmark setup with Calvo wage rigidities and stochastic patent duration. With this caveat in mind, we proceed by assuming local determinacy to characterize theoretical implications for policy. In all numerical simulations, we verify the local determinacy of the efficient steady state.

${ }^{15}$ For any variable $x, \hat{x}_{t}=\log \left(\frac{x_{t}}{\bar{x}}\right)$, where $\bar{x}$ is the efficient/non-distortionary steady state. With few exceptions: $\hat{g}_{t+1}$ is the deviation of gross growth rate from the steady state value that is $\hat{g}_{t+1} \equiv \log \left(\frac{1+g_{t+1}}{1+\bar{g}}\right)$. We verify that the growth rate is always non-negative in numerical simulations. The log-linearized representation of liquidity demand shock $\hat{\xi}_{t} \equiv c A_{t} \xi_{t}$ since the steady state value of the shock $\xi$ is assumed to be $0 . \hat{\xi}_{t}$ is scaled-version of the non-linear liquidity demand shock, where the scaling variable is the balanced growth level of consumption under flexible wages. $\mathrm{AR}(1)$ shock to $\xi_{t}$ maps one-to-one to a shock to $\hat{\xi}_{t}$.
} 
where $\eta_{g}=\frac{1+g}{g}>1, \eta_{y}=1-\frac{(1-z) \beta}{1+g}>0, \eta_{z}=\frac{\beta}{\gamma-1}>0, \eta_{q}=\frac{(1-z) \beta}{1+g}>0$

Market clearing:

$$
\begin{aligned}
& \frac{c}{y} \hat{c}_{t}+\frac{\mathbb{R}}{Y} \varrho \eta_{g} \hat{g}_{t+1}=\hat{y}_{t} \\
& \hat{y}_{t}=\hat{M}_{t}+\hat{L}_{t}
\end{aligned}
$$

Wage setting:

$$
\begin{aligned}
& \hat{\pi}_{t}^{w}=\tilde{\beta} \mathbb{E}_{t} \hat{\pi}_{t+1}^{w}+\kappa_{w}\left[\hat{c}_{t}+\nu \hat{L}_{t}-\hat{w}_{t}\right]+\kappa_{w} \hat{\lambda}_{w t} \\
& \hat{w}_{t}=\hat{M}_{t} \\
& \hat{\pi}_{t}^{w}=\hat{w}_{t}-\hat{w}_{t-1}+\hat{\pi}_{t}+\hat{g}_{t}
\end{aligned}
$$

where $\kappa_{w} \equiv \frac{\left(1-\theta_{w}\right)\left(1-\beta \theta_{w}\right)}{\theta_{w}\left(1+\nu\left(1+\frac{1}{\lambda_{w}}\right)\right)}>0$

Monetary policy rule:

$$
\hat{i}_{t}=\max \left(-\frac{\bar{i}}{1+\bar{i}}, \phi_{\pi} \hat{\pi}_{t}^{w}+\phi_{y} \hat{L}_{t}+\hat{\varepsilon}_{t}^{i}\right)
$$

The aggregate demand, market clearing and wage Phillips curves are familiar to scholars of the new Keynesian business cycle literature. The new ingredient is the endogenous growth block (eqns 23-24). It is a log-linear transformation of profit-maximization condition of the entrepreneur.

The endogenous growth condition (eq 23) states that the entrepreneur makes her R\&D investment decision based on the expected present discounted value of the future profits. Thus there are two forces governing her decision: the rate at which she discounts the future, and the expected value of future profits. In our model, the households retain ownership over all firms. Therefore, the rate at which a firm discounts the future is given by the stochastic discount factor of the household. A higher stochastic discount factor increases the entrepreneur's incentive to innovate (discounting effect) because of lower discounting of future profits. Second, higher expected future output increases her incentive to invest in innovation because of the market size effect, discussed above. Furthermore, a percentage change in innovation investment translates into $\frac{1}{\varrho \eta_{g}}$

p.p. change in productivity (gross) growth rate, where $\frac{1}{\varrho}$ is the elasticity of innovation intensity, and $\varrho$ is assumed to be greater than 1 following the innovation literature (see Acemoglu and Akcigit 2012). This implies decreasing returns to investment in innovation- a higher value of $\varrho$ signifies lower responsiveness of innovation success (and productivity growth rate as a result) to innovation investment.

\section{Equilibrium Concepts and Policy instruments}

We now provide a brief discussion of the natural rate allocation, the first-best allocation and the pre-recession trend allocation under the endogenous growth setting. Importantly, we underscore the subtleties introduced in the endogenous growth setup relative to the exogenous growth setting. This allows us to formally define potential output, which becomes an endogenous object under endogenous growth.

We assume that the (normalized) economy is in the efficient steady state at beginning of time $t=0$. The 
first-best allocation is the competitive equilibrium allocation under flexible wages such that the fiscal authority utilizes (non-distortionary) time-varying taxes in order to maximize the representative agent's welfare. The natural-rate allocation (or interchangeably flexible-wage allocation) is the competitive equilibrium allocation under flexible wages such that the fiscal authority provides (non-distortionary) constant tax instruments outlined in Proposition 1.

Under liquidity demand and monetary policy shocks, the natural-rate and the first-best allocations coincide. Moreover, these shocks do not affect the flexible-wage equilibrium output, consumption and investment in R\&D. The economy stays on the initial balanced growth path (BGP), also referred to as the pre-recession trend. Thus, any change in output in the sticky-wage economy emerges solely because of nominal rigidities. An implication of this statement is that the natural rate of interest, $r$-star, is exogenous even in the presence of endogenous growth. This helps to isolate the role of monetary policy. For the sake of transparency, our main analysis in this paper is conducted with these two shocks. We provide a brief discussion of discount rate shocks, cost push shocks and stationary TFP shocks in Section $4 .{ }^{16}$

Whether potential output is endogenous or not depends on the precise definition. There are two concepts of price/wage flexibility in the presence of a pre-determined state variable. One is the Neiss and Nelson (2003) definition of flexible wages, under which wages have been set flexibly since time 0 and remain flexible indefinitely. Wages set under this concept are called time-0 flexible wages. Second concept of flexibility is the Woodford (2003)'s definition where wages are set flexibly in the current and future periods taking as given the evolution of state variable. Wages set under this concept are called time-t flexible wages. Based on two concepts of flexible wages, there are time-0 first best, time-0 natural rate, time-t first best and time-t natural rate allocations. We provide formal definitions in the appendix section D.9. To avoid clutter of notation, henceforth we will use first best allocation for time-0 first best allocation and natural rate for time-0 natural rate allocation whenever possible without ambiguity. For the ease of exposition, we refer to time-0 flexible wages as flexible wages. We define potential output as the level of output that coincides with the time-t first-best allocation. We believe this is more appealing definition than the one based on time- 0 concept because it coincides with the maximum non-inflationary output an economy can produce at a given time.

We emphasize that the distinction between two natural rate concepts defined here is different from that imposed in exogenous growth environments with capital investment (Edge 2003). In our benchmark endogenous growth model, the natural rate of interest is always same under the two concepts of flexibility. Only the levels of productivity and output differ. Importantly, this difference in levels may be permanent depending on the central bank's policy rule. In contrast, the introduction of capital investment introduces a temporary difference in the levels of capital, output as well as the interest rates depending on the nature of flexibility assumed. In those models, there is no medium or long-run difference between various concepts

\footnotetext{
${ }^{16}$ The distinction between the natural-rate, the first-best and the pre-recession trend allocations will become crucial in Section 4. This is because under discount rate and supply shocks there can be a divergence among these concepts. Thereafter, in order to provide a data counterpart for hysteresis, we define hysteresis as the deviation of output under a competitive equilibrium allocation from the pre-recession trend. Under liquidity demand and monetary policy shocks, it does not matter whether the output hysteresis is defined as deviation from the (time-0) first-best or the (time-0) natural rate or the pre-recession trend of output.
} 
as capital always returns to initial steady state value. Hence, in contrast to the setups in Neiss and Nelson (2003) and Woodford (2003), the potential output is an endogenous object even in the long-run, as will become clear in the next section.

Sticky wage allocation is the equilibrium allocation under staggered (nominal) wages such that the fiscal authority provides (non-distortionary) constant tax instruments outlined in Proposition 1 . We refer the reader to Appendices D.9.1, D.9.2 and D.9.3 for a formal definition of these equilibria concepts.

Proposition 2. The (time-0) natural rate allocation coincides with the (time-0) first-best allocation under liquidity demand and monetary policy shocks.

Proof. See appendix E

Proposition 2 implies that the representative agent's welfare is maximized if the policy maker could replicate the natural rate allocation. This outcome is always possible if the policymaker has access to timevarying tax instruments (see for example Correia, Nicolini and Teles 2008, and Correia, Farhi, Nicolini and Teles 2013). In appendix D.6, we illustrate how the first-best can be implemented by appropriate statecontingent fiscal instruments even at the ZLB. Henceforth, we assume that the policy maker does not have access to these time varying fiscal instruments: fiscal authority satisfies Assumption 1, and adjusts lump-sum taxes every period to balance the budget. The central bank sets the nominal interest rate $i_{t}$ on the risk-free (nominal) bond $B_{t}$ subject to the ZLB constraint:

$$
i_{t} \geq 0 \quad \forall t
$$

This is the bank's only policy instrument.

\section{Calibration and Impulse Responses}

Our approximate equilibrium is linearized around a locally determinate steady state. We can analytically solve for the impulse responses under the assumption of $\mathrm{AR}(1)$ process for shocks. The exact solution is provided in the appendix $\mathrm{C}$ for the case of liquidity demand shocks. However in order to illustrate the dynamics for the benchmark model, we calibrate the model with parameters reported in Table 1 . Time is quarterly. There are eight parameters - we calibrate five of these using values standard in the New Keynesian literature. The discount factor $\beta$ equals 0.99 . Labor share $1-\alpha$ is set to 0.67 . Preferences are logarithmic in consumption and the inverse Frisch elasticity $\nu$ is set at 2 . The wage adjustment probability is set such that wages are reset once every 4 quarters and the steady state wage markup is 10\%. Monetary policy is assumed to follow a standard Taylor rule (eq 30) with $\phi_{\pi}=1.5$ and $\phi_{y}=0.5$.

We choose remaining three innovation parameters - step size of innovation $\gamma$, the (inverse of the) innovation elasticity $\varrho$, and cost parameter in $\mathrm{R} \& \mathrm{D}$ investment $\delta$ such that the model replicates annual steady state growth rate of $2 \%$, annual firm entry rate of $10 \%$, and R\&D to GDP ratio of $25 \%{ }^{17}$ In the data,

\footnotetext{
${ }^{17}$ Innovation success probability is interpreted as firm entry rate, consistent with the "creative destruction" literature.
} 
Table 1: Parameters for Welfare Analysis in the Simple Benchmark Model

\begin{tabular}{lcc}
\hline \hline Standard Parameters & Formula & Value \\
\hline Labor share & $1-\alpha$ & 0.67 \\
Discount rate & $\beta$ & 0.99 \\
Steady State Wage Markup & $\lambda_{w}$ & 0.10 \\
Calvo probability of wage adjustment & $\left(1-\theta_{w}\right)$ & $1-0.75$ \\
Inverse Frisch Elasticity & $\nu$ & 2 \\
Innovation Step Size & $\gamma$ & 1.20 \\
Inverse Innovation Elasticity & $\varrho$ & 1.47 \\
Innovation Cost parameter & $\delta$ & 22.6 \\
\hline \hline
\end{tabular}

the private R\&D to GDP ratio is $2 \%$ (NIPA 1953-2007). We do not have a data counterpart of this ratio under an efficient steady state. As shown in Proposition 1, the steady state in the private sector equilibrium may feature over/under-investment in R\&D because of the research externalities. Jones and Williams (1998) estimated that the social return on R\&D investment is at least four times the private return on R\&D. In a more general setup than ours, they find that the forces such as business stealing effect are quantitatively dominated by loss in profits to innovating firms due to technological spillovers to other firms. Because agents cannot appropriate the full extent of profits from innovation, they underinvest. We choose a higher value of R\&D to GDP ratio for the ease of illustrating our results. We show robustness of our results to choosing a grid of R\&D /GDP ratio in the range of $10 \%$ - 30\% later in Section 3.3. ${ }^{18}$ In Section 4.5, we show a quantitatively realistic calibration of model, away from an efficient steady state, that can replicate key variable moments in the data.

Figure 2: Model based impulse response functions
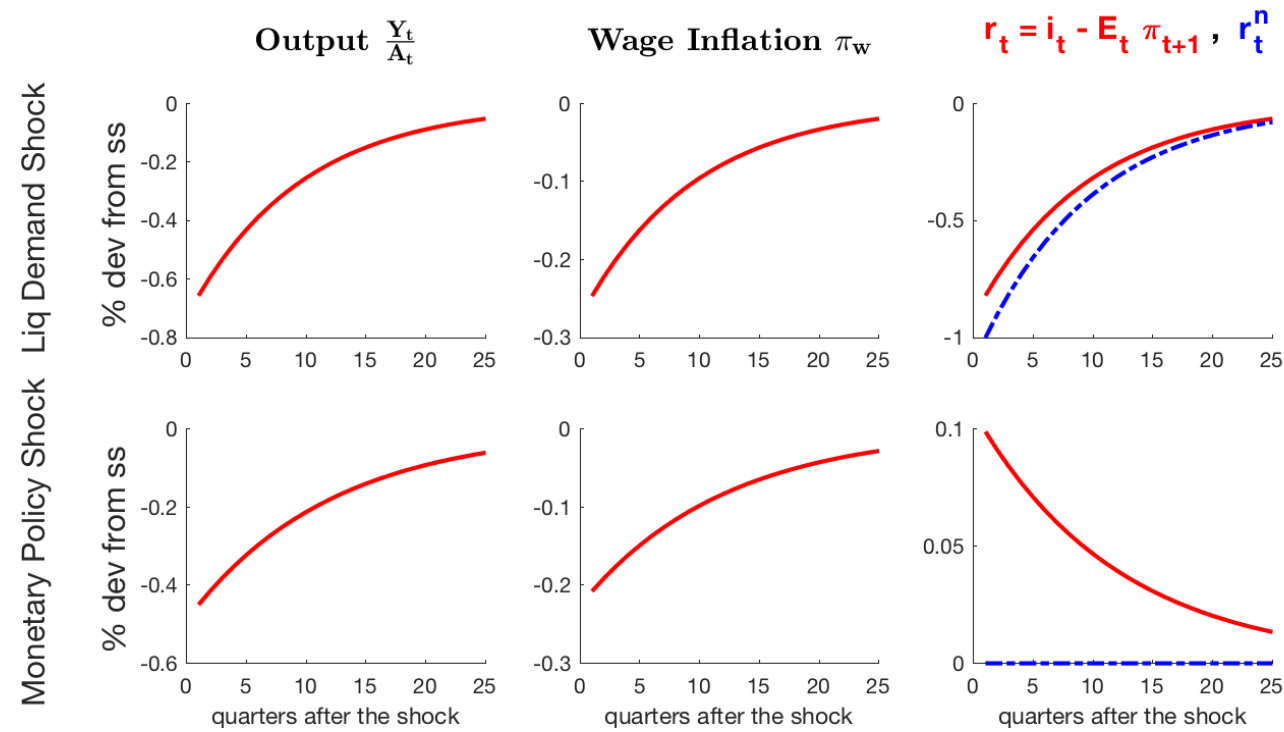

TFP growth rate $g_{t}$ response to liquidity demand shock, and monetary policy shock, with persistence 0.9 and 0.92 respectively..

Rows 1 and 2 in Figure 2 plot the impulse responses for normalized output, wage inflation, real interest

\footnotetext{
${ }^{18}$ See Table 3.
} 
rate and productivity growth rate for a positive shock to liquidity demand $\xi_{t}$ and a contractionary monetary policy shock $\varepsilon_{t}$, each following an $\mathrm{AR}(1)$ process with persistence 0.90 and 0.92 respectively. A positive liquidity demand shock corresponds to a fall in annualized natural interest rate of one percentage point. It increases the desire for saving in the risk-free bond and thus diverts the resources away from consumption. Lower anticipated aggregate demand reduces investment in R\&D by entrepreneurs, exerting a drag on productivity growth. Furthermore, a positive liquidity demand shock reduces household's stochastic discount factor, for a given nominal interest rate. This is equivalent to an increase in the "borrowing cost" for investment in innovation for the entrepreneur. These two forces act in the same direction to reduce investment in innovation. Hence, the productivity growth rate is lower following a contraction in demand induced by the liquidity demand shock.

Similarly, a surprise contractionary monetary policy shock (annualized 68 basis points) implies a 10 basis points increase in the real interest rate and tends to lower the nominal wage. Due to the stickiness of nominal wages, aggregate demand adjusts downwards. The equilibrium increase in the real interest rate combined with expectations of a lower future aggregate demand leads to a reduction in investment in $R \& D$ and, therefore, in TFP growth.

\section{Normative Implications for Conduct of Monetary Policy}

Next, we analyze the normative implications for the conduct of monetary policy. In order to do so, we derive a quadratic approximation of the welfare function of the household. We use this to analyze optimal policy in response to aggregate demand shocks. We highlight three results. One, away from the ZLB, optimal policy is equivalent to a strict inflation targeting rule, and does not involve permanent shifts in output. Two, at the ZLB, optimal policy commits to keeping interest rates lower in the future. Such a policy returns the economy close to the pre-shock trend. Three, a discretionary policy (time-consistent policy) at the ZLB involves excessive output hysteresis relative to commitment policy. We label this as the hysteresis bias of discretionary policy. This result implies that output hysteresis is an artifact of policy-constraints faced by the central bank rather than irrational or inept behavior on part of the central bank. Lack of credibility tools with the central bank is sufficient to generate hysteresis. Numerically, we show that a new strict hysteresis targeting policy closely replicates optimal policy, thereby implying significant welfare gains over discretionary policy. This is true for a range of values of the key parameter $\varrho$, which determines the innovation sensitivity to investment fluctuations.

\subsection{Quadratic approximation of welfare}

One primary contribution of our paper is that we derive a purely quadratic approximation of welfare of the representative household under endogenous growth. This expression can enable researchers to solve for optimal policy in a tractable manner. It generalizes the quadratic objective derived by Benigno and 
Woodford (2004) to an endogenous growth setting.

Proposition 3. Assume that the economy is at the efficient steady state at time $t=0$, with given productivity level $A_{0}$. Under the sticky wage allocation, quadratic approximation of representative agent's lifetime utility function $\mathbb{W}_{0}$ around the non-stochastic efficient steady state is given by

$$
\begin{aligned}
& \frac{\mathbb{W}_{0}-\mathbb{W}_{0}^{*}}{U_{c_{s s}} y_{s s}} \\
& =-\frac{1}{2} \sum_{t=0}^{\infty} \beta^{t}[\lambda_{y} \underbrace{\left(\hat{y}_{t}-\frac{\beta}{1-\beta} \frac{1}{\nu+\frac{y}{c}} \hat{g}_{t+1}\right)^{2}}_{(i)}+\lambda_{g} \underbrace{\hat{g}_{t+1}^{2}}_{(i i)}+\lambda_{\pi} \underbrace{\left(\hat{\pi}_{t}^{w}\right)^{2}}_{(i i i)}]+\mathcal{O}\left(\left\|\hat{\xi}_{t}, \hat{\varepsilon}_{t}^{i}\right\|^{3}\right)+\text { t.i.p. }
\end{aligned}
$$

(i) : labor efficiency gap, (ii): productivity growth rate gap, and (iii): wage inflation gap

where $\lambda_{y}=\left(\nu+\frac{y}{c}\right)>0, \lambda_{g}=\frac{c}{y} \frac{\beta}{1-\beta}\left[\frac{\nu}{\nu+\frac{y}{c}} \frac{\beta}{1-\beta}+\left[(\varrho-1) \eta_{g}+1\right]\right]>0, \lambda_{\pi}=\frac{1+\lambda_{w}}{\lambda_{w}} \frac{1}{\kappa_{w}}>0, \kappa_{w} \equiv \frac{\left(1-\theta_{w}\right)\left(1-\beta \theta_{w}\right)}{\theta_{w}\left(1+\nu\left(1+\frac{1}{\lambda_{w}}\right)\right)}>$ $0, \eta_{g}=\frac{1+g}{g}>1$ and t.i.p. stands for "terms independent of policy". $\mathbb{W}^{*}$ denotes welfare under the (time-0) first-best allocation. The approximation is scaled by the constant $U_{c_{s s}} y_{s s}=\frac{y_{s s}}{c_{s s}}$ (evaluated at the efficient steady state).

\section{Proof. See Appendix E}

This approximation is composed of three gaps/wedges - (i) labor efficiency gap, (ii) productivity growth rate gap, and (iii) wage inflation gap. These are the three stabilization goals for a planner maximizing social welfare. The first and the third terms are standard in a textbook NK model.

The first term, labor efficiency gap, is the difference between the marginal product of labor and the marginal rate of substitution between consumption and leisure for the representative household.

$$
(i)=m r s_{t}-m p n_{t}
$$

where these terms denote deviations from the respective steady state values. Since we do not model price setting frictions in this simple benchmark model, and do not consider price-markup shocks, $m p n_{t}$ corresponds to the (productivity-adjusted) real wage. Thus the labor efficiency gap captures the time-varying wedge in the disutility of the household from supplying labor at a pre-set nominal wage.

The third term, wage inflation gap, describes the loss in efficiency resulting from dispersion in wages across the members of the household. Wage dispersion, similar to price dispersion in standard New Keynesian models, is costly because firms hire different number of hours from various members of the household, causing marginal disutility of labor to vary within the household. Under flexible wages, both labor inefficiency gap and the wage inflation gap go to zero.

The second term, productivity growth rate gap, is a key new ingredient of the endogenous growth model. Investment in $\mathrm{R} \& \mathrm{D}$ in a given period contributes to increase in productivity which persists into the indefinite 
future. These intertemporal spillovers of $R \& D$ investment may not be internalized by the private agents and may result in too high or low responsiveness of investment relative to the first-best. Starting from a productivity level $A_{0}$, the growth rate gap in eq. (32) captures the sub-optimality of deviations from the first-best level of productivity given by $A_{t}^{*}=A_{0}\left(1+g_{s s}\right)^{t}$ at all times $t>0$. Under nominal rigidities, as discussed in last section, demand shocks may induce this permanent gap, thus leaving the agent permanently worse off. This gap disappears under the exogenous growth assumption and the quadratic approximation simplifies to the setting discussed in the graduate textbook treatment of Galí (2015, Ch. 4).

In Corollary 1, we show the conditions under which the welfare loss resulting from these productivity growth rate deviations is larger than that arising due to changes in the labor efficiency gap. We provide a sufficient condition for the growth rate gap to be of higher importance for stabilization than the labor efficiency wedge. We argue below that this condition is likely to be satisfied even for extreme values of parameters considered in the literature. This highlights the importance of stabilizing the productivity growth rate around the first-best allocation.

Corollary 1 (Importance of Growth Stabilization). The relative weight on growth rate gap is higher than the relative weight on labor efficiency wedge if

$$
\frac{\beta}{1-\beta}>\frac{y}{c}\left(\nu+\frac{y}{c}\right)
$$

Proof. See Appendix E

Common calibration values of discount rate $\beta$ at quarterly frequency lie in the range of $[0.98,1)$. This implies a lower bound on the left hand side of the condition (33) at 49 . We bound the right hand side as follows: consumption to output ratio in the US has fluctuated between 0.54 and 0.66 from 1960 -2014 (BEA). Estimates of Frisch elasticity of labor $1 / \eta$ in the micro literature lie between 0.1 and 0.5 (Chetty et al. 2016) while the macro literature uses the estimates in the range of $(2,4)$. Using value of 0.1 for $\eta^{-1}$ and 0.54 for $c / y$ ratio, this implies an upper bound on the right hand side at 22. Hence for a wide range of parameter estimates used in the macroeconomics literature, the welfare loss from a given growth rate deviation is higher than the welfare loss from a similar change in labor efficiency gap. Intuitively, a given deviation in growth rate from steady state has long run, potentially permanent effects. On the other hand, fluctuations in the labor efficiency pertain to welfare losses only in the period these are encountered.

\subsection{Away from the ZLB}

\section{Optimal policy away from ZLB}

We now turn to investigating the implications for the conduct of monetary policy in our model and show the main results outlined at the beginning of this section. First, we show that optimal policy involves setting the nominal interest rate in order to perfectly stabilize output and productivity along the first-best allocation. 
Proposition 4 (Optimal policy away from ZLB). Given a process for liquidity demand and monetary policy shocks, optimal policy under sticky wage allocation tracks the natural rate of interest when the zero lower bound constraint is slack.

Proof. See Appendix E

From Proposition 2, we know that the flexible wage allocation coincides with the first-best allocation. Under a sticky wage allocation, setting the nominal interest rate to track the natural interest rate implements the flexible wage allocation, thereby replicating the first-best allocation. This implies that the output follows a trend stationary process since normalized output and productivity growth rate are always at the steady state. Hence, the following corollary follows;

Corollary 2. When the ZLB is slack, the time series of output under optimal policy is a trend stationary process (integrated of order zero), that is,

$$
\log Y_{t}=a+b * t
$$

where $a=\log Y_{0}$ is the initial level of output, and $b=\log \left(1+g_{s s}\right)$ is the steady state productivity growth rate.

Proof. See Appendix E

We established that permanent output gaps are an undesirable feature of the endogenous growth economy in response to temporary demand shocks. The optimal policy does not allow for these hysteresis effects. Next, we characterize how policy rules used in the standard new Keynesian model fare in this environment.

\section{Policy rules away from the ZLB}

Assume that the central bank follows the Taylor rule shown in equation eq 30. Given local determinacy, we can derive the deviations in level of productivity and output from the respective levels under flexible wages as:

$$
\log A_{t}-\log A_{t}^{e}=\sum_{s=0}^{t-1} \psi_{g}^{i} \epsilon_{s}^{i} ; \quad \log Y_{t}-\log Y_{t}^{e}=\hat{y}_{t}+\sum_{s=0}^{t-1} \psi_{g}^{i} \epsilon_{s}^{i}
$$

where $\psi_{g}^{i}>0$ (detailed expression in the appendix C) and $\epsilon_{t}^{i}$ is the liquidity demand shock or the monetary policy shock at time $t$. We refer to the permanent deviation in output from the flexible wage benchmark as the output hysteresis (or alternately as permanent gap). Then we can show the following proposition, generalizing the standard new Keynesian model results to an endogenous growth environment:

Proposition 5 (Output hysteresis). Given the monetary policy rule (eq 30) and in the absence of a zero lower bound constraint on the nominal interest rate, transitory (modeled as AR(1) process) liquidity demand shocks or monetary policy shocks induce a permanent gap in the time series of output from the counterfactual 
(flexible wage-) level of output if and only if monetary policy is not a strict targeting rule i.e.

$$
Y_{T} \neq Y_{T}^{e} \Longleftrightarrow\left\{\phi_{\pi}, \phi_{y}>0: \phi_{\pi} \nrightarrow \nrightarrow \infty \cup \phi_{y} \nrightarrow \rightarrow \infty\right\}
$$

where $1<T<\infty$ such that $y_{T}=y$ (steady state value) and $y_{T} \equiv \frac{Y_{T}}{A_{T}}$ is the normalized (or stochastically detrended) output.

Proof. See Appendix E

Intuitively, as long as there is incomplete stabilization of normalized output i.e. $\hat{y}_{t} \neq 0 \forall t$, permanent gaps emerge in this economy. This is a consequence of a standard monetary policy specification assumed in eq 30. Normalized output (and the growth rate of productivity) exhibits a monotonic response to the shocks which approaches zero as the shocks die out. Thus, the sum of the productivity growth rate deviations from the steady state cumulate to the output hysteresis denoted henceforth by $h_{t} \equiv \sum_{s=1}^{t} \hat{g}_{s}=\hat{g}_{t}+h_{t-1}$. This result generalizes the textbook results (Galí, 2015, Ch. 3) to an endogenous productivity environment.

Since entrepreneurs are forward looking, expectations of low future demand depresses investment in innovation. This causes a slowdown in productivity growth, which is not offset by the monetary policy rule. Hence, the potential output is permanently lower relative to the flexible wage economy. As inflation and employment approach the steady state, output tends to this permanently lower level of potential output. Had the monetary policy followed a strict inflation targeting rule, these permanent effects would not have emerged. Note that under the considered demand shocks, the property of divine coincidence (Blanchard and Galí, 2007) holds. This implies that the central bank faces no trade-off in stabilizing output and inflation. Setting nominal interest rate so as to track the natural interest rate leads to perfect stabilization of the economy, and therefore there are no long-lasting supply effects from the demand shocks. Inability of the central bank to track the natural interest rate perfectly gives rise to permanent supply side deviations following demand shocks. This is the second key implication of our framework and formalizes the concept of Inverse Say's law recently put forward by Lawrence Summers.

However, it may not be possible to implement the optimal policy due to a binding ZLB constraint. As a result, under standard monetary policy rule, temporary contractions in aggregate demand may result in permanent downward shifts in output.

\subsection{At the ZLB}

We first show that a policy rule which perfectly stabilizes the economy away from the ZLB may fail to do so when monetary policy is constrained by a lower bound on the nominal interest rate. Thus, output hysteresis arises with policies that are optimal away from the ZLB in the endogenous growth environment.

To illustrate, we follow Eggertsson and Woodford (2003) in setting up a two-state Markov chain for the natural interest rate $\hat{r}_{t}^{n}$ in the endogenous growth economy. ${ }^{19}$ Structurally, a negative shock to the natural

\footnotetext{
${ }^{19}$ In the notation of our framework, $\hat{r}_{t}^{n}=-\xi_{t}+(1-\beta) . \xi>1-\beta$ makes the ZLB binding.
} 
interest rate is an increase in the demand for risk-free bonds representing the flight to safety aspects of the financial crisis of 2007-09 (Krishnamurthy and Vissing-Jorgensen, 2012). We assume that the economy hits the ZLB unexpectedly in period 1, that is the nominal interest rate consistent with the stable inflation target breaches a policy lower bound constraint $r_{t}^{n}<i^{L B}$ (assume $i^{L B}=0$ ).

$$
\text { A1a } \quad \hat{r}_{t}^{n}=\hat{r}_{S}<0 \quad \forall 1 \leq t<T^{e}
$$

With probability $\mu$, it continues to stay in the low state and with complementary probability, the shock returns to the steady state. We assume that the economy is back at the no-deflation steady state after a stochastic but finite time $T^{e}<\infty$.

$$
\text { A1b } \quad \hat{r}_{t}^{n}=(1-\beta)>0 \quad \forall t \geq T^{e}
$$

Further, we assume restrictions on parameters such that the equilibrium is locally determinate around the no-deflation steady state (Assumption A2). We calibrate the expected duration of ZLB at 4.6 quarters (14 months approx.) and the natural interest rate at $-3 \%$ (annual). This calibration implies a drop of $5 \%$ in (normalized) output and $1 \%$ in nominal wage inflation relative to the target. The central bank is assumed to follow a strict inflation targeting rule.

Proposition 6 (Output Hysteresis at the ZLB). Under a strict inflation targeting rule $\left(\phi_{\pi} \rightarrow \infty\right.$ in eqn 30), a positive shock to liquidity demand such that the zero lower bound is binding for finite time $T^{e}$ results in a permanent gap in output from the flexible wage counterfactual.

Proof. See Appendix E

This result follows from the fact that a) when the ZLB $\left(t<T^{e}\right)$ is binding, there is wage deflation and low output along equilibrium path, and b) after time $t \geq T^{e}$ (when the ZLB is non-binding), monetary authority raises the nominal interest rate to the level consistent with wage inflation target and full employment. While the economic indicators of employment and wage inflation return back to full capacity levels, the productive potential of the economy is permanently lower relative to the counterfactual path, in which the ZLB is not binding. Such losses in potential output can be sizable for reasonable durations of binding ZLB constraint.

While we leave a thorough quantitative analysis to Section 4.5 , here we illustrate the extent of hysteresis in our model at the efficient steady state. In Figure 3, we plot output (solid line) when ZLB is binding for 28 quarters. Output falls on impact by $5 \%$ and in the subsequent periods productivity continues to grow at a rate slower than its (annual) steady state growth rate of $2 \%$ because investment in $R \& D$ is reduced during the recessionary period. This results in a persistent output shortfall.

In Section 3.2, we proved that the strict inflation targeting rule implements optimal policy under endogenous growth away from the ZLB. After a ZLB episode, such a rule prescribes raising interest rates as soon as deflationary pressures subside and employment is back to full capacity leading to a persistent output 
Figure 3: Strict Targeting Policy at ZLB
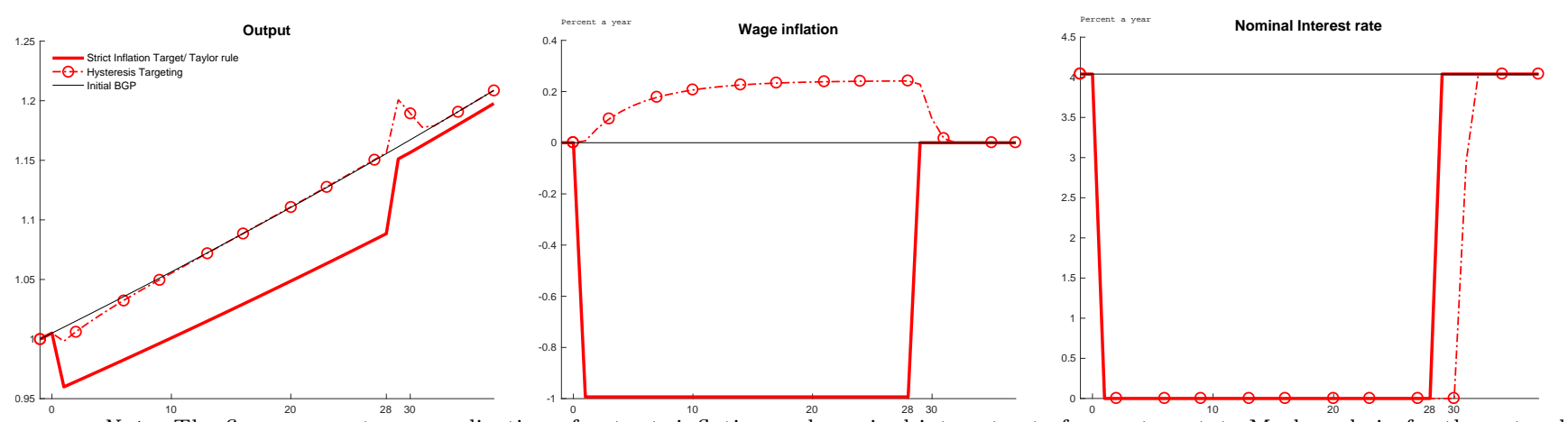

Note: The figures reports one realization of output, inflation and nominal interest rate from a two-state Markov chain for the natural interest rate under alternate policy equilibria. In period 1 , the natural interest rate becomes negative and stays there for 28 quarters, and returns back to the full employment steady state. Realizations under a strict inflation targeting rule and under hysteresis targeting rule are shown. Wage inflation is plotted in deviation from steady state. Output in period -1 is normalized at 1. Black line in the output graph plots evolution of deterministic trend at an annual $2 \%$ steady state growth rate.

shortfall. The ensuing long-lasting supply effects of demand shocks in our framework suggest a role for policy based on an inertial rule. Reifschneider and Williams (2000), Eggertsson and Woodford (2003) and others have shown that optimal policy at the ZLB involves some form of history dependence. The key new result in our setting is that an inertial rule is needed in order to offset negative supply side effects at the ZLB.

Instead of strict inflation (or output) targeting, the central bank can target the history of deviations of productivity growth rate due to current and past shocks, which we refer to as output hysteresis targeting rule. Specifically if the central bank follows a hysteresis-augmented Taylor rule of the form:

$$
\hat{i}_{t}=\max \left(-\frac{\bar{i}}{1+\bar{i}}, \phi_{\pi} \hat{\pi}_{t}^{w}+\phi_{y} \hat{L}_{t}+\phi_{h} h_{t+1}+\hat{\varepsilon}_{t}^{i}\right)
$$

which incorporates an additional target of cumulative sum of all deviations in productivity growth rate $h_{t+1}$ resulting from history of shocks until time $t$, it could avoid the permanent gaps by committing to maintaining a path of interest rates until output is restored to the counterfactual path of output. When $\phi_{h} \rightarrow \infty$, we label the rule as strict output hysteresis targeting rule.

The dashed line in Figure 3 tracks the level of output under the hysteresis-augmented Taylor rule. This is an inertial policy which signals commitment by the central bank to maintain a path of nominal interest rates consistent with reversing past policy constraints/mistakes. A positive liquidity demand shock results in a drop in (normalized) output and wage inflation. However, since the central bank is committed to undoing any permanent gaps in output, it is willing to tolerate excess wage inflation (Figure 3, panel B). This reduces the real interest rate gap, which results in lower growth rate deviations on impact, and allows subsequent growth rate overshooting to undo past constraints on policy. Thus the hysteresis targeting policy embeds a forward guidance mechanism, credibly signaling the intention to tolerate excess inflation. ${ }^{20}$

20 Note that our use of "targeting" is distinct from that in the delegation literature. See Vestin (2006) for examples and references. That literature specifies a target for monetary authority in that the monetary authority chooses an instrument in order to maximize a welfare-objective with a quadratic term for the target. In most cases, this welfare objective is different from the societal welfare objective function. Instead, we simply augment the policy rule of central bank with an additional objective following Chung, Herbst and Kiley (2015). Strict targets may be implemented without an explicit instrument rule 
Should monetary policy offset these hysteresis effects at the ZLB? We take up this question next. Our normative analysis at the ZLB retains the assumptions (A1 and A2) regarding exogenous dynamics of natural interest rate and local determinacy.

\section{Optimal policy at the ZLB}

We first solve the optimal commitment policy, when the central bank can credibly commit to future statecontingent policy actions. At the ZLB, the economy is characterized by deflation and drop in output. By committing to pursuing accommodative policy in the future, the central bank manages expectations of private agents regarding the future path of inflation. Commitment policy achieves two objectives - (i) it reduces the severity of economic contraction during the ZLB, and (ii) it allows aggregate demand to overshoot the steady state level after the the ZLB stops binding. While the first (forward guidance) channel reduces the drops in output from the trend through reduced contraction in demand, the second channel tends to reverse past drops in output that occurred during the ZLB. The key takeaway from this analysis is that the optimal policy returns the economy close to the pre-recession trend. In the baseline calibration, the strict inflation targeting rule rule admits a permanent output gap of 0.88 percent. On the other hand, the optimal policy involves a permanent gap of only 0.085 percent.

The policy maker maximizes the lifetime utility of the household subject to assumption 1 and the competitive equilibrium conditions: (i) Euler Equation (eq 22), (ii) Wage Setting Block (eqns 27-29), (iii) Endogenous growth block (eqns 23-24), (iv) resource constraints and market clearing conditions (eqns 25-26), and (v) the lower bound on the nominal interest rate (eq 31).

Since the first order conditions involve a complementary slackness condition, the solution to the optimal policy problem does not have a closed form. We solve it numerically for each state contingent realization of the shock. We provide the first order conditions in the appendix. The solution method is a version of shooting algorithm outlined in Eggertsson and Woodford (2003).

Figure 4 shows the equilibrium output, inflation and nominal interest rate under a realization of the shock binding for 28 quarters. A central bank with the ability to credibly commit offsets the permanent output gap by promising to keep interest rates lower after the ZLB stops binding. Under optimal policy, the central bank minimizes total losses in welfare by trading welfare losses during the ZLB against the welfare losses from policy that arise after the ZLB stops binding. By committing to keeping interest rates lower upon exit from the ZLB, the central bank creates anticipation of a boom, which lowers the real interest rate during the ZLB. This has the effect of reducing the impact of the shock relative to a discretionary policy. On impact, the drop in wage inflation and output are only $0.04 \%$ and $1.23 \%$ respectively.

Upon exit from the ZLB, the central bank keeps interest rate lower for two additional quarters to follow through with its promise and thus creates a boom in output and inflation. Because of procyclicality of

as in Chung, Herbst and Kiley (2015). For example, they implement a nominal GDP target with an equation that sums price level and output gap (from flexible level) to zero. We leave the extension of our framework to delegation problems as in Vestin (2006) to future work. 
Figure 4: Optimal Policy at the ZLB
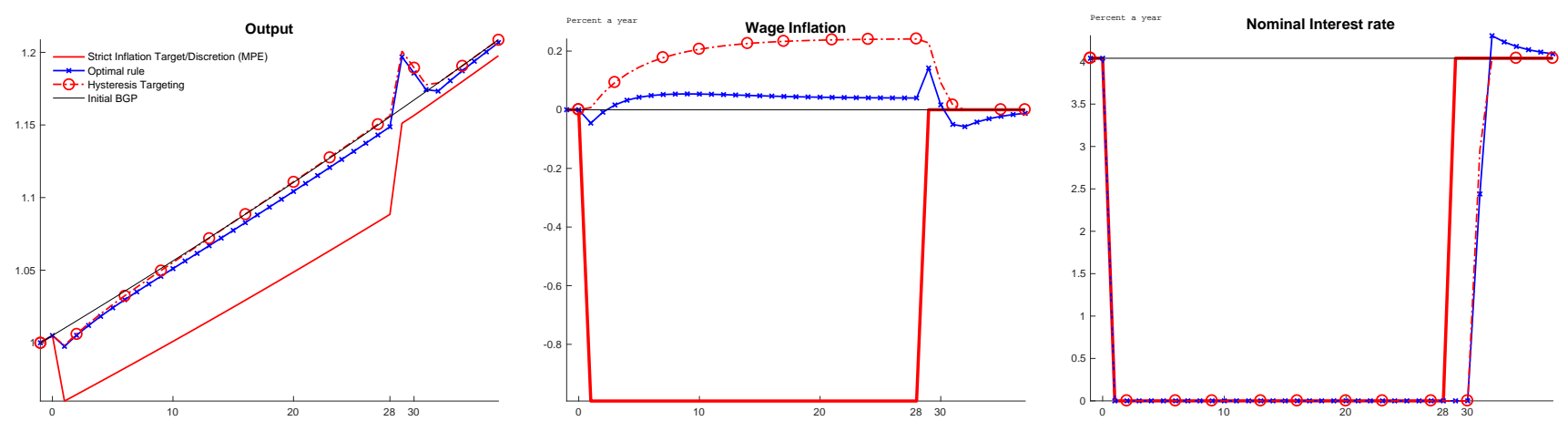

Note: The figure reports one realization of output, inflation and nominal interest rate from a two-state Markov chain for the natural interest rate under alternate policy equilibria. In period 1 , the natural interest rate becomes negative and stays there for 28 quarters, and returns back to the full employment steady state. Realizations under a Taylor rule, Markov-Perfect Equilibrium (or discretionary) optimal policy, optimal commitment policy and hysteresis targeting are shown. Wage inflation is plotted in deviation from steady state. Output in period -1 is normalized at 1 . Black line in the output graph plots evolution of deterministic trend at an annual $2 \%$ steady state growth rate.

investment in innovation, the boom in output allows for growth rate to overshoot its target. Hence the permanent output gap is reduced substantially on account of two reasons: a) the forward guidance channel of optimal policy, and b) the accommodation of excess wage inflation upon exit from the ZLB. In the steady state, output is only 0.085 percent below the (time -0) efficient path of output (solid line). In our numerical example, we have a two-state Markov chain for the shock process with an expected duration of ZLB of 4.6 quarters. On average, agents expect the central bank to keep interest rates lower for two quarters beyond 4.6 quarters implied by the shock. While we illustrate one realization of ZLB binding for 28 quarters, we emphasize that the expansionary effects of commitment do not arise because agents at time 0 expect the central bank to keep interest rates lower after 28 quarters.

Note that this is the optimal policy subject to the binding ZLB constraint. ${ }^{21}$ It is possible to avoid the permanent output gap altogether by a commitment to accommodating even higher inflation post the ZLB. Such a policy would be optimal had the social planner put higher weight on growth rate stabilization relative to the "true" welfare weight in eq (32) (as shown in row 3 of Table 2). However, under the "true" welfare weights, the policy maker allows some permanent output gap because perfectly neutralizing the permanent output gap comes at the expense of higher wage dispersion inefficiency upon exit from ZLB. Thus, the ZLB introduces a short-run versus long-run tradeoff for the central bank even when we have assumed away initial steady state distortions (by assumption 1).

\section{Comparison with exogenous growth benchmark at the ZLB}

How does this optimal policy compare to the policy when the central bank does not internalize that it can influence productivity growth rate? That is, a policy-maker solves the optimal policy problem as before except she does not choose productivity growth rate. The optimal policy under this non-internalizing scenario

\footnotetext{
${ }^{21}$ If the policymaker had access to time-varying proportional tax instruments such that it could replicate the flexible wage allocation, then the first-best allocation can be implemented (as shown in Appendix D.6) However, the optimal monetary policy, in the absence of these time-varying taxes, trades off welfare losses during the ZLB episode against welfare losses in the future in the absence of appropriate time-varying tax instruments.
} 
does not allow the central bank to accommodate as high inflation after a ZLB episode as the optimal policy considered above would. Consequently, the permanent output gap is somewhat larger. Figure 5 shows the optimal policy under this "misspecified" setting and compares it to the optimal policy when the central bank internalizes the consequence of its actions on TFP growth rate.

Figure 5: Exogenous Productivity Comparison

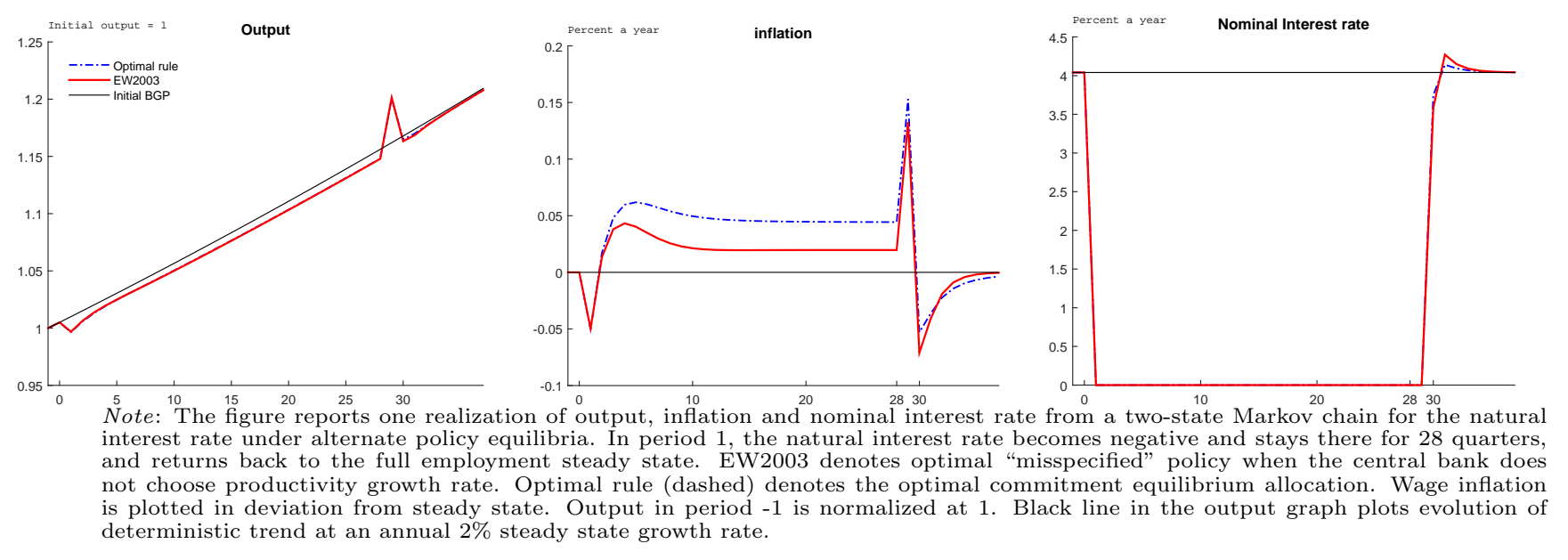

Quantitatively, this difference in the optimal policies is negligible (permanent output loss is $0.09 \%$ under misspecified problem compared to $0.085 \%$ under fully optimal rule). This is because the key problem in this economy is deficiency of aggregate demand. Since the R\&D investment is pro-cyclical under liquidity demand shocks, stabilizing inflation stabilizes aggregate output and hence R\&D investment. The main implication of this analysis is that while optimal commitment policy prescriptions are not quantitatively different under the two environments, the cost of not adhering to optimal commitment rules is elevated because of permanent output gaps. The key insight that we illustrate next is that we do not need a vastly sub-optimal rule to generate output gaps. A minimum departure from a fully optimal policy by introducing lack of credibility is sufficient to generate permanent output gaps.

\section{Markov-perfect policy at the ZLB and the hysteresis bias}

Next, we analyze the optimal policy when the policy maker is unable to commit to policy actions announced in the future. Such a policy is referred to as the discretionary policy and the resulting equilibrium as the Markov Perfect equilibrium (MPE, formally defined in Maskin and Tirole 2001). The key result here is that the discretionary policy is characterized by a new dynamic inconsistency (Kydland and Prescott 1977) problem that we label as the hysteresis bias: once the ZLB stops binding, the nominal interest rate is set without any intent to offset the long-run effects of past contractions in aggregate demand. Hence, a policy of committing to lower future interest rates is not time-consistent because the central bank would increase the interest rates as soon as employment recovers back to full employment. The discretionary policy-maker treats past productivity losses as bygones. 
The policy maker sets the current short-term nominal interest rate in order to maximize the quadratic approximation of the welfare function (eq 32) subject to assumption 1 and the constraints: (i) Euler equation (eq 22), (ii) wage setting block (eqns 27-29), (iii) endogenous growth block (eqns 23-24), (iv) resource constraints and market clearing conditions (eqns 25-26), and (v) the lower bound on the nominal interest rate (eq 31). The problem is similar to the optimal commitment problem, except the policy maker cannot commit to future policy actions.

Proposition 7 (Optimal Discretionary Policy at the ZLB). If Assumptions A1 and A2 hold and for a given level of productivity at time $0, A_{0}$, the Markov perfect equilibrium is characterized by:

$$
\log A_{1}=\log A_{0}+\log \left(1+g_{s s}\right)
$$

for $0<t<T^{e}$

$$
\begin{gathered}
\hat{y}_{t}=\psi_{y} r_{S}^{n}<0 ; \hat{\pi}_{t}^{w}=\psi_{p} r_{S}^{n}<0 ; \hat{g}_{t}=\psi_{g} r_{S}^{n}<0 \\
\log A_{t+1}=\log A_{t}+\psi_{g} r_{S}^{n}
\end{gathered}
$$

and when $t \geq T^{e}$

$$
\begin{gathered}
\hat{y}_{t}=\hat{\pi}_{t}^{w}=\hat{g}_{t}=0 \\
\log A_{t+1}=\log A_{t+1}^{*}+\left(T^{e}-1\right) \psi_{g} r_{S}^{n}<\log A_{t+1}^{*}
\end{gathered}
$$

where $\psi_{y}=\frac{(1-\beta \mu) \eta_{C}^{-1}}{(1-\beta \mu)(1-\mu)-\kappa_{w}\left(\nu+\eta_{C}\right) \mu \eta_{C}^{-1}}>0, \psi_{p}=\frac{\kappa_{w}\left(\nu+\eta_{C}\right)}{1-\mu \beta} \psi_{y}>0$, and $\psi_{g}=\frac{1-\frac{c}{y} \eta_{C}}{\frac{\mathbb{R}}{y} \varrho \eta_{g}} \psi_{y}>0 . A_{t+1}^{*}$ is the (time-0) first-best output at time $t+1$.

Proof. See Appendix E.1.2

Since the policymaker is unable to commit to future actions, optimal policy involves setting interest rates such that the economy returns to the (normalized) steady state as soon as the shock abates. This leads to excessive deflation during the ZLB relative to the commitment policy that involves $\hat{\pi}_{T^{e}}^{w}>0$. This dynamic inconsistency problem identified as the deflation bias by Eggertsson (2006) is also present in our setup. The new feature is that when the ZLB stops binding at stochastic time $T^{e}$, the discretionary policy maker does not offset the difference in level of productivity from the first-best. MPE thus admits a unit root in the time-series of productivity and hence output. This is the hysteresis bias we identify. Absence of credibility is sufficient to generate a permanent output shortfall.

Under discretionary policy, the policymaker re-optimizes every period, hence past deviations in growth rate from the steady state are no longer under the influence of a policy-maker at time $T^{e}$ onwards. In order to bring the output back to the first-best output, the policy maker needs to incentivize excess investment in $\mathrm{R} \& \mathrm{D}$ after the economy has recovered back to full employment. Such an allocation is not desirable from the perspective of policymaker from time $T^{e}$ onwards. This can be seen by directly looking at the first-order conditions of discretionary equilibrium. Once the shock to the natural interest rate is over, the policy-maker 
sets interest rate equal to the natural interest rate implying zero slack in the economy. Intuitively, this happens because even though the level of productivity is an endogenous state variable, it only affects the absolute level of the stochastically-trending variables. The efficiency of resource allocation in the normalized economy is independent of the level of productivity. As soon as the central bank is able to set the normalized variables to their steady state values, it does so. Past deviations of growth rate enter the welfare-loss as additive inefficiencies that cannot be influenced by policymaker optimizing at time $t \geq T^{e}$. In other words, what is relevant for the stabilization at time $t$ is the gap from the time-t first-best allocation. Once the ZLB has stopped binding, setting interest rates such that employment is back to the efficient steady state implements the time-t first-best allocation.

Figure 4 plots the path of output under MPE. There is an unanticipated shock at time $t=1$. The output falls by $5 \%$ and continues to grow at a slower pace. When the shock stops binding in period $T^{e}=28$, the economy is permanently at a lower output trajectory. This also corresponds to the policy under a strict inflation targeting rule specification discussed above. The output in the new steady state is permanently lower by 0.88 percent. Compare the equilibrium evolution of variables under discretionary policy to that under optimal commitment policy. The discretionary policy leads to excessive deflation and slack in the economy during the ZLB. Since the discretionary policy does not offset output hysteresis, it also leads to a larger permanent output gap.

This hysteresis bias of discretionary policy thus strengthens the result from Proposition 6 that output hysteresis is an artifact of policy-constraints faced by the central bank and does not arise because of irrational or inept behavior on part of the central bank. An implication of the hysteresis bias, we emphasize, is that it is sub-optimal for the central bank to redesign policy ex-post in order to offset past output hystereses. Hence, if the central bank could credibly commit to being irresponsible as suggested by Krugman (1998), it could not only reduce the deflation during the ZLB but also minimize the permanent output gaps. This raises the stakes for optimal commitment policy that the central bank must credibly communicate to the public ex-ante.

\section{Alternative policy rules at the ZLB}

Eggertsson and Woodford (2003) have underscored the complex nature of the optimal commitment policy in that it may not be feasible to properly communicate the policy stance to the public even if full credibility can be achieved. On the other hand, we showed that the discretionary policy-maker suffers from hysteresis bias and does not offset past inefficiencies. In this regard, alternate simple policy rules that have built-in commitment to reverse past policy mistakes assume importance. Such policy rules are presumably easier to communicate to the public, for example a commitment to keep interest rates low until the permanent output gap is filled may be more readily understood. Earlier, we illustrated the potency of this strict output hysteresis targeting rule, given by:

$$
h_{t+1} \equiv \sum_{s=1}^{t+1} \hat{g}_{s}=0
$$


where growth rate $g_{t+1}$ is determined at time $t$.

Table 2: Policy Rules at the ZLB: Welfare Comparison

\begin{tabular}{lcc}
\hline Policy Rule & Welfare Loss & Permanent Output Gap \\
\hline Optimal rules & & \\
\hline Discretion (MPE) & $100 \%$ & $-0.88 \%$ \\
Commitment & $0.043 \%$ & $-0.085 \%$ \\
Commitment with & & \\
$\quad$ higher wt on $\hat{g}_{t}$ & $0.11 \%$ & 0 \\
\hline \hline & & \\
Simple rules & & \\
\hline & & $-0.88 \%$ \\
Strict Inflation Target & $100 \%$ & 0 \\
Hysteresis Targeting & $0.049 \%$ & $-0.30 \%$ \\
Wage Level Targeting & $0.053 \%$ & $-0.37 \%$ \\
W $\times$ Y targeting & $0.311 \%$ & \\
\hline \hline
\end{tabular}

Notes: Values report the conditional welfare loss starting from an efficient steady state. Loss is expressed in consumption equivalent units relative to discretionary rule. Computation details in the Appendix. The true relative weight on growth rate gap is 3.94 . Under a weight of 165 , the permanent output gap is 0 .

The central bank ex-ante announces to set interest rates in order to completely cut down permanent losses in output. Such a rule is fully optimal in the absence of the zero lower bound. At the ZLB, though not fully optimal, this rule may have a relative advantage in ease of communication to the public. Figure 6 plots nominal interest rate, output and wage inflation under such a rule contrasting it with the realized paths of these variables under the optimal commitment rule. The central bank keeps the interest rates low for additional two quarters as in the optimal policy. The forward guidance element through anticipation of higher inflation leads to a reduction in the real interest rate, which implies a lower drop in inflation and normalized output (on impact). In the calibrated experiment, output drops by $1.17 \%$ on impact. The commitment to this simple rule implies that the central bank accommodates excess wage inflation up to $0.25 \%$ before it starts to raise interest rates gradually. Such a policy is relatively more accommodative than the optimal policy. Rows 2 and 5 in Table 2 show that the hysteresis targeting policy achieves most of the welfare gains under optimal policy relative to a strict inflation target (or a discretionary) policy, conditional on ZLB being binding in period 1. An optimal commitment policy with higher weight on output gap can also close the output gap (as shown in row 3 of Table 2) but it results in somewhat higher welfare losses compared to the strict hysteresis targeting rule.

Contrast this policy with the policy of nominal wage level targeting (analogue of a simple price level targeting rule), where the central bank ex-ante announces its intention to set interest rates in order to attain a particular level $w^{*}$ for the normalized output $y_{t}$ adjusted nominal wages $w_{t}^{n}$ :

$$
w_{t}^{n}+\lambda y_{t}=w^{*} ; \quad \text { where } \lambda \equiv \frac{1+\lambda_{w}}{\lambda_{w}}
$$


Figure 6: Alternate Rules at the ZLB
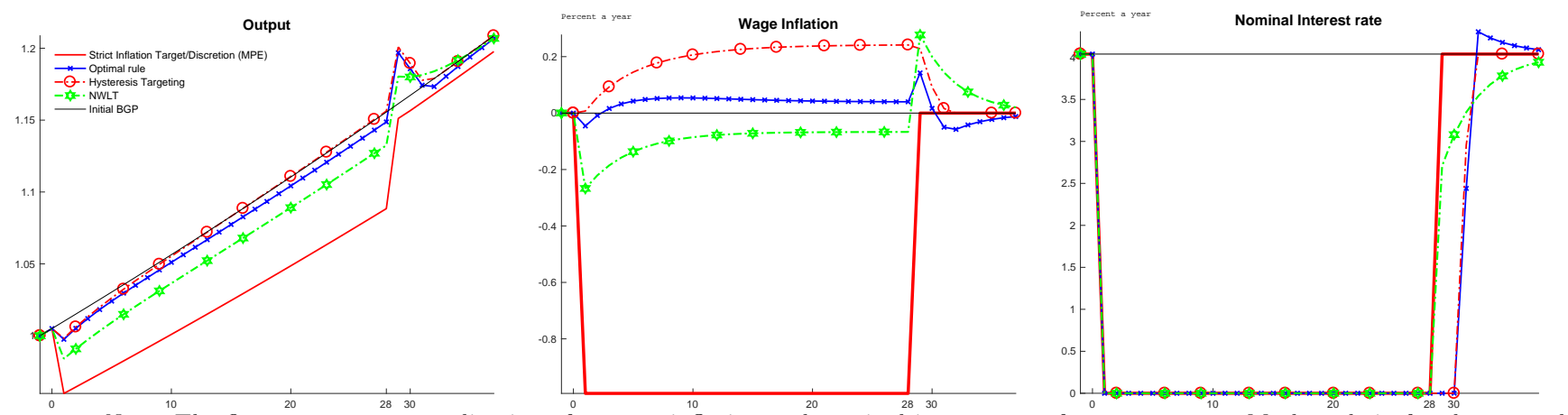

Note: The figure reports one realization of output, inflation and nominal interest rate from a two-state Markov chain for the natural interest rate under alternate policy equilibria. In period 1 , the natural interest rate becomes negative and stays there for 28 quarters, and returns back to the full employment steady state. Realizations under a Taylor rule, Markov-Perfect Equilibrium (or discretionary) optimal policy, optimal commitment policy, hysteresis targeting and nominal wage level targeting rule are shown. Wage inflation is plotted in deviation from steady state. Output in period -1 is normalized at 1 . Black line in the output graph plots evolution of deterministic trend at an annual $2 \%$ steady state growth rate.

Figure 6 shows the realized paths of output inflation and nominal interest rate under wage level targeting against those obtained under optimal commitment policy. This simple policy also approximates the welfare gains achieved under optimal commitment policy (as seen in row 6 of Table 2) relative to the discretion policy, but results in a permanent output gap of 0.3 percent given that it is not as accommodative as the optimal policy.

Compared with wage level targeting, the hysteresis targeting rule requires the central bank to be more tolerant of higher inflation upon exit from ZLB. But it may have an advantage in communication and operationalization over a policy of wage-level targeting. A central bank's commitment to keep interest rate lower until output has been restored to pre-shock trend is perhaps more readily observable and implementable, assuming that achieving credibility is not a constraint for the central bank. Such a policy of hysteresis targeting is equivalent to a real GDP targeting rule because:

$$
\log Y_{t}-\log Y_{t}^{e}=h_{t}
$$

where $Y_{t}^{e}$ denotes the counterfactual path of output under time-0 flexible-wage allocation

A third simple targeting rule is the nominal GDP (NGDP) targeting rule (see Woodford 2012 and references therein). Since our benchmark model features only nominal wage-frictions, a comparison with conventional NGDP targeting rule may not be a useful comparison. The analogue of NGDP targeting in this simple framework is the $W \times Y$ rule:

$$
W_{t} \times Y_{t}=W_{t}^{e} \times Y_{t}^{e}
$$

where $W_{t}^{e}$ is the counterfactual path of nominal wages under time-0 flexible-wage allocation. The central bank commits to adjusting interest rates in order to achieve this target relationship whenever possible. As shown in row 6 of Table 2 , this $W \times Y$ rule also implies significant welfare gains and smaller persistent output 
shortfalls than under discretionary policy.

Table 3: Policy Rules at the ZLB: Welfare Comparison for Range of $\varrho$

\begin{tabular}{lccccccc}
\hline Innovation Intensity $\varrho$ & 1.02 & 1.09 & 1.20 & $\begin{array}{c}\text { Benchmark } \\
1.47\end{array}$ & 1.50 & 1.71 & 2.78 \\
\hline \begin{tabular}{l} 
Permanent Output \\
\multicolumn{1}{c}{ Gap }
\end{tabular} & & & & & & & \\
\hline & & & & & & \\
Discretion (MPE) & $-1.74 \%$ & $-1.58 \%$ & $-1.25 \%$ & $-0.88 \%$ & $-0.867 \%$ & $-0.695 \%$ & $-0.346 \%$ \\
Commitment & $0.0149 \%$ & $-0.073 \%$ & $-0.085 \%$ & $-0.085 \%$ & $-0.084 \%$ & $-0.076 \%$ & $-0.044 \%$ \\
Hysteresis Targeting & 0 & 0 & 0 & 0 & 0 & 0 & 0 \\
Wage Level Targeting & $0.048 \%$ & $-0.291 \%$ & $-0.354 \%$ & $-0.297 \%$ & $-0.29 \%$ & $-0.246 \%$ & $-0.129 \%$ \\
W $\times$ Y targeting & $0.026 \%$ & $-0.11 \%$ & $-0.136 \%$ & $-0.145 \%$ & $-0.143 \%$ & $-0.132 \%$ & $-0.08 \%$ \\
\hline & & & & & & & \\
Welfare Loss & & & & & & & \\
\hline & & & & & & & \\
Commitment & $0.021 \%$ & $1.17 \%$ & $2.26 \%$ & $4.33 \%$ & $4.48 \%$ & $5.48 \%$ & $7.62 \%$ \\
Hysteresis Targeting & $0.031 \%$ & $1.27 \%$ & $2.53 \%$ & $4.87 \%$ & $5.02 \%$ & $6.09 \%$ & $8.13 \%$ \\
Wage Level Targeting & $0.073 \%$ & $5.90 \%$ & $13.83 \%$ & $5.25 \%$ & $23.41 \%$ & $26.67 \%$ & $32.63 \%$ \\
W $\times$ Y targeting & $0.04 \%$ & $1.36 \%$ & $2.88 \%$ & $6.43 \%$ & $6.66 \%$ & $8.56 \%$ & $13.13 \%$ \\
\hline \hline
\end{tabular}

Notes: Values report the conditional welfare loss starting from an efficient steady state. Loss is expressed in consumption equivalent units relative to discretionary rule. Only two parameters are adjusted. Innovation Intensity elasticity $(1 / \varrho)$ and research $\operatorname{cost} \delta$ to target $2 \%$ annual growth rate.

Table 3 compares permanent output gaps and welfare losses in these three operational rules against the optimal commitment policy for a range of innovation elasticity parameters. Ceteris paribus, we vary $\varrho$ (inverse of innovation intensity elasticity) and $\delta(\mathrm{R} \& \mathrm{D}$ cost parameter) in order to hit $2 \%$ growth, $10 \%$ firm entry rate and R\&D to GDP ratio in the range of $10 \%$ to $30 \%$, while keeping all other parameters fixed at values described in Table 1. Hysteresis targeting policy approximates the welfare gains achieved under optimal policy for this range of parameters. This analysis highlights that a new operational rule that approximates welfare gains achieved under optimal policy is available for implementation in our framework. Since the standard NK models feature exogenous productivity, this rule is not available to the policy-maker in those environments.

\section{Discussion: Optimal policy under alternate shocks}

In the analysis so far, we focused on shocks such that the economy exhibits divine coincidence. The virtue of this exercise was that it did not matter whether output hysteresis was defined as deviation from the (time- 0 ) first best, (time-0) natural rate or pre-recession trend output. In this section, we consider alternate demand and supply shocks, and analyze the optimal response of monetary policy in each case. The distinction between the three equilibrium concepts will become crucial now. 
Figure 7: Path of GDP under TFP and wage markup shocks
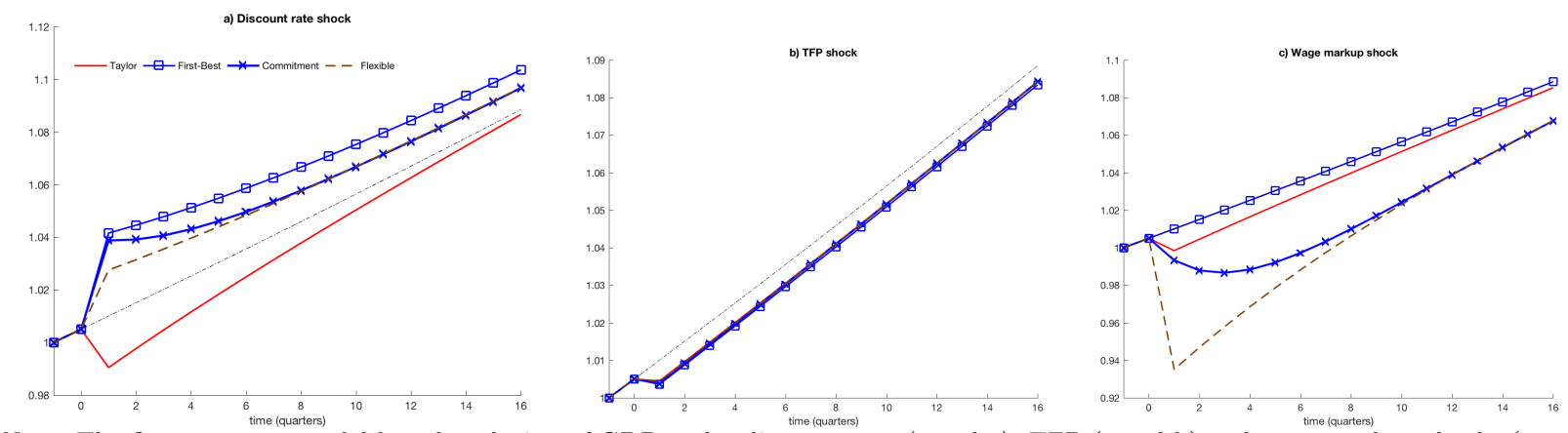

Note: The figure reports model based evolution of GDP under discount rate (panel a), TFP (panel b) and wage markup shocks (panel c). Shocks are parametrized such that output falls by 1 percent on impact. For illustration, persistence of shocks is chosen to equal 0.9. Output in period -1 is normalized at 1 . Black line plots evolution of deterministic trend at an annual $2 \%$ steady state growth rate.

\subsection{Discount rate shocks}

Discount rate shocks are modeled as shocks to household's discount rate. A positive shock to the discount rate temporarily makes the household more patient. This transmits to innovation through two opposing channels: One, lower discounting of future profits increases the present discounted value of innovation, thereby increasing investment in R\&D. Two, in the presence of nominal rigidities, increased patience lowers aggregate consumption demand. If the aggregate demand channel is strong enough, output falls, thereby reducing the investment in $\mathrm{R} \& \mathrm{D}$ due to a shrunken market (aggregate demand effect). Under the first-best allocation, however, prices are flexible, so there is no negative aggregate demand channel. This leads to an increase in $R \& D$ relative to the pre-recession trend (figure 7a, squared-blue graph). In the presence of nominal rigidities, however, the overall effect on $\mathrm{R} \& \mathrm{D}$ is determined by two opposing forces as described above. In our calibration, the aggregate demand channel dominates and investment in R\&D and hence, TFP growth rate and output fall under a standard Taylor rule (figure 7a, red graph).

The response of the first-best allocation and the flexible-wage allocation (figure 7a, dashed-maroon graph) differ because of breakdown in divine coincidence under discount rate shocks. The entrepreneurs do not internalize the long-run benefits of innovation compared to the social planner despite the presence of an efficient steady state (Nuño, 2011). Replicating the flexible wage allocation is no longer an optimal policy. Infact, the natural rate of interest $r$-star is an endogenous object in this environment. Under optimal commitment equilibrium, the policy maker lowers the real rate in order to closely replicate the welfare gains under first-best allocation. This results in overshooting of output relative to both the flexible-price GDP and Taylor rule GDP (figure 7a, crossed-blue graph).

\subsection{Stationary TFP shocks}

A negative productivity shock shrinks the resources available for consumption and R\&D investment. It is optimal to reduce $\mathrm{R} \& \mathrm{D}$ investment in response to a temporary reduction in the level of total factor productivity. Temporarily lower productivity growth, as a result of low investment, cumulates to generate a 
permanent output gap relative to the pre-shock trend. Hence, the time-0 first best allocation features a unitroot process for output (figure $7 \mathrm{~b}$, squared-blue graph). Since optimal monetary policy approximates the first-best allocation, the optimal commitment solution also admits output hysteresis (figure 7b, crossed-blue graph).

Table 4: Policy Rules : Welfare Comparison

\begin{tabular}{|c|c|c|c|c|c|}
\hline Policy Rule & Discount rate shock & Markup shock & Productivity Shock & Liq Demand Shock & MP shock \\
\hline \multicolumn{6}{|l|}{ Optimal rules } \\
\hline $\begin{array}{l}\text { Commitment } \\
\text { Discretion }\end{array}$ & $\begin{array}{l}0.0022 \% \\
0.0032 \%\end{array}$ & $\begin{array}{r}0.18 \% \\
0.753 \%\end{array}$ & $\begin{array}{r}0.00009 \% \\
0.0001 \%\end{array}$ & $\begin{array}{l}0 \\
0\end{array}$ & $\begin{array}{l}0 \\
0\end{array}$ \\
\hline \multicolumn{6}{|l|}{ Simple rules } \\
\hline $\begin{array}{l}\text { Taylor rule eq } 27 \\
\text { Hysteresis Targeting } \\
\text { Wage Level Targeting } \\
\text { W } \times \text { Y targeting }\end{array}$ & $\begin{array}{l}0.0253 \% \\
0.0024 \% \\
0.0024 \% \\
0.0024 \% \\
\end{array}$ & $\begin{array}{r}2.04 \% \\
4.61 \% \\
0.2881 \% \\
4.6 \% \\
\end{array}$ & $\begin{array}{r}0.0003 \% \\
0.0015 \% \\
0.00009 \% \\
0.0015 \% \\
\end{array}$ & $\begin{array}{c}0.022 \% \\
0 \\
0 \\
0 \\
\end{array}$ & $\begin{array}{c}0.019 \% \\
0 \\
0 \\
0 \\
\end{array}$ \\
\hline
\end{tabular}

\subsection{Wage markup shocks}

In the presence of cost-push shocks, the central bank faces a tradeoff in stabilizing short-term inflation and long-run output. The optimal commitment allocation (figure $7 \mathrm{c}$, crossed-blue graph) admits a permanent output gap. This result is a generalization of the short-run tradeoff in the exogenous growth new Keynesian model. With exogenous growth, the central bank counters a positive wage markup shock by committing to generating a negative output gap in the future. The same commitment under endogenous growth implies a reduction in market size for entrepreneurs and hence reduced incentive to undertake R\&D. Thus, in a bid to reduce current wage inflation, the central bank keeps output permanently below the time-0 first best allocation. The inflation stabilization objective generates a long-run tradeoff for the central bank. ${ }^{22}$

\subsection{Welfare analysis}

In table 4 we report the consumption equivalent welfare losses conditional on starting from an efficient steady state. These losses are computed as an average over 10,000 simulations with each starting at the same efficient steady state. Hysteresis targeting rule is of the form $h_{t+1}+y_{t}-y_{t}^{f}=0$ rule, where superscript $f$ denotes flexible wage allocation, $h_{t}$ is $(\log )$ hysteresis determined at time $t-1$ and $y_{t}$ is $(\log )$ stationarized output. Wage level targeting rule is implemented as $W_{t}+y_{t}-y_{t}^{f}=0$, where $W_{t}$ is the (log) nominal wage. $\mathrm{W} \times \mathrm{Y}$ targeting takes the form: $W_{t}+h_{t+1}+y_{t}-y_{t}^{f}=0$. In response to demand shocks, hysteresis targeting closely replicates the welfare achieved under optimal commitment. In response to supply shocks, however, it is an order of magnitude more costly (in terms of welfare) to implement hysteresis targeting

\footnotetext{
${ }^{22}$ Note that the time-0 first best allocation is a trend stationary process (figure $7 c$, squared-blue graph). This is because we assume that the social planner has access to time-varying taxes to counter these shocks (Correia et al., 2013).
} 
relative to the optimal policy. This highlights the importance of correctly identifying the source of business cycle fluctuations in the design of optimal monetary policy.

\subsection{Quantitative assessment}

In Appendix G, we build and calibrate a quantitative model, extending the Smets and Wouters (2007) model with endogenous (Schumpeterian) growth mechanism, to evaluate the quantitative import of output hysteresis. Since the model is fairly standard, we relegate its full presentation to the appendix (see also Guerron-Quintana and Jinnai (2019) for a an estimated endogenous growth business cycle model). ${ }^{23}$ The key finding here is that quantitative magnitude of output hysteresis in our model depends on the elasticity of innovation intensity, measured by inverse of parameter $\rho$. Lower $\rho$ implies higher sensitivity of innovation success to a given change in $\mathrm{R} \& \mathrm{D}$ investment, which in turn allows the model to generate large changes in productivity growth rate and hence level of GDP. We illustrate this with a simulation of the model under a liquidity demand shock calibrated to replicate the US Great Recession episode. Under a standard Taylor rule, the two calibrations of $\rho$ of 1.07 and 3.08 generate a permanent output gap relative to the pre-recession trend of $1.25 \%$ and $0.08 \%$, respectively. In the innovation literature, these two values of $\rho$ lie in the range of empirically estimated values. Hence, our exercise suggests plausibility of quantitatively significant hysteresis under a commonly assumed monetary policy rule. Furthermore, we show that a hysteresis targeting rule also buffers the output impact of the liquidity demand shock (immediate output drop of $0.3 \%$ compared to $2.6 \%$ under a Taylor rule for $\rho=3.08$, and similar difference for low $\rho$ ) via its built-in commitment mechanism to keeping interest rates lower for longer. More details are provided in the appendix.

\section{Conclusion}

This paper undertakes optimal monetary policy analysis in an environment where the long-run potential output of the economy is endogenous to short-run fluctuations in demand. An optimizing policy maker at the ZLB commits to keeping interest rates lower in order to offset the long-run effects of contraction in aggregate demand. However, a policymaker unable to commit to future interest rates does not offset permanent output gaps following a ZLB episode. This is the hysteresis bias of discretionary policy that we formalize.

There are however certain shortcomings in our analysis that we now highlight. Our modeling assumption in the paper is that a new innovation gets adopted with certainty in the following period. This is clearly unrealistic. Comin and Hobijn (2010) and others have found that firms adopt new technology with a lag of upto seven years on average. As long as contraction in demand results in lower investment in knowledge creation, the model of output hysteresis presented in this paper has insights for the conduct of monetary

\footnotetext{
${ }^{23}$ citeguerron2014liquidity also show that endogenous growth can generate positive co-movement of equity prices and investment in recent models of financial frictions with adverse asset liquidity shocks.
} 
policy. The key elasticity determining the long-run effect of sub-optimal monetary policy is the elasticity of innovation to $R \& D$ expenditure. We have discussed robustness to calibrating various parameterizations of this elasticity. However we leave the investigation of optimal monetary policy in a richer model with implementation lags and technology diffusion (see for example Anzoategui et al. 2019) for future work.

While the empirical evidence on the interaction between monetary policy and long-term investment in research is still scant, there is a large literature emphasizing the potency of tax credits for spurring R\&D growth. Time-varying fiscal instruments in the presence of non-distortionary lump-sum taxation can replicate the first-best outcome in our framework (see appendix D.6). However, in this paper we limit our focus to time-varying use of monetary policy instrument. We leave the analysis of optimal fiscal policy for future research.

\section{References}

Acemoglu, Daron, and Ufuk Akcigit. 2012. "Intellectual property rights policy, competition and innovation." Journal of the European Economic Association, 10(1): 1-42.

Acharya, Sushant, Julien Bengui, Keshav Dogra, and Shu Wee. 2018. "Slow Recoveries and Unemployment Traps: Monetary Policy in a Time of Hysteresis."

Aghion, P, and P Howitt. 1992. "A Model of Growth through Creative Destruction." Econometrica, 60(2).

Aghion, Philippe, and Peter W Howitt. 2008. The Economics of Growth. MIT Press.

Aghion, Philippe, George-Marios Angeletos, Abhijit Banerjee, and Kalina Manova. 2010. "Volatility and growth: Credit constraints and the composition of investment." Journal of Monetary Economics, 57(3): 246-265.

Aghion, Philippe, Ufuk Akcigit, and Peter Howitt. 2014. "The Schumpeterian Model." Lecture Notes, Chapter 5 .

Amano, Robert, and Malik Shukayev. 2012. "Risk premium shocks and the zero bound on nominal interest rates." Journal of Money, Credit and Banking, 44(8): 1475-1505.

Annicchiarico, Barbara, and Alessandra Pelloni. 2016. "Innovation, Growth and Optimal Monetary Policy." CEIS Working Paper.

Anzoategui, Diego, Diego Comin, Mark Gertler, and Joseba Martinez. 2019. "Endogenous Technology Adoption and R\&D as Sources of Business Cycle Persistence." American Economic Journal: Macroeconomics, 11(3): $67-110$.

Barnichon, Régis, and Christian T Brownlees. 2016. "Impulse Response Estimation By Smooth Local Projections."

Benigno, Gianluca, and Luca Fornaro. 2018. "Stagnation Traps." The Review of Economic Studies.

Benigno, Pierpaolo, and Michael Woodford. 2004. "Optimal monetary and fiscal policy: A linear-quadratic approach." In NBER Macroeconomics Annual 2003, Volume 18. 271-364. The MIT Press.

Bianchi, Francesco, Howard Kung, and Gonzalo Morales. 2019. "Growth, slowdowns, and recoveries." Journal of Monetary Economics, 101: 47-63.

Blanchard, Olivier. 2018. "Should we reject the natural rate hypothesis?" Journal of Economic Perspectives, 32(1): $97-120$.

Blanchard, Olivier, and Jordi Galí. 2007. "Real wage rigidities and the New Keynesian model." Journal of Money, Credit and Banking, 39(s1): 35-65. 
Blanchard, Olivier J, and Lawrence H Summers. 1986. "Hysteresis and the European unemployment problem." In NBER Macroeconomics Annual 1986, Volume 1. 15-90. MIT Press.

Bloom, Nicholas, Charles I Jones, John Van Reenen, and Michael Webb. 2017. "Are ideas getting harder to find?" National Bureau of Economic Research.

Brown, James R, Steven M Fazzari, and Bruce C Petersen. 2009. "Financing innovation and growth: Cash flow, external equity, and the 1990s R\&D boom." The Journal of Finance, 64(1): 151-185.

Calvo, Guillermo A. 1983. "Staggered prices in a utility-maximizing framework." Journal of Monetary Economics, 12(3): 383-398.

Cette, Gilbert, John Fernald, and Benoît Mojon. 2016. "The pre-Great Recession slowdown in productivity." European Economic Review.

Chetty, Raj, Adam Guren, Day Manoli, and Andrea Weber. 2016. "Does indivisible labor explain the difference between micro and macro elasticities? A meta-analysis of extensive margin elasticities." In . University of Chicago Press.

Christiano, L.J., and Jonas DM Fisher. 1998. "Stock market and investment good prices: Implications for macroeconomics."

Christiano, L.J., M. Eichenbaum, and C.L. Evans. 2005. "Nominal Rigidities and the Dynamic Effects of a Shock to Monetary Policy." Journal of Political Economy, 113(1).

Chung, Hess, Edward Herbst, and Michael T Kiley. 2015. "Effective Monetary Policy Strategies in New Keynesian Models: A Reexamination." NBER Macroeconomics Annual, 29(1): 289-344.

Comin, Diego, and Bart Hobijn. 2010. "An exploration of technology diffusion." American Economic Review, 100(5): 2031-2059.

Correia, Isabel, Emmanuel Farhi, Juan Pablo Nicolini, and Pedro Teles. 2013. "Unconventional fiscal policy at the zero bound." American Economic Review, 103(4): 1172-1211.

Correia, Isabel, Juan Pablo Nicolini, and Pedro Teles. 2008. "Optimal fiscal and monetary policy: Equivalence results." Journal of Political Economy, 116(1): 141-170.

Decker, Ryan, John Haltiwanger, Ron S Jarmin, and Javier Miranda. 2014. "The Secular Decline in Business Dynamism in the US."

Del Negro, Marco, Gauti Eggertsson, Andrea Ferrero, and Nobuhiro Kiyotaki. 2017. "The great escape? A quantitative evaluation of the Fed's non-standard policies." The American Economic Review.

DeLong, Bradford J., and Lawrence H. Summers. 2012. "Fiscal Policy in a Depressed Economy." Brookings Papers on Economic Activity, 1: 233-297.

Eberly, Janice C. 1997. "International evidence on investment and fundamentals." European Economic Review, 41(6): 1055-1078.

Edge, Rochelle. 2003. "A utility-based welfare criterion in a model with endogenous capital accumulation." Board of Governors of the Federal Reserve System (US).

Eggertsson, Gauti B. 2006. "The Deflation Bias and Committing to Being Irresponsible." Journal of Money, Credit and Banking, 38(2): 283-321.

Eggertsson, Gauti B. 2008. "Great Expectations and the End of the Depression." American Economic Review, 98(4): 1476-1516

Eggertsson, Gauti B. 2011. "What fiscal policy is effective at zero interest rates?" In NBER Macroeconomics Annual 2010, Volume 25. 59-112. University of Chicago Press.

Eggertsson, Gauti B, and Michael Woodford. 2003. "Zero bound on interest rates and optimal monetary policy." Brookings Papers on Economic Activity, 2003(1): 139-233.

Eggertsson, Gauti B., and Neil R. Mehrotra. 2015. "A Model of Secular Stagnation.” Mimeo, Brown University. 
Eggertsson, Gauti B, Neil R Mehrotra, Sanjay R Singh, and Lawrence H Summers. 2016. "A Contagious Malady? Open Economy Dimensions of Secular Stagnation." National Bureau of Economic Research.

Erceg, Christopher J, and Andrew T Levin. 2014. "Labor force participation and monetary policy in the wake of the Great Recession." Journal of Money, Credit and Banking, 46(S2): 3-49.

Erceg, Christopher J, Dale W Henderson, and Andrew T Levin. 2000. "Optimal monetary policy with staggered wage and price contracts." Journal of Monetary Economics, 46(2): 281-313.

Fatas, Antonio. 2000. "Do business cycles cast long shadows? Short-run persistence and economic growth." Journal of Economic Growth, 5(2): 147-162.

Fatás, Antonio, and Lawrence H Summers. 2015. "The permanent effects of fiscal consolidations."

Fernald, John G. 2014a. "Productivity and Potential Output before, during, and after the Great Recession." NBER Macroeconomics Annual, 29(1): 1-51.

Fernald, John G. 2014b. "A quarterly, utilization-adjusted series on total factor productivity." Federal Reserve Bank of San Francisco Working paper, 19: 2014.

Fisher, Jonas DM. 2015. "On the Structural Interpretation of the Smets-Wouters "Risk Premium" Shock." Journal of Money, Credit and Banking, 47(2-3): 511-516.

Galí, Jordi. 2015. Monetary policy, inflation, and the business cycle: an introduction to the new Keynesian framework and its applications. Princeton University Press.

Galí, Jordi. 2016. "Hysteresis and the European unemployment problem revisited." National Bureau of Economic Research.

Garcia-Macia, Daniel. 2015. "The Financing of Ideas and the Great Deviation."

Gertler, Mark, and Peter Karadi. 2015. "Monetary Policy Surprises, Credit Costs, and Economic Activity." American Economic Journal: Macroeconomics, 7(1): 44-76.

Gordon, Robert J. 2015. "Secular stagnation: A supply-side view." American Economic Review, 105(5): 54-59.

Griliches, Zvi. 1990. "Patent Statistics as Economic Indicators: A Survey." Journal of Economic Literature, 28(4): 1661-1707.

Grossman, Gene M, and Elhanan Helpman. 1991. "Quality ladders in the theory of growth." The Review of Economic Studies, 58(1): 43-61.

Guerrieri, Veronica, and Guido Lorenzoni. 2017. "Credit crises, precautionary savings, and the liquidity trap." The Quarterly Journal of Economics, 132(3): 1427-1467.

Guerron-Quintana, Pablo A, and Ryo Jinnai. 2019. "Financial frictions, trends, and the great recession." Quantitative Economics, 10(2): 735-773.

Gürkaynak, Refet S, Brian Sack, and Eric Swanson. 2005. "The sensitivity of long-term interest rates to economic news: evidence and implications for macroeconomic models." The American Economic Review, 95(1): 425436.

Hall, Bronwyn, Jacques Mairesse, and Pierre Mohnen. 2010. "Measuring the Returns to R\&D." In Handbook of Economics of Innovation, Volume 2. Chapter Chapter 24, 1033-1082. Elsevier.

Hall, Robert E. 2016. "Why Has the Unemployment Rate Fared Better than GDP Growth?" September 27,2016 Draft for the Boston Federal Reserve's conference, "The Elusive 'Great Recovery': Causes and Implications for Future Business Cycle Dynamics".

Hansen, Alvin H. 1939. "Economic progress and declining population growth." American Economic Review, 29(1): 1-15.

Howitt, Peter. 2000. "Endogenous growth and cross-country income differences." American Economic Review, 829-846. 
Howitt, Peter, and Philippe Aghion. 1998. "Capital accumulation and innovation as complementary factors in long-run growth." Journal of Economic Growth, 3(2): 111-130.

Ikeda, Daisuke, and Takushi Kurozumi. 2014. "Post-Crisis Slow Recovery and Monetary Policy."

Jones, Charles I. 2005. "Growth and ideas." Handbook of economic growth, 1: 1063-1111.

Jones, Charles I, and John C Williams. 1998. "Measuring the social return to R \& D." Quarterly Journal of Economics, 1119-1135.

Jordà, Òscar. 2005. "Estimation and Inference of Impulse Responses Local Projections." The American Economic Review, 95(1): 161-182.

Jordà, Òscar, Moritz Schularick, and Alan M Taylor. 2019. "The effects of quasi-random monetary experiments." Journal of Monetary Economics.

Jordà, Òscar, Sanjay R. Singh, and Alan M. Taylor. 2019. "The long-run effects of monetary policy." Mimeo, UC Davis.

Justiniano, Alejandro, Giorgio E Primiceri, and Andrea Tambalotti. 2013. "Is there a trade-off between inflation and output stabilization?" American Economic Journal: Macroeconomics, 5(2): 1-31.

Kortum, Samuel. 1993. "Equilibrium R\&D and the Patent-R\&D ratio: US evidence." American Economic Review, 83(2): 450-457.

Krishnamurthy, Arvind, and Annette Vissing-Jorgensen. 2012. "The aggregate demand for treasury debt." Journal of Political Economy, 120(2): 233-267.

Krugman, Paul R. 1998. "It's Baaack: Japan's Slump and the Return of the Liquidity Trap." Brookings Papers on Economic Activity, 2: 137-205.

Kydland, Finn E, and Edward C Prescott. 1977. "Rules Rather than Discretion: The Inconsistency of Optimal Plans." Journal of Political Economy, 85(3): 473-492.

Martin, Robert, Teyanna Munyan, and Beth Anne Wilson. 2015. "Potential output and recessions: are we fooling ourselves?" FRB International Finance Discussion Paper \#1145.

Maskin, Eric, and Jean Tirole. 2001. "Markov perfect equilibrium: I. Observable actions." Journal of Economic Theory, 100(2): 191-219.

Meier, Matthias, and Timo Reinelt. 2019. "Monetary Policy, markup dispersion and aggregate TFP." Mimeo, Universitat Mannheim.

Mertens, Karel, and Morten O Ravn. 2013. "The dynamic effects of personal and corporate income tax changes in the United States." American Economic Review, 103(4): 1212-1247.

Michaillat, Pascal, and Emmanuel Saez. 2014. "An Economical Business-Cycle Model." National Bureau of Economic Research.

Moran, Patrick, and Albert Queraltó. 2018. "Innovation, productivity, and monetary policy." Journal of Monetary Economics, 93(C): 24-41.

Nakamura, Emi, and Jón Steinsson. 2008. "Five facts about prices: A reevaluation of menu cost models." The Quarterly Journal of Economics, 123(4): 1415-1464.

Neiss, Katharine S, and Edward Nelson. 2003. "The real-interest-rate gap as an inflation indicator." Macroeconomic Dynamics, 7(02): 239-262.

Nuño, Galo. 2011. "Optimal research and development and the cost of business cycles." Journal of Economic Growth, 16(3): 257-283.

Ottonello, Pablo, and Thomas Winberry. 2017. "Financial Heterogeneity and the Investment Channel of Monetary Policy." Working paper, July.

Queralto, Albert. 2019. "A model of slow recoveries from financial crises." Journal of Monetary Economics. 
Ramey, Valerie A, and Sarah Zubairy. 2017. "Government spending multipliers in good times and in bad: evidence from US historical data." Journal of Political Economy (forthcoming).

Reifschneider, David, and John C Williams. 2000. "Three lessons for monetary policy in a low-inflation era." Journal of Money, Credit and Banking, 936-966.

Romer, Christina D, and David H Romer. 2004. "A New Measure of Monetary Shocks: Derivation and Implications." The American Economic Review.

Smets, Frank, and Rafael Wouters. 2007. "Shocks and frictions in US business cycles: A Bayesian DSGE approach." American Economic Review, 97(3): 586-606.

Stadler, George W. 1990. "Business cycle models with endogenous technology." American Economic Review, $763-778$.

Stock, James H. 2008. "What?s New in Econometrics: Time Series, Lecture 7." Short course lectures, NBER Summer Institute.

Stock, James H., and Mark W. Watson. 2012. "Disentangling the Channels of the 2007-09 Recession." Brookings Papers on Economic Activity.

Stock, James H., and Mark W. Watson. 2016. "Why Has GDP Growth Been So Slow to Recover?" Draft for the Boston Federal Reserve's conference, "The Elusive 'Great Recovery': Causes and Implications for Future Business Cycle Dynamics".

Stock, James H., and Mark W. Watson. 2017. "Identification and Estimation of Dynamic Causal Effects in Macroeconomics." Working Paper.

Summers, Lawrence H. 2015. "Demand side secular stagnation." American Economic Review, 105(5): 60-65.

Taylor, John B. 1993. "Discretion versus policy rules in practice." In Carnegie-Rochester conference series on public policy. Vol. 39, 195-214.

Vestin, David. 2006. "Price-level versus inflation targeting." Journal of Monetary Economics, 53(7): 1361-1376.

Wieland, Johannes F, and Mu-Jeung Yang. 2016. "Financial dampening." National Bureau of Economic Research.

Wong, Arlene. 2015. "Population aging and the transmission of monetary policy to consumption." Working paper.

Woodford, Michael. 2003. Interest and prices: Foundations of a theory of monetary policy. Princeton University Press Princeton, NJ.

Woodford, Michael. 2012. "Methods of policy accommodation at the interest-rate lower bound." In ProceedingsEconomic Policy Symposium-Jackson Hole.

Yellen, Janet L. 2015. "The outlook for the economy." Speech at the Providence Chamber of Commerce, Providence, Rhode Island, May.

Yellen, Janet L. 2016. "Macroeconomic Research After the Crisis." Speech at the "The Elusive 'Great' Recovery: Causes and Implications for Future Business Cycle Dynamics" conference, Federal Reserve Bank of Boston, October. 
For Online Publication

\section{Output Hysteresis and Optimal Monetary Policy Appendix}

Vaishali Garga and Sanjay R. Singh ${ }^{\dagger}$

August 18, 2019

$\dagger$ Garga: vaishali.garga@bos.frb.org, Research Department, Federal Reserve Bank of Boston, MA 02210. Singh: sjrsingh@ucdavis.edu. Department of Economics, University of California at Davis, Davis, CA 95616.

The views expressed herein are those of the authors and do not indicate concurrence by the Federal Reserve Bank of Boston, the principals of the Board of Governors, or the Federal Reserve System. 


\section{A Competitive Equilibrium}

Definition A.1 (Competitive Equilibrium). The competitive equilibrium is defined as a sequence of 9 quantities $\left\{C_{t}, z_{t}, V_{t}, \Gamma_{t}, Y_{t}^{G}, Y_{t}, R D_{t}, L_{t}, A_{t}\right\}$ and 7 prices $\left\{i_{t}, Q_{t, t+1}, P_{t}, W_{t}, K_{t}, F_{t}, \pi_{W, t},\right\}$ which satisfy the following 16 equations, for a given sequence of exogenous shocks $\left\{\varepsilon_{t}, \xi_{t}, M_{t}, \lambda_{w, t}\right\}$ and exogenously specified policy variables $\left\{\tau_{t}^{b}, \tau_{t}^{r}, \tau_{t}^{p}, \tau_{t}^{w}\right\}$.

1. Euler Equation and Stochastic Discount Factor

$$
\begin{gathered}
1=\beta \mathbb{E}_{t}\left[\frac{C_{t+1}^{-1}}{C_{t}^{-1}}\left(1+i_{t}\right) \frac{P_{t}}{P_{t+1}}\left(1-\tau_{t}^{b}\right)\right]+\xi_{t} C_{t} \\
Q_{t, t+1}=\beta \frac{C_{t+1}^{-1}}{C_{t}^{-1}} \frac{P_{t}}{P_{t+1}}
\end{gathered}
$$

2. Endogenous Growth Block

$$
\begin{gathered}
\left(1-\tau_{t}^{r}\right) P_{t} \delta \varrho z_{t}^{\varrho-1}=\mathbb{E}_{t} Q_{t, t+1} V_{t+1}\left(A_{t+1}\right) \\
V_{t}\left(A_{t}\right)=\Gamma_{t}+\left(1-z_{t}\right) \mathbb{E}_{t} Q_{t, t+1} V_{t+1}\left(A_{t}\right) \\
\Gamma_{t}=(\zeta-1)\left(\frac{\alpha}{\zeta}\right)^{\frac{1}{1-\alpha}} P_{t} M_{t} L_{t} A_{t}
\end{gathered}
$$

where $\zeta \equiv \min \left(\gamma^{1-\alpha}, \frac{1}{\left(1-\tau_{t}^{p}\right) \alpha}\right)$, and $\gamma>1$.

3. Wage Setting frictions

$$
\begin{gathered}
\frac{K_{t}}{F_{t}}=\left(\frac{1-\theta_{w}\left(\pi_{t}^{w}\right)^{\frac{1}{\lambda_{w, t}}}}{1-\theta_{w}}\right)^{-\lambda_{w, t}+\left(1+\lambda_{w, t}\right) \nu} \\
K_{t}=\omega\left(1+\lambda_{w, t}\right) L_{t}^{1+\nu}+\theta_{w} \beta \bar{\Pi}_{W}^{-\frac{\left(1+\lambda_{w, t+1}\right)(1+\nu)}{\lambda_{w, t+1}}} \Pi_{W, t+1}^{\frac{\left(1+\lambda_{w, t+1}\right)(1+\nu)}{\lambda_{w}, t+1}} K_{t+1} \\
F_{t}=\left(1+\tau_{t}^{w}\right) L_{t} C_{t}^{-1} \frac{W_{t}}{P_{t}}+\theta_{w} \beta \bar{\Pi}_{W}^{\frac{-1}{\lambda_{w}, t+1}} \Pi_{W, t+1}^{\frac{1}{\lambda_{w}, t+1}} F_{t+1} \\
\Pi_{W, t}=\frac{W_{t}}{W_{t-1}}
\end{gathered}
$$

4. Law of motion of productivity

$$
A_{t}=A_{t-1}+z_{t-1}(\gamma-1) A_{t-1}
$$

5. Market Clearing Conditions and Production Technologies

$$
Y_{t}^{G}=\left(\frac{\alpha}{\zeta}\right)^{\frac{\alpha}{1-\alpha}} M_{t} L_{t} A_{t}
$$




$$
\begin{gathered}
R D_{t}=\delta z_{t}^{\varrho} A_{t} \\
\left(1-\frac{\alpha}{\zeta}\right) Y_{t}^{G}=Y_{t} \\
Y_{t}=C_{t}+R D_{t} \\
W_{t}=(1-\alpha)\left(\frac{\alpha}{\zeta}\right)^{\frac{\alpha}{1-\alpha}} M_{t} A_{t} P_{t}
\end{gathered}
$$

6. Monetary Policy Rule

$$
1+i_{t}=\max \left(1,\left(1+i_{s s}\right)\left(\frac{\pi_{W, t}}{\bar{\pi}_{W}}\right)^{\phi_{\pi}}\left(\frac{L_{t}}{\bar{L}}\right)^{\phi_{y}} \varepsilon_{t}^{i}\right) ; \quad \phi_{\pi}>1 ; \phi_{y}>0
$$

\section{Stationarizing the System}

The competitive equilibrium defined above is non-stationary. Specifically, consumption, output, nominal wage, are co-integrated with TFP level $A_{t}$. We normalize the variables as follows:

$$
c_{t} \equiv \frac{C_{t}}{A_{t}} ; y_{t} \equiv \frac{Y_{t}}{A_{t}} ; y_{t}^{G} \equiv \frac{Y_{t}^{G}}{A_{t}} ; r d_{t} \equiv \frac{R D_{t}}{A_{t}} ; \tilde{\Gamma}_{t} \equiv \frac{\Gamma_{t}}{P_{t} A_{t}} ; w_{t} \equiv \frac{W_{t}}{P_{t} A_{t}}
$$

Further note that because of the linearity assumption in the production of final goods, the Value function is a linear function in productivity with which an entrepreneur enters the sector:

$$
\tilde{V}_{t}=\frac{V_{t}}{A_{t}}=\tilde{\Gamma}_{t}+\left(1-z_{t}\right) \mathbb{E}_{t} Q_{t, t+1} \tilde{V}_{t+1}
$$

where $\tilde{V}$ is normalized by the productivity with which the entrepreneur enters the sector. Finally the growth rate of productivity, determined in period $t$, is given by

$$
\left(1+g_{t+1}\right)=1+z_{t}(\gamma-1)
$$

Remaining variables are stationary.

Definition A.2 (Normalized Competitive Equilibrium). The normalized competitive equilibrium is defined as a sequence of 9 stationary quantities $\left\{c_{t}, \tilde{V}_{t}, \tilde{\Gamma}_{t}, y_{t}^{G}, y_{t}, r d_{t}, L_{t}, g_{t+1}, z_{t}\right\}$ and 6 stationary prices $\left\{i_{t}, w_{t}\right.$, $\left.K_{t}, F_{t}, \pi_{W, t}, \Pi_{t}\right\}$ which satisfy the following 15 equations, for a given sequence of exogenous shocks $\left\{\varepsilon_{t}, \xi_{t}\right.$, $\left.M_{t}, \lambda_{w, t}\right\}$ and exogenously specified policy variables $\left\{\tau_{t}^{b}, \tau_{t}^{r}, \tau_{t}^{p}, \tau_{t}^{w}\right\}$.

1. Euler Equation and Stochastic Discount Factor

$$
1=\beta \mathbb{E}_{t}\left[\frac{c_{t+1}^{-1}\left(1+g_{t+1}\right)^{-1}}{c_{t}^{-1}} \frac{1+i_{t}}{\pi_{t+1}}\left(1-\tau_{t}^{b}\right)\right]+\xi_{t}^{\prime} c_{t}
$$

where $\xi_{t}^{\prime}=\xi_{t} A_{t}$ 
2. Endogenous Growth Block

$$
\begin{gathered}
\left(1-\tau_{t}^{r}\right) \delta \varrho z_{t}^{\varrho-1}=\mathbb{E}_{t} \frac{c_{t+1}^{-1}\left(1+g_{t+1}\right)^{-1}}{c_{t}^{-1}} \gamma \tilde{V}_{t+1} \\
\tilde{V}_{t}=\tilde{\Gamma}_{t}+\left(1-z_{t}\right) \mathbb{E}_{t} \frac{c_{t+1}^{-1}\left(1+g_{t+1}\right)^{-1}}{c_{t}^{-1}} \tilde{V}_{t+1} \\
\tilde{\Gamma}_{t}=(\zeta-1)\left(\frac{\alpha}{\zeta}\right)^{\frac{1}{1-\alpha}} M_{t} L_{t}
\end{gathered}
$$

where $\zeta \equiv \min \left(\gamma^{1-\alpha}, \frac{1}{\left(1-\tau_{t}^{p}\right) \alpha}\right)$, and $\gamma>1$.

3. Wage Setting frictions

$$
\begin{gathered}
\frac{K_{t}}{F_{t}}=\left(\frac{1-\theta_{w}\left(\pi_{t}^{w}\right)^{\frac{1}{\lambda_{w}, t}}}{1-\theta_{w}}\right)^{-\lambda_{w, t}+\left(1+\lambda_{w, t}\right) \nu} \\
K_{t}=\omega\left(1+\lambda_{w, t}\right) L_{t}{ }^{1+\nu}+\theta_{w} \beta \bar{\Pi}_{W}^{-\frac{\left(1+\lambda_{w, t+1}(1+\nu)\right.}{\lambda_{w, t+1}}} \Pi_{W, t+1}^{\frac{\left(1+\lambda_{w, t+1}\right)(1+\nu)}{\lambda_{w} t+1}} K_{t+1} \\
F_{t}=\left(1+\tau_{t}^{w}\right) L_{t} c_{t}^{-1} w_{t}+\theta_{w} \beta \bar{\Pi}_{W}^{\frac{-1}{\lambda_{w}, t+1}} \Pi_{W, t+1}^{\frac{1}{\lambda_{w}, t+1}} F_{t+1} \\
\pi_{w, t}=\frac{w_{t}}{w_{t-1}}\left(1+g_{t}\right) \pi_{t}
\end{gathered}
$$

4. Productivity growth rate

$$
\left(1+g_{t+1}\right)=1+z_{t}(\gamma-1)
$$

5. Market Clearing Conditions and Production Technologies

$$
\begin{gathered}
y_{t}^{G}=\left(\frac{\alpha}{\zeta}\right)^{\frac{\alpha}{1-\alpha}} M_{t} L_{t} \\
r d_{t}=\delta z_{t}^{\varrho} \\
\left(1-\frac{\alpha}{\zeta}\right) y_{t}^{G}=y_{t} \\
y_{t}=c_{t}+r d_{t} \\
w_{t}=(1-\alpha)\left(\frac{\alpha}{\zeta}\right)^{\frac{\alpha}{1-\alpha}} M_{t}
\end{gathered}
$$

6. Monetary Policy Rule

$$
1+i_{t}=\max \left(1,\left(1+i_{s s}\right)\left(\frac{\pi_{W, t}}{\bar{\pi}_{W}}\right)^{\phi_{\pi}}\left(\frac{L_{t}}{\bar{L}}\right)^{\phi_{y}} \varepsilon_{t}^{i}\right) ; \quad \phi_{\pi}>1 ; \phi_{y}>0
$$

\section{Steady State}


Six variables $z, g, V, L, C, Y$ solve the following six equations

1. Endogenous Growth Equation

$$
\left(1-\tau^{r}\right) \varrho z^{\varrho-1}=\frac{\beta}{1+g} \frac{\gamma \tilde{V}}{\delta}
$$

2. Value Function

$$
\tilde{V}=\frac{(\zeta-1)\left(\frac{\alpha}{\zeta}\right)^{\frac{1}{1-\alpha}} L}{1+g-(1-z)}(1+g)
$$

3. Intra-temporal Labor Supply condition

$$
\omega L^{\nu} c=(1-\alpha)\left(\frac{\alpha}{\zeta}\right)^{\frac{\alpha}{1-\alpha}}
$$

4. Aggregate Production Function

$$
y=\left(1-\frac{\alpha}{\zeta}\right)\left(\frac{\alpha}{\zeta}\right)^{\frac{\alpha}{1-\alpha}} L
$$

5. Resource Constraint

$$
c+\delta z^{\varrho}=y
$$

6. Growth equation (law of motion of productivity)

$$
g=z(\gamma-1)
$$

Other steady state variables can be backed out after solving this system. We look for steady state such that $z \in(0,1)$ and $c \geq 0$.

Definition A.3 (Approximate Equilibrium). An approximate competitive equilibrium in this economy with endogenous growth is defined as a sequence of variables $\left\{\hat{\pi}_{t}^{w}, \hat{c}_{t}, \hat{y}_{t}, \hat{g}_{t+1}, \hat{i}_{t}, \hat{L}_{t}, \hat{w}_{t}, \hat{\pi}_{t}, \hat{V}_{t}\right\}$ which satisfy the following equations, for a given sequence of exogenous shocks $\left\{\hat{\xi}_{t}, \hat{M}_{t}, \hat{\epsilon}_{t}^{i}, \hat{\lambda}_{w t}\right\}$.

Aggregate Demand:

$$
-\left(\mathbb{E}_{t} \hat{c}_{t+1}-\hat{c}_{t}+\hat{g}_{t+1}\right)+\hat{i}_{t}-\mathbb{E}_{t} \hat{\pi}_{t+1}+\hat{\xi}_{t}=0
$$

Endogenous growth equations:

$$
\begin{aligned}
& (\varrho-1) \eta_{g} \hat{g}_{t+1}=-\left(\mathbb{E}_{t} \hat{c}_{t+1}-\hat{c}_{t}+\hat{g}_{t+1}\right)+\mathbb{E}_{t} \hat{V}_{t+1} \\
& \hat{V}_{t}=\eta_{y} \hat{y}_{t}-\eta_{z} \hat{g}_{t+1}-\eta_{q}\left(\mathbb{E}_{t} \hat{c}_{t+1}-\hat{c}_{t}+\hat{g}_{t+1}\right)+\eta_{q} \mathbb{E}_{t} \hat{V}_{t+1}
\end{aligned}
$$

where $\eta_{y}=1-\frac{(1-z) \beta}{1+g}>0, \eta_{z}=\frac{\beta}{\gamma-1}>0, \eta_{q}=\frac{(1-z) \beta}{1+g}>0$ 
Market clearing:

$$
\begin{aligned}
& \frac{c}{y} \hat{c}_{t}+\frac{\mathbb{R}}{y} \varrho \eta_{g} \hat{g}_{t+1}=\hat{y}_{t} \\
& \hat{y}_{t}=\hat{M}_{t}+\hat{L}_{t}
\end{aligned}
$$

Wage setting:

$$
\begin{aligned}
& \hat{\pi}_{t}^{w}=\tilde{\beta} \mathbb{E}_{t} \hat{\pi}_{t+1}^{w}+\kappa_{w}\left[\hat{c}_{t}+\nu \hat{L}_{t}-\hat{w}_{t}\right]+\kappa_{w} \hat{\lambda}_{w t} \\
& \hat{w}_{t}=\hat{M}_{t} \\
& \hat{\pi}_{t}^{w}=\hat{w}_{t}-\hat{w}_{t-1}+\hat{\pi}_{t}+\hat{g}_{t}
\end{aligned}
$$

where $\kappa_{w} \equiv \frac{\left(1-\theta_{w}\right)\left(1-\beta \theta_{w}\right)}{\theta_{w}\left(1+\nu\left(1+\frac{1}{\lambda_{w}}\right)\right)}>0$

Monetary policy rule:

$$
\hat{i}_{t}=\max \left(-\frac{\bar{i}}{1+\bar{i}}, \phi_{\pi} \hat{\pi}_{t}^{w}+\phi_{y} \hat{L}_{t}+\hat{\varepsilon}_{t}^{i}\right)
$$

\section{B Local Determinacy with one-period patent and exogenous nom- inal wages}

To analytically characterize the determinacy condition, we make following two assumptions, that we will refer to as $\mathrm{T} 1$ and $\mathrm{T} 2$ :

Assumption T1 Deterministic patent length of one period: Upon successful innovation, the entrepreneur gets the monopoly right over production of intermediate good in the following period $t+1$. if a randomly selected entrepreneur fails to innovate at $t+1$, the planner selects a producer from a fringe of measure zero to produce using period $t+1$ 's productivity in the following period. The first order condition reported in the endogenous growth block above is modified to:

$$
\left(1-\tau_{t}^{r}\right) P_{t} \delta \varrho z_{t}^{\varrho-1}=\mathbb{E}_{t} Q_{t, t+1} \Gamma_{t+1}\left(A_{t+1}\right)
$$

where $\Gamma_{t}\left(A_{t}\right)=(\zeta-1)\left(\frac{\alpha}{\zeta}\right)^{\frac{1}{1-\alpha}} P_{t} M_{t} L_{t} A_{t}, \zeta \equiv \min \left(\gamma^{1-\alpha} \frac{1}{\left(1-\tau_{t}^{p}\right) \alpha}\right)$, and $\gamma>1$.

Assumption T2 Perfect nominal wage rigidity with indexation: Nominal wages are assumed to evolve :

$$
W_{t}=\bar{\pi}_{W} W_{t-1}
$$

This equation replaces the wage Phillips curve derived above.

Both these assumptions allow us to analytically derive determinacy conditions, at and away from the ZLB. 


\section{B.1 Away from ZLB}

Under T1 and T2, the approximate equilibrium (assuming no shocks) is given by:

$$
\begin{gathered}
\hat{L}_{t}=\mathbb{A}_{1} \mathbb{E}_{t} \hat{L}_{t+1}+\mathbb{A}_{2} \mathbb{E}_{t} \hat{g}_{t+2} \\
\hat{g}_{t+1}=\mathbb{A}_{3} \mathbb{E}_{t} \hat{L}_{t+1}+\mathbb{A}_{4} \mathbb{E}_{t} \hat{g}_{t+2}
\end{gathered}
$$

where $\mathbb{A}_{1} \equiv \frac{\frac{y}{c}+\frac{\left(\frac{y}{c}-1\right) \varrho \eta_{g}}{(\varrho-1) \eta_{g}+1}}{\frac{y}{c}+\phi\left(1+\frac{\left(\frac{y}{c}-1\right)}{(\varrho-1) \eta_{g}+1}\right)}, \mathbb{A}_{2} \equiv \frac{\left(\frac{y}{c}-1\right) \varrho \eta_{g}}{\frac{y}{c}+\phi\left(1+\frac{\left(\frac{y}{c}-1\right)}{(\varrho-1) \eta_{g}+1}\right)}, \mathbb{A}_{3} \equiv \frac{1-\phi \mathbb{A}_{1}}{(\varrho-1) \eta_{g}+1}, \mathbb{A}_{4} \equiv \frac{-\phi \mathbb{A}_{2}}{(\varrho-1) \eta_{g}+1}, \eta_{g}=\frac{1+g}{g}$ and lowercase letter $y, c$, and $g$ denote steady state values. The system is locally determinate iff following two conditions are met:

$$
\left|\mathbb{A}_{1} \mathbb{A}_{4}-\mathbb{A}_{2} \mathbb{A}_{3}\right|<1 ; \quad\left|\mathbb{A}_{1}+\mathbb{A}_{4}\right|<1+\mathbb{A}_{1} \mathbb{A}_{4}-\mathbb{A}_{2} \mathbb{A}_{3}
$$

The second condition is met as long as $\phi>0$. The first condition is met if:

$$
\eta_{g}>\frac{\beta \gamma}{\gamma-1}>1
$$

This condition also implies that consumption is positive and there is positive R\&D investment. Assuming $\varrho=1$, this condition can be rewritten solely in terms of parameters as in Benigno and Fornaro (2017):

$$
1+\frac{\Psi(\gamma-1)}{\delta}>\frac{\beta \gamma \varpi}{\delta}>1 ; \quad \text { where } \Psi \equiv\left(1-\frac{\alpha}{\zeta}\right)\left(\frac{\alpha}{\zeta}\right)^{\frac{\alpha}{1-\alpha}} ; \quad \varpi \equiv(\zeta-1)\left(\frac{\alpha}{\zeta}\right)^{\frac{1}{1-\alpha}}
$$

For a general $\phi$, conditional on a steady state with positive consumption and positive R\&D investment, following two conditions guarantee determinacy:

$$
\phi>0 ; \quad \text { and } \quad \eta_{g}>\frac{\beta \gamma}{\gamma-1}>1
$$

\section{B.2 ZLB with two-state Markov Chain}

Assuming the two-state Markov Chain where with probability $\mu \in(0,1)$ the economy continues to stay at the ZLB and with $1-\mu$ it escapes the ZLB, the system (with T1 and T2) in the short-run ZLB state (S) can be expressed as:

$$
\begin{gathered}
\hat{L}_{t}^{S}=\mathbb{A}_{1}^{S} \mathbb{E}_{t} \hat{L}_{t+1}^{S}+\mathbb{A}_{2}^{S} \mathbb{E}_{t} \hat{g}_{t+2}^{S}+\mathbb{Q}_{1}^{S} \xi_{S} \\
\hat{g}_{t+1}^{S}=\mathbb{A}_{3}^{S} \mathbb{E}_{t} \hat{L}_{t+1}^{S}+\mathbb{A}_{4}^{S} \mathbb{E}_{t} \hat{g}_{t+2}^{S}+\mathbb{Q}_{2}^{S} \xi_{S}
\end{gathered}
$$

where $\mathbb{A}_{1}^{S} \equiv \mu\left(1+\frac{\left(1-\frac{c}{y}\right) \varrho \eta_{g}}{(\varrho-1) \eta_{g}+1}\right), \mathbb{A}_{2}^{S} \equiv-\mu\left(1-\frac{c}{y}\right) \varrho \eta_{g}, \mathbb{A}_{3}^{S} \equiv \frac{\mu}{(\varrho-1) \eta_{g}+1}, \mathbb{A}_{4}^{S} \equiv 0, \eta_{g}=\frac{1+g}{g}$ and lowercase letter $y, c$, and $g$ denote steady state values. The system is locally determinate iff:

$$
\mu<\frac{\left((\varrho-1) \eta_{g}+1\right)(\gamma-1)}{\beta \gamma}
$$


Most calibrations have $\gamma \in(1.05,1.55)$ and $\beta \in(0.96,1)$. For values of $\varrho \geq 1.105,2 \%$ annual steady state growth rate and the above parameter bounds on $\gamma$ and $\beta$, this condition is always satisfied. Given these empirically plausible parameter restrictions, we obtain local determinacy at the Zero Lower Bound.

\section{Impulse Responses under Taylor rule eq 30}

We show the detailed derivation for impulse response under the Taylor rule eq 30 and liquidity demand shock. For monetary policy shock, productivity shock and markup shock, the proof is similar. Assume that the liquidity demand shock follows the $\operatorname{AR}(1)$ process:

$$
\hat{\xi}_{t}=\rho_{i} \hat{\xi}_{t-1}+\hat{\epsilon}_{t}
$$

Guess the solution takes the form:

$$
\hat{c}_{t}=\psi_{c} \hat{\epsilon}_{t} ; \hat{y}_{t}=\psi_{y} \hat{\epsilon}_{t} ; \hat{g}_{t+1}=\psi_{g} \hat{\epsilon}_{t} ; \hat{\pi}_{t}^{w}=\psi_{p} \hat{\epsilon}_{t} ; \hat{V}_{t}=\psi_{v} \hat{\epsilon}_{t}
$$

From Euler equation, we get:

$$
\left(1-\rho_{i}\right) \psi_{c}=-\left(\phi_{\pi}-\rho_{i}\right) \psi_{p}-\phi_{y} \psi_{y}-1
$$

From the Endogeneous Growth equation:

$$
\left(1-\rho_{i}\right) \psi_{c}+\rho_{i} \psi_{v}=\left[(\varrho-1) \eta_{g}+1\right] \psi_{g}
$$

From the Resource constraint:

$$
\frac{c}{y} \psi_{c}+\frac{\mathbb{R}}{y} \varrho \eta_{g} \psi_{g}=\psi_{y}
$$

From the Wage Phillips curve

$$
\left(1-\beta \rho_{i}\right) \psi_{p}=\kappa_{w}\left(\psi_{c}+\nu \psi_{y}\right)
$$

From the Value function:

$$
\left(1-\eta_{V} \rho_{i}\right) \psi_{v}=\eta_{y} \psi_{y}-\left(\eta_{z}+\eta_{q}\right) \psi_{g}+\eta_{q}\left(1-\rho_{i}\right) \psi_{c}
$$

From equations 47,48 , and 50 , we can find a relation between $\psi_{c}$ and $\psi_{y}$. Rest of the system is pretty standard NK system where we can solve for $\psi_{p}$ and $\psi_{y}$ from equations 46 and 49 using:

$$
\psi_{c}=\frac{\frac{1-\eta_{V} \rho_{i}}{\rho_{i}} \frac{(\varrho-1) \eta_{g}+1}{\frac{\mathbb{R}}{y} \varrho \eta_{g}}+\frac{\eta_{z}+\eta_{q}}{\frac{\mathbb{R}}{\varrho} \varrho \eta_{g}}-\eta_{Y}}{\left[\frac{1-\eta_{V} \rho_{i}}{\rho_{i}} \frac{(\varrho-1) \eta_{g}+1}{\frac{\mathbb{R}}{y} \varrho \eta_{g}} \frac{c}{y}+\left(1-\rho_{i}\right)\right]+\frac{\eta_{z}+\eta_{q}}{\frac{\mathbb{R}}{y} \varrho \eta_{g}} \frac{c}{y}+\eta_{q}\left(1-\rho_{i}\right)} \psi_{y}=A_{1} \psi_{y} ; \quad 0<A_{1}<1
$$


We get:

$$
\psi_{p}=\frac{\kappa\left(A_{1}+\nu\right)}{1-\beta \rho_{i}} \psi_{y} \equiv A_{2} \psi_{y}
$$

And thus:

$$
\psi_{y}=\frac{-1}{\left(1-\rho_{i}\right) A_{1}+\left(\phi_{\pi}-\rho_{i}\right) A_{2}+\phi_{y}}<0
$$

Further, from the resource constraint we find :

$$
\psi_{g}=\frac{\psi_{y}-\frac{c}{y} \psi_{c}}{\frac{\mathbb{R}}{y} \varrho \eta_{g}}=\frac{1-\frac{c}{y} A_{1}}{\frac{\mathbb{R}}{y} \varrho \eta_{g}} \psi_{y}
$$

Since $A_{1}<1$, it follows that $A_{1}<\frac{y}{c}$. Hence there is a positive co-movement of output and growth rate under liquidity demand shock. Further it must be that the following holds

$$
\psi_{v}=\frac{\left[(\varrho-1) \eta_{g}+1\right] \psi_{g}-\left(1-\rho_{i}\right) \psi_{c}}{\rho_{i}}=\frac{\eta_{y} \psi_{y}-\left(\eta_{z}+\eta_{q}\right) \psi_{g}+\eta_{q}\left(1-\rho_{i}\right) \psi_{c}}{1-\eta_{v} \rho_{i}}
$$

\section{Solution to Social Planner's Problem}

\section{D.1 Social Planner problem I}

The Social Planner chooses $\left\{C_{t}, L_{t}, A_{t+1}, z_{t}\right\}$ to maximize the welfare function:

$$
\max \log C_{t}-\frac{\omega}{1+\nu} L_{t}^{1+\nu}
$$

subject to the constraints:

$$
\begin{gathered}
C_{t}+R D_{t}=\alpha^{\frac{\alpha}{1-\alpha}}(1-\alpha) A_{t} L_{t} \\
\frac{A_{t+1}-A_{t}}{A_{t}}=(\gamma-1) z_{t} \\
R_{t}=\delta z_{t}^{\varrho} A_{t} \\
z_{t} \geq 0
\end{gathered}
$$

Combining the constraints and using the functional form for R\&D Investment, we get:

$$
C_{t}+\delta\left(\frac{A_{t+1}-A_{t}}{A_{t}} \frac{1}{\gamma-1}\right)^{\varrho} A_{t}=\alpha^{\frac{\alpha}{1-\alpha}}(1-\alpha) A_{t} L_{t}
$$

Let $\lambda_{t}$ be the Lagrange multiplier on the constraint. Solution to this problem is thus :

$$
\begin{gathered}
\lambda_{t}=\frac{1}{C_{t}} \\
L_{t}^{\nu} C_{t}=\alpha^{\frac{\alpha}{1-\alpha}}(1-\alpha)
\end{gathered}
$$


$\frac{-\lambda_{t} \delta \varrho}{(\gamma-1)^{\varrho}}\left(\frac{A_{t+1}-A_{t}}{A_{t}}\right)^{\varrho-1}+\frac{\lambda_{t+1} \beta \delta \varrho}{(\gamma-1)^{\varrho}}\left(\frac{A_{t+2}-A_{t+1}}{A_{t+1}}\right)^{\varrho-1}-\frac{\lambda_{t+1} \beta \delta(\varrho-1)}{(\gamma-1)^{\varrho}}\left(\frac{A_{t+2}-A_{t+1}}{A_{t+1}}\right)^{\varrho}+\alpha^{\frac{\alpha}{1-\alpha}}(1-\alpha) L_{t+1} \lambda_{t+1} \beta=0$

Since growth rate is defined as $g_{t+1}=\frac{A_{t+1}-A_{t}}{A_{t}}$, we can rewrite the above condition as:

$$
\frac{C_{t+1}}{C_{t}} \frac{\delta \varrho}{(\gamma-1)^{\varrho}} g_{t+1}^{\varrho-1}=\frac{\beta \delta \varrho}{(\gamma-1)^{\varrho}} g_{t+2}^{\varrho-1}-\frac{\beta \delta(\varrho-1)}{(\gamma-1)^{\varrho}} g_{t+2}^{\varrho}+\alpha^{\frac{\alpha}{1-\alpha}}(1-\alpha) L_{t+1} \beta
$$

This can be rewritten as:

$$
\frac{C_{t+1}}{C_{t}}=\beta\left[\left(\frac{g_{t+2}}{g_{t+1}}\right)^{\varrho-1}-\frac{1-\varrho}{\varrho} g_{t+2}\left(\frac{g_{t+2}}{g_{t+1}}\right)^{\varrho-1}+\frac{\alpha^{\frac{\alpha}{1-\alpha}}(1-\alpha)}{\delta \varrho} \frac{L_{t+1}(\gamma-1)^{\varrho}}{g_{t+1}^{\varrho-1}}\right]
$$

This the Euler equation for R\&D investment in the Social Planner's allocation. The right hand side gives the return on R\&D investment. Writing the LHS in normalized terms i.e. $C_{t}=c_{t} A_{t}$, we get

$$
\frac{c_{t+1}\left(1+g_{t+1}\right)}{c_{t}}=\beta\left[\left(\frac{g_{t+2}}{g_{t+1}}\right)^{\varrho-1}-\frac{1-\varrho}{\varrho} g_{t+2}\left(\frac{g_{t+2}}{g_{t+1}}\right)^{\varrho-1}+\frac{\alpha^{\frac{\alpha}{1-\alpha}}(1-\alpha)}{\delta \varrho} \frac{L_{t+1}(\gamma-1)^{\varrho}}{g_{t+1}^{\varrho-1}}\right]
$$

The (interior) equilibrium (with positive growth) is thus given by the sequence of three variables $\left\{c_{t}, L_{t}, g_{t+1}\right\}$ such that equation 51 and following two conditions (intra-temporal labor supply and budget constraint) are satisfied:

$$
\begin{gathered}
\omega L_{t}^{\nu} c_{t}=\alpha^{\frac{\alpha}{1-\alpha}}(1-\alpha) \\
c_{t}+\delta\left(\frac{g_{t+1}}{\gamma-1}\right)^{\varrho}=\alpha^{\frac{\alpha}{1-\alpha}}(1-\alpha) L_{t}
\end{gathered}
$$

\section{D.2 Policy Relevant Welfare Function}

The representative agent's lifetime welfare function at time $t$ can be rewritten as

$$
V_{t}=\sum_{s=t}^{\infty} \beta^{s-t}\left[\log C_{s}-v\left(L_{s}\right)\right]=\sum_{s=t}^{\infty} \beta^{s-t}\left[\log c_{s}-v\left(L_{s}\right)+\frac{\beta}{1-\beta} \log \left(1+g_{s+1}\right)\right]+\frac{1}{1-\beta} \log A_{t}
$$

We redefine the terms in the square brackets as the policy relevant per period welfare function:

$$
\mathbf{W}_{t}=\log c_{t}-v\left(L_{t}\right)+\frac{\beta}{1-\beta} \log \left(1+g_{t+1}\right)
$$

Thus the policy relevant lifetime welfare function is given by

$$
\mathbb{W}_{t}=\sum_{s=t}^{\infty} \beta^{s-t}\left[\log c_{s}-v\left(L_{s}\right)+\frac{\beta}{1-\beta} \log \left(1+g_{s+1}\right)\right]
$$




\section{D.3 Social Planner problem II}

The Social Planner chooses $\left\{c_{t}, L_{t}, g_{t+1}, z_{t}\right\}$ to maximize lifetime-policy relevant welfare function:

$$
\max \sum_{s=t}^{\infty} \beta^{s-t}\left[\log c_{s}-\frac{\omega}{1+\nu} L_{s}^{1+\nu}+\frac{\beta}{1-\beta} \log \left(1+g_{s+1}\right)\right]
$$

subject to

$$
\begin{gathered}
c_{t}+r d_{t}=\alpha^{\frac{\alpha}{1-\alpha}}(1-\alpha) L_{t}=y_{t} \\
g_{t+1}=z_{t}(\gamma-1) \\
r d_{t}=\delta z_{t}^{\varrho} \\
z_{t} \geq 0
\end{gathered}
$$

Solution (for $z>0$ ) is given by:

$$
\begin{gathered}
\frac{r d^{\prime}\left(z_{t}\right)}{c_{t}}=(\gamma-1) \frac{\beta}{1-\beta} \frac{1}{1+g_{t+1}} \\
\omega L_{t}^{\nu} c_{t}=\alpha^{\frac{\alpha}{1-\alpha}}(1-\alpha) \\
c_{t}+r d_{t}=\alpha^{\frac{\alpha}{1-\alpha}}(1-\alpha) L_{t}=y_{t} \\
r d_{t}=\delta z_{t}^{\varrho} \\
g_{t+1}=z_{t}(\gamma-1)
\end{gathered}
$$

Substituting out for research intensity $z_{t}$ in terms of growth rate and using the functional form for $\mathrm{R} \& \mathrm{D}$ Investment, Solution is given by Intra-temporal labor supply condition eq 52, Budget constraint eq 53 and the following $\mathrm{R} \& \mathrm{D}$ investment condition:

$$
\varrho \delta\left(\frac{g_{t+1}}{\gamma-1}\right)^{\varrho-1}=(\gamma-1) \frac{\beta}{1-\beta} \frac{c_{t}}{1+g_{t+1}}
$$

\section{D.4 Equivalence of two solutions}

It is clear that Euler condition derived in eq 51 is not as amenable to analytical manipulations as is the corresponding $\mathrm{R} \& \mathrm{D}$ investment condition eq 54 derived under the modified Social Planner problem II. Remains to be shown that the resulting equilibrium is identical in both scenarios.

In Steady State eq 51 simplfies to:

$$
(1+g)=\beta\left[1-\frac{1-\varrho}{\varrho} g+\frac{\alpha^{\frac{\alpha}{1-\alpha}}(1-\alpha)}{\delta \varrho} \frac{L(\gamma-1)^{\varrho}}{g^{\varrho-1}}\right]
$$

It is straightforward to show that eq 54 combined with eq 53 also yields the above condition. Thus, the 
solutions are identical at the steady state. ${ }^{\dagger}$ As regards the dynamics away from the steady state, eq 51 can be rewritten as:

$$
\frac{c_{t+1}\left(1+g_{t+1}\right)}{c_{t}}=\beta\left[\left(\frac{g_{t+2}}{g_{t+1}}\right)^{\varrho-1}\left(1+g_{t+2}\right)+\frac{c_{t+1}}{\delta \varrho} \frac{(\gamma-1)^{\varrho}}{g_{t+1}^{\varrho-1}}\right]
$$

From eq 54, we can write out the RHS of the above equation 55 as

$$
\frac{c_{t+1}\left(1+g_{t+1}\right)}{c_{t}}=\left(\frac{g_{t+2}}{g_{t+1}}\right)^{\varrho-1}\left(1+g_{t+2}\right)
$$

Thus, it remains to show that the LHS of two equations 55 and 56 are equal. We prove by reduction. Substitute LHS of equation 56 into RHS of eq 55 to get:

$$
\left(\frac{g_{t+2}}{g_{t+1}}\right)^{\varrho-1}\left(1+g_{t+2}\right)=\beta\left[\left(\frac{g_{t+2}}{g_{t+1}}\right)^{\varrho-1}\left(1+g_{t+2}\right)+\frac{c_{t+1}}{\delta \varrho} \frac{(\gamma-1)^{\varrho}}{g_{t+1}^{\varrho-1}}\right]
$$

Simple algebraic manipulation yields:

$$
(1-\beta)\left(\frac{g_{t+2}}{g_{t+1}}\right)^{\varrho-1}\left(1+g_{t+2}\right)=\beta \frac{c_{t+1}}{\delta \varrho} \frac{(\gamma-1)^{\varrho}}{g_{t+1}^{\varrho-1}}
$$

which can be simplified to yield:

$$
\frac{1-\beta}{\beta} \frac{\varrho \delta}{\gamma-1}\left(\frac{g_{t+2}}{\gamma-1}\right)^{\varrho-1}\left(1+g_{t+2}\right)=c_{t+1}
$$

which is true since it is eq 54 forwarded by one period. Since we do not use the labor-supply intra-temporal condition to show the equivalence between the two solutions under flexible wages, the two approaches are also equivalent under nominal wage rigidities which introduces a wedge in the labor-supply intra-temporal condition.

\section{D.5 Efficient Steady State}

Efficient Steady State is given by following system of equations in three variables $c, L, g$ :

$$
\begin{gathered}
L=\left[\frac{\alpha^{\frac{\alpha}{1-\alpha}}(1-\alpha)}{\omega c}\right]^{\frac{1}{\nu}} ; \quad c=\frac{\varrho \delta}{\gamma-1} \frac{1-\beta}{\beta}(1+g)\left(\frac{g}{\gamma-1}\right)^{\varrho-1} \\
c+\delta\left(\frac{g}{\gamma-1}\right)^{\varrho}=\alpha^{\frac{\alpha}{1-\alpha}}(1-\alpha) L
\end{gathered}
$$

These yield the above Euler equation.

$$
\frac{\beta c}{\varrho \delta} \frac{(\gamma-1)^{\varrho}}{g^{\varrho-1}}=(1-\beta)(1+g) ; \quad c=\alpha^{\frac{\alpha}{1-\alpha}}(1-\alpha) L-\delta\left(\frac{g}{\varrho-1}\right)^{\varrho}
$$


When $\varrho=1$, the solution is given by a fixed point of the following equation:

$$
\chi_{1}(1+g)+\frac{\delta}{\gamma-1} g=\left[\frac{\alpha^{\frac{\alpha}{1-\alpha}}(1-\alpha)}{\omega \chi_{1}(1+g)}\right]^{\frac{1}{\nu}} ; \quad \text { where } \chi_{1} \equiv \frac{\delta}{\gamma-1} \frac{1-\beta}{\beta}
$$

The LHS is a linear monotonically increasing function of $g$. RHS is a monotonically decreasing function of $g$. By single crossing, one can show that there is a unique locally determinate solution for a given condition on $\chi_{1}$. For higher values of $\varrho$, numerically we verify local determinacy.

\section{D.6 Unconventional Policy away from the ZLB: Implementable Allocation}

Now we show that the first-best equilibrium allocation can be implemented as the competitive equilibrium using the time-varying fiscal and monetary instruments - nominal interest rate $i_{t}$, Tax on interest income $\tau_{t}^{b}$, Tax on intermediate goods $\tau_{t}^{p}$, Research subsidy for entrepreneurs $\tau_{t}^{r}$ and Labor tax for household $\tau_{t}^{w}$ as follows:

$$
\begin{gathered}
\tau_{t}^{p}=1-\frac{1}{\alpha} \\
\tau_{t}^{w}=\lambda_{w, t} \\
1-\tau_{t}^{r}=\frac{1-\beta}{\beta} \frac{\gamma}{\gamma-1} c_{t+1} \tilde{V}_{t+1} \\
\tau_{t}^{b}=0
\end{gathered}
$$

and the nominal interest rate is set such that $W_{t}=\bar{\pi}_{W}^{t} W_{-1}$ - consistent with perfect nominal wage inflation targeting.

Proof. Follows from comparing the system of equations derived under first-best allocation in Appendix C.3 and the (normalized) competitive equilibrium defined in Definition A.2.

\section{D.7 Unconventional Fiscal Policy at the ZLB: Implementable Allocation}

At the zero lower bound, the nominal interest rate is stuck at 0 . However, the first best can still be implemented using the tax subsidy on interest income to offset the ZLB shock. The fiscal instruments are used are as follows: Tax on interest income $\tau_{t}^{b}$, Tax on intermediate goods $\tau_{t}^{p}$, Research subsidy for entrepreneurs $\tau_{t}^{r}$ and Labor tax for household $\tau_{t}^{w}$ as follows:

$$
\begin{gathered}
\tau_{t}^{b}=\frac{\xi_{t}^{\prime}}{\beta c_{t+1}^{-1}\left(1+g_{t+1}\right)^{-1}} \frac{\pi_{t+1}}{1+i_{t}} \\
\tau_{t}^{p}=1-\frac{1}{\alpha} \\
\tau_{t}^{w}=\lambda_{w, t}
\end{gathered}
$$




$$
1-\tau_{t}^{r}=\frac{1-\beta}{\beta} \frac{\gamma}{\gamma-1} c_{t+1} \tilde{V}_{t+1}
$$

Proof. Follows from comparing the system of equations derived under first-best allocation in Appendix C.3 and the (normalized) competitive equilibrium defined in Definition A.2.

As in Correia et al. (2013), it can be shown that the resulting equilibrium is revenue-neutral and timeconsistent.

We can re-define the first-best allocation as the equilibrium allocation defined in Definition 1 such that the government provides the time-varying fiscal and monetary instruments listed in eq 57-60.

\section{D.8 Approximate First-Best Equilibrium}

We log-linearize the non-linear equilibrium conditions around the non-stochastic efficient steady state. Approximate first-best equilibrium is given by a sequence of 4 quantities: $\left\{\hat{L}_{t}^{*}, \hat{c}_{t}^{*}, \hat{y}_{t}^{*}, \hat{g}_{t+1}^{*}\right\}$ that solve the following equations for a given exogenous process of shocks $\hat{M}_{t}$ :

$$
\begin{gathered}
\nu \hat{L}_{t}^{*}+\hat{c}_{t}^{*}=\hat{M}_{t} \\
(\varrho-1) \eta_{g} \hat{g}_{t+1}^{*}=\hat{c}_{t}^{*}-\hat{g}_{t+1}^{*} \\
\frac{c}{y} \hat{c}_{t}^{*}+\frac{r d}{y} \varrho \eta_{g} \hat{g}_{t+1}^{*}=\hat{y}_{t}^{*} \\
\hat{M}_{t}+\hat{L}_{t}^{*}=\hat{y}_{t}^{*}
\end{gathered}
$$

\section{Efficient solution}

The above system can be solved to derive the following closed form solution:

$$
\hat{g}_{t+1}^{*}=\psi_{g}^{*} \hat{M}_{t} ; \quad \hat{c}_{t}^{*}=\psi_{c}^{*} \hat{M}_{t} ; \quad \hat{y}_{t}^{*}=\psi_{y}^{*} \hat{M}_{t} ; \quad \hat{L}_{t}^{*}=\psi_{l}^{*} \hat{M}_{t}
$$

where $\psi_{g}^{*}=\frac{1+\nu}{\left(\nu \frac{c}{y}+1\right)\left((\varrho-1) \eta_{g}+1\right)+\varrho \frac{r d}{y} \varrho \eta_{g}}>0$,

$0<\psi_{c}^{*}=\left((\varrho-1) \eta_{g}+1\right) \psi_{g}^{*}<1$,

$\psi_{y}^{*}=\frac{c}{y} \psi_{c}^{*}+\frac{r d}{y} \varrho \eta_{g} \psi_{g}^{*}>0$, and

$\psi_{l}^{*}=\frac{1-\psi_{c}^{*}}{\nu}>0$

\section{D.9 Time-t vs. time-0 flexibility}

There are two concepts of flexibility in the presence of a pre-determined state variable. One is the Neiss and Nelson (2003) definition of flexible wages, under which wages have been set flexibly since time 0 and remain flexible indefinitely. Wages set under this concept are called time-0 flexible wages. Second concept of flexibility is the Woodford (2003, Ch. 5)'s definition where wages are set flexibly in the current and future 
periods taking as given the current period value of the state variable. Wages set under this concept are called time-t flexible wages. Based on two concepts of flexible wages, there are time-0 first best, time-0 natural rate, time-t first best and time-t natural rate allocations.

Since the normalized equilibrium can be written without any reference to the level of productivity $A_{t}$, the normalized allocations based on the two flexibility concepts coincide.

Definition D.1 (normalized natural rate allocation). The normalized natural rate allocation is given by a sequence of variables $\left\{\hat{c}_{t}^{f}, \hat{y}_{t}^{f}, \hat{g}_{t+1}^{f}, \hat{V}_{t}^{f}\right\}$ such that these satisfy the following equations for a given sequence of shocks $\left\{\hat{\xi}_{t}, \hat{\varepsilon}_{t}^{i}, \hat{M}_{t}, \hat{\lambda}_{w, t}\right\}$ :

$$
\begin{aligned}
& \left.\hat{c}_{t}^{f}+\nu \hat{y}_{t}^{f}-(1+\nu) \hat{M}_{t}\right)+\hat{\lambda}_{w t}=0 \\
& \frac{c}{y} \hat{c}_{t}^{f}+\frac{r d}{y} \varrho \eta_{g} \hat{g}_{t+1}^{f}=\hat{y}_{t}^{f} \\
& (\varrho-1) \eta_{g} \hat{g}_{t+1}^{f}=-\left(\mathbb{E}_{t} \hat{c}_{t+1}^{f}-\hat{c}_{t}^{f}+\hat{g}_{t+1}^{f}\right)+\mathbb{E}_{t} \hat{y}_{t+1}^{f} \\
& \hat{V}_{t}^{f}=\eta_{y} \hat{y}_{t}^{f}-\eta_{z} \hat{g}_{t+1}^{f}-\eta_{q}\left(\mathbb{E}_{t} \hat{c}_{t+1}^{f}-\hat{c}_{t}^{f}+\hat{g}_{t+1}^{f}\right)+\eta_{V} \mathbb{E}_{t} \hat{V}_{t+1}^{f}
\end{aligned}
$$

In other words, if $x_{t}^{f}=\left[\hat{c}_{t}^{f}, \hat{y}_{t}^{f}, \hat{g}_{t+1}^{f}, \hat{L}_{t}^{f}, \hat{V}_{t}^{f}\right]$ is vector of endogenous variables and $\epsilon_{t}=\left[\hat{\xi}_{t}, \hat{\varepsilon}_{t}^{i}, \hat{M}_{t}, \hat{\lambda}_{w, t}\right]$ is a vector of shocks, then there is a unique flexible allocation independent of history of nominal distortions and is given by the solution of following rational expectations system:

$$
F x_{t+1}^{f}+G x_{t}^{f}+H \epsilon_{t}=0
$$

where $F, G$, and $H$ are matrices of coefficients corresponding to definition A.2. Using a standard rational expectations solution method, the system can be solved as:

$$
x_{t}^{f}=M \epsilon_{t}
$$

Therefore the major difference that these two flexibility concepts generate in the context of our framework is that under time- 0 flexibility setting, productivity $A^{f,-\infty}$ is a hypothetical construct that would have occurred had prices and wages been flexible since the beginning of time. Under time-t flexibility, the level of productivity $A^{f, t}$ is the pre-determined level of productivity corresponding to the data $A^{\text {data }}$. Following are the law of motions of the two productivity concepts:

$$
\begin{gathered}
A_{t+1}^{f,-\infty}=A_{t}^{f,-\infty}\left(1+g_{t+1}^{f}\right) \\
A_{t+1}^{f, t}=A_{t}^{\text {data }}\left(1+g_{t+1}^{f}\right)
\end{gathered}
$$

where $A_{t}^{f,-\infty}$ is the level of productivity under flexible wages at time $t$ when wages have been flexible since the infinite past. $A_{t}^{\text {data }}$ is the level of productivity given by the Definition A.1 of the competitive equilibrium and $g_{t+1}^{f}$ is the flexible-wage productivity growth rate solved in the system 70 . 


\section{D.9.1 time- 0 allocations}

We can therefore define the time-0 allocations as follows:

Definition D.2 (time-0 first-best allocation). The time-0 first best allocation is defined as sequence of variables $\left\{Y_{t}^{*,-\infty}, A_{t+1}^{*,-\infty}, C_{t}^{*,-\infty}, \hat{c}_{t}^{*}, \hat{y}_{t}^{*}, \hat{g}_{t+1}^{*}, \hat{L}_{t}^{*}\right\}$ which satisfy the equations $61-64$ and the following equations, given a sequence of shocks $\left\{\hat{\xi}_{t}, \hat{\varepsilon}_{t}^{i}, \hat{M}_{t}, \hat{\lambda}_{w, t}\right\}$ and initial level of productivity $A_{0}$ :

$$
\begin{gathered}
A_{t+1}^{*,-\infty}=A_{t}^{*,-\infty}\left(\hat{g}_{t+1}^{*}+\log \left(1+g_{s s}\right)\right) \\
Y_{t}^{*,-\infty}=A_{t}^{*,-\infty}\left(\hat{y}_{t}^{*}+\log y_{s s}\right) \\
C_{t}^{*,-\infty}=A_{t}^{*,-\infty}\left(\hat{c}_{t}^{*}+\log c_{s s}\right)
\end{gathered}
$$

Definition D.3 (time-0 natural rate allocation). The time-0 natural rate allocation is defined as sequence of variables $\left\{Y_{t}^{f,-\infty}, A_{t+1}^{f,-\infty}, C_{t}^{f,-\infty}, \hat{c}_{t}^{f}, \hat{y}_{t}^{f}, \hat{g}_{t+1}^{f}, \hat{V}_{t}^{f}\right\}$ which satisfy the equations $65-68$ and the following equations, given a sequence of shocks $\left\{\hat{\xi}_{t}, \hat{\varepsilon}_{t}^{i}, \hat{M}_{t}, \hat{\lambda}_{w, t}\right\}$ and initial level of productivity $A_{0}$ :

$$
\begin{gathered}
A_{t+1}^{f,-\infty}=A_{t}^{f,-\infty}\left(\hat{g}_{t+1}^{f}+\log \left(1+g_{s s}\right)\right) \\
Y_{t}^{f,-\infty}=A_{t}^{f,-\infty}\left(\hat{y}_{t}^{f}+\log y_{s s}\right) \\
C_{t}^{f,-\infty}=A_{t}^{f,-\infty}\left(\hat{c}_{t}^{f}+\log c_{s s}\right)
\end{gathered}
$$

\section{D.9.2 time- $\mathrm{t}$ allocations}

Similarly, we define the time-t allocations as follows:

Definition D.4 (time-t first-best allocation). The time-t first best allocation is defined as sequence of variables $\left\{Y_{t}^{*, t}, A_{t+1}^{*, t}, C_{t}^{*, t}, \hat{c}_{t}^{*}, \hat{y}_{t}^{*}, \hat{g}_{t+1}^{*}, \hat{L}_{t}^{*}\right\}$ which satisfy the equations $61-64$ and the following equations, given a sequence of shocks $\left\{\hat{\xi}_{t}, \hat{\varepsilon}_{t}^{i}, \hat{M}_{t}, \hat{\lambda}_{w, t}\right\}$ and the actual level of productivity at date t, $A_{t}^{\text {data }}$ :

$$
\begin{gathered}
A_{t+1}^{*, t}=A_{t}^{\text {data }}\left(\hat{g}_{t+1}^{*}+\log \left(1+g_{s s}\right)\right) \\
Y_{t}^{*, t}=A_{t}^{\text {data }}\left(\hat{y}_{t}^{*}+\log y_{s s}\right) \\
C_{t}^{*, t}=A_{t}^{\text {data }}\left(\hat{c}_{t}^{*}+\log c_{s s}\right)
\end{gathered}
$$

Definition D.5 (time-t natural rate allocation). The time-t natural rate allocation is defined as sequence of variables $\left\{Y_{t}^{f, t}, A_{t+1}^{f, t}, C_{t}^{f, t}, \hat{c}_{t}^{f}, \hat{y}_{t}^{f}, \hat{g}_{t+1}^{f}, \hat{V}_{t}^{f}\right\}$ which satisfy the equations $65-68$ and the following equations, given a sequence of shocks $\left\{\hat{\xi}_{t}, \hat{\varepsilon}_{t}^{i}, \hat{M}_{t}, \hat{\lambda}_{w, t}\right\}$ and the actual level of productivity at date t, $A_{t}^{\text {data }}$ : 


$$
\begin{gathered}
A_{t+1}^{f,-\infty}=A_{t}^{\text {data }}\left(\hat{g}_{t+1}^{f}+\log \left(1+g_{s s}\right)\right) \\
Y_{t}^{f,-\infty}=A_{t}^{\text {data }}\left(\hat{y}_{t}^{f}+\log y_{s s}\right) \\
C_{t}^{f,-\infty}=A_{t}^{\text {data }}\left(\hat{c}_{t}^{f}+\log c_{s s}\right)
\end{gathered}
$$

\section{D.9.3 sticky-wage allocation}

Definition D.6 (sticky-wage allocation). The sticky-wage allocation is defined as sequence of variables $\left\{Y_{t}\right.$, $\left.A_{t+1}, C_{t}, \hat{\pi}_{t}^{w}, \hat{c}_{t}, \hat{y}_{t}, \hat{g}_{t+1}, \hat{i}_{t}, \hat{L}_{t}, \hat{w}_{t}, \hat{\pi}_{t}, \hat{V}_{t}\right\}$ which satisfy the equations $37-45$ and the following equations, given a sequence of shocks $\left\{\hat{\xi}_{t}, \hat{\varepsilon}_{t}^{i}, \hat{M}_{t}, \hat{\lambda}_{w, t}\right\}$ and initial level of productivity $A_{0}$ :

$$
\begin{gathered}
A_{t+1}=A_{t}\left(\hat{g}_{t+1}+\log \left(1+g_{s s}\right)\right) \\
Y_{t}=A_{t}\left(\hat{y}_{t}+\log y_{s s}\right) \\
C_{t}=A_{t}\left(\hat{c}_{t}+\log c_{s s}\right)
\end{gathered}
$$

$A_{t}^{\text {data }}$ corresponds to $A_{t}$ defined under the sticky-wage allocation.

\section{E Proposition Proofs}

Proposition (Proposition 1: Steady State Efficiency). Assuming the policy maker has access to nondistortionary lump-sum taxes, the steady state of the competitive equilibrium can be made efficient using the following three fiscal tools :

a) sales subsidy $\tau^{p}=1-\frac{1}{\alpha}$

b) wage tax cut $\tau^{w}=\lambda_{w}$, and

c) research tax $/$ subsidy $\tau^{r}=1-\left[\left(\frac{\gamma l^{*}(1-\alpha) \alpha^{\frac{\alpha}{1-\alpha}}}{1-\beta\left(1-z^{*}\right)}\right)\left(\frac{1-\beta}{(\gamma-1) c^{*}}\right)\right]$, where terms with $*$ denote the efficient steady state values.

Proof. Follows from Appendix C.6 above.

Proposition (Proposition 2). The (time-0) natural rate allocation coincides with the (time-0) first-best allocation under liquidity demand and monetary policy shocks.

Proof. From Appendix C.9, the time-0 natural rate allocation under liquidity demand shocks and monetary policy shocks is characterized by:

$$
\hat{y}_{t}^{f}=0, \hat{c}_{t}^{f}=0, \hat{g}_{t+1}^{f}=0 ; \quad \forall t \geq 0
$$


Because of the presence of time-varying taxes, the time-0 first-best allocation has the same solution for the corresponding variables $\left\{\hat{y}_{t}^{*}, \hat{c}_{t}^{*}, \hat{g}_{t+1}^{*}\right\}$. Hence, output at any time under (time-0) natural rate and (time- 0 ) first-best allocations coincide (follows from the accounting identity eq 71). Moreover, time-t natural rate and time-t first best allocations also coincide with each other.

Proposition (Proposition 5: Output hysteresis). Given the monetary policy rule (eq 27) and in the absence of a zero lower bound constraint on the nominal interest rate, transitory (modeled as AR(1) process) liquidity demand shocks or monetary policy shocks induce a permanent deviation in the time series of output from the counterfactual (flexible wage-) level of output if and only if monetary policy is not a strict targeting rule i.e.

$$
Y_{T} \neq Y_{T}^{e} \Longleftrightarrow\left\{\phi_{\pi}, \phi_{y}>0: \phi_{\pi} \not \rightarrow \infty \cup \phi_{y} \not \rightarrow \infty\right\}
$$

where $1<T<\infty$ such that $y_{T} \equiv \frac{Y_{T}}{A_{T}}=y$ (steady state value).

Proof. We give the proof for liquidity demand shocks. The proof is identical for monetary policy shocks. Note that

$$
Y_{T}^{e}=\left(1+g_{s s}\right)^{T} A_{0} y ; \quad Y_{T}=\prod_{k=0}^{T-1}\left(1+g_{k}\right) A_{0} y
$$

Taking a log difference in the two series

$$
\log Y_{T}-\log Y_{T}^{e}=\sum_{k=0}^{T-1} \hat{g}_{k+1}=\psi \psi_{g}^{\xi} \sum_{k=0}^{T-1} \epsilon_{k}
$$

where $\psi_{g}^{\xi}$ is the coefficient derived in Appendix $\mathrm{C}$ above. For a given sequence of shocks that does not add to zero (which is the case with $\operatorname{AR}(1)$ process), the difference in the two series depends on $\psi_{g}^{\xi}$. This parameter is 0 if and only if monetary policy rule is either a strict inflation targeting $\left(\phi_{\pi} \rightarrow \infty\right)$ or a strict employment targeting rule $\phi_{y} \rightarrow \infty$.

Proposition (Proposition 6: Output Hysteresis at the ZLB). Given the monetary policy rule (eq 27), a positive shock to liquidity demand such that the zero lower bound is binding for finite time $T^{e}$ results in a permanent gap in output from the flexible wage counterfactual.

Proof. A positive shock to the liquidity demand that induces the ZLB under the Taylor rule results in wage deflation and drop in output for the duration of ZLB.

Under Eggertsson and Woodford (2003) two-state Markov Chain assumption, the system at time $t<T^{e}$ is in state $S$ (short run) and can be expressed as:

$$
\begin{gathered}
(1-\mu) \hat{c}_{S}=\mu \hat{\pi}_{S}^{w}+\hat{r}_{S} \\
(1-\beta \mu) \hat{\pi}_{S}^{w}=\kappa_{w}\left(\hat{c}_{S}+\nu \hat{y}_{S}\right)
\end{gathered}
$$




$$
\begin{gathered}
{\left[(\varrho-1) \eta_{g}+1\right] \hat{g}_{S}=\mu \hat{V}_{S}+(1-\mu) \hat{c}_{S}} \\
\frac{r d}{y} \varrho \eta_{g} \hat{g}_{S}=\hat{y}_{S}-\frac{c}{y} \hat{c}_{S} \\
\hat{V}_{S}=\frac{1}{1-\eta_{V} \mu}\left[\eta_{V} \hat{y}_{S}+\eta_{q}(1-\mu) \hat{c}_{S}-\left(\eta_{z}+\eta_{q}\right) \hat{g}_{S}\right]
\end{gathered}
$$

We can solve the last three equations to find a relationship between $c$ and $y$ :

$$
\hat{c}_{S}=\eta_{C} \hat{y}_{S} ; \quad \eta_{C} \equiv \frac{\frac{1-\eta_{V} \mu}{\mu} \frac{(\varrho-1) \eta_{g}+1}{\frac{r d}{y} \varrho \eta_{g}}+\frac{\eta_{z}+\eta_{q}}{\frac{r d}{y} \varrho \eta_{g}}-\eta_{Y}}{\left[\frac{1-\eta_{V} \mu}{\mu} \frac{(\varrho-1) \eta_{g}+1}{\frac{r d}{y} \varrho \eta_{g}} \frac{c}{y}+(1-\mu)\right]+\frac{\eta_{z}+\eta_{q}}{\frac{r d}{y} \varrho \eta_{g}} \frac{c}{y}+\eta_{q}(1-\mu)}<1
$$

We can solve the system for $t<T^{e}$ :

$$
\hat{y}_{t}=\psi_{y} r_{S}^{n}<0 ; \hat{\pi}_{t}^{w}=\psi_{p} r_{S}^{n}<0 ; \hat{g}_{t}=\psi_{g} r_{S}^{n}<0
$$

where $\psi_{y}=\frac{(1-\beta \mu) \eta_{C}^{-1}}{(1-\beta \mu)(1-\mu)-\kappa_{w}\left(\nu+\eta_{C}\right) \mu}>0, \psi_{p}=\frac{\kappa_{w}\left(\nu+\eta_{C}\right)}{1-\mu \beta} \psi_{y}>0$, and $\psi_{g}=\frac{1-\frac{c}{y} \eta_{C}}{\frac{r d}{y} \varrho \eta_{g}} \psi_{y}>0$. We assume (by A2 in the main text) the system is locally determinate around the state $\mathrm{S}$ equilibrium defined above. Therefore using the accounting identity eq 71 derived in the proof of Proposition 1, we can derive:

$$
\log Y_{t}-\log Y_{t}^{e}=\sum_{k=0}^{t-1} \hat{g}_{k+1}=\left(T^{e}-1\right) \psi_{g} r_{S}^{n}<0 ; \quad \forall t \geq T^{e}
$$

This is the permanent output hysteresis in our framework following a ZLB episode.

Proposition (Proposition 3). Assume that the economy is at the efficient steady state at time $t=0$, with given productivity level $A_{0}$. Under sticky wage allocation, quadratic approximation of representative agent's lifetime utility function $\mathbb{W}_{0}$ around the non-stochastic efficient steady state is given by

$$
\begin{aligned}
& \frac{\mathbb{W}_{0}-\mathbb{W}_{0}^{*}}{U_{c_{s s}} y_{s s}} \\
& =-\frac{1}{2} \sum_{t=0}^{\infty} \beta^{t}[\lambda_{y} \underbrace{\left(\hat{y}_{t}-\frac{\beta}{1-\beta} \frac{1}{\nu+\frac{y}{c}} \hat{g}_{t+1}\right)^{2}}_{(i)}+\lambda_{g} \underbrace{\hat{g}_{t+1}^{2}}_{(i i)}+\lambda_{\pi} \underbrace{\left(\hat{\pi}_{t}^{w}\right)^{2}}_{(i i i)}]+\mathcal{O}\left(\left\|\hat{\xi}_{t}, \hat{\varepsilon}_{t}^{i}\right\|^{3}\right)+\text { t.i.p. }
\end{aligned}
$$

(i) : labor efficiency gap, (ii): productivity growth rate gap, and (iii): wage inflation gap

where $\lambda_{y}=\left(\nu+\frac{y}{c}\right)>0, \lambda_{g}=\frac{c}{y} \frac{\beta}{1-\beta}\left[\frac{\nu}{\nu+\frac{y}{c}} \frac{\beta}{1-\beta}+\left[(\varrho-1) \eta_{g}+1\right]\right]>0, \lambda_{\pi}=\frac{1+\lambda_{w}}{\lambda_{w}} \frac{1}{\kappa_{w}}>0, \kappa_{w} \equiv$ $\frac{\left(1-\theta_{w}\right)\left(1-\beta \theta_{w}\right)}{\theta_{w}\left(1+\nu\left(1+\frac{1}{\lambda_{w}}\right)\right.}>0, \eta_{g}=\frac{1+g}{g}>1$ and t.i.p. stands for "terms independent of policy". $\mathbb{W}^{*}$ denotes welfare under the (time-0) first-best allocation. The approximation is scaled by the constant $U_{c_{s s}} y_{s s}=\frac{y_{s s}}{c_{s s}}$ (evaluated at the efficient steady state).

Proof. The proof for this is detailed and builds on results shown above. First, note from Appendix C.4 that 
the solution of welfare function of the representative household is equivalent to the solution of the policyrelevant welfare function derived in Appendix C.2

We then derive a quadratic approximation of the policy-relevant lifetime welfare function. Since the problem is relatively complicated, we break the approximation into first solving for a setting with flexible wages. We show the derivation in the case of flexible wages, i.e. no pricing distortions, in Lemma 1 below. This simplifies the exposition. It is relatively standard to extend this proof to include nominal wage setting frictions. The extended proof is similar to the textbook proof of Galí (2015, Ch. 4) and is available on request.

Lemma 1. Quadratic approximation of $\boldsymbol{W}_{t}$ under flexible wages is given by

$$
-\frac{1}{2}\left[\lambda_{y}\left(\left(\hat{y}_{t}-\hat{y}_{t}^{*}\right)-\frac{\beta}{1-\beta} \frac{1}{\nu+\frac{y}{c}}\left(\hat{g}_{t+1}-\hat{g}_{t+1}^{*}\right)\right)^{2}+\lambda_{g}\left(\hat{g}_{t+1}-\hat{g}_{t+1}^{*}\right)^{2}\right]+\text { h.o.t. }+ \text { t.i.p. }
$$

Proof. We will make use of following two approximation results as in Erceg Henderson Levin 2000:

$$
\frac{d x}{x} \approx \hat{x}+\frac{1}{2} \hat{x}^{2}, \quad \hat{x} \equiv \ln x-\ln \bar{x}
$$

If $x=\left[\int_{0}^{1} x(j)^{\phi} d j\right]^{\frac{1}{\phi}}$, the logarithmic approximation of $x$ is

$$
\hat{x} \approx \int_{0}^{1} \hat{x}(j) d j+\frac{1}{2} \operatorname{vvar}_{j} \hat{x}(j)=\int_{0}^{1} \hat{x}(j) d j+\frac{1}{2} \phi\left[\int_{0}^{1} \hat{x}(j)^{2} d j-\left(\int_{0}^{1} \hat{x}(j) d j\right)^{2}\right]
$$

Writing the per period utility as sum of three components:

$$
W_{t}=u\left(c_{t}\right)-\int_{0}^{1} v\left(L_{t}(h)\right) d h+\frac{\beta}{1-\beta} w\left(g_{t+1}\right)
$$

At the Efficient Steady state,

$$
\begin{gathered}
\varrho \delta \frac{g^{\varrho-1}(1+g)}{c(\gamma-1)^{\varrho}}=\frac{\beta}{1-\beta} \\
y=\alpha^{\frac{\alpha}{1-\alpha}}(1-\alpha) L ; \quad \omega=\frac{y}{c L^{1+\nu}} \\
c+\delta\left(\frac{g}{\gamma-1}\right)^{\varrho}=y \\
u_{y}=\frac{1}{c} ; u_{g}=\frac{-1}{c} \frac{\varrho \delta g^{\varrho-1}}{(\gamma-1)^{\varrho}} ; u_{y g}=\frac{1}{c^{2}} \frac{\varrho \delta g^{\varrho-1}}{(\gamma-1) \varrho} \\
u_{y y}=-\frac{1}{c^{2}} ; u_{g g}=-\left[\left(\frac{\varrho \delta g^{\varrho-1}}{c(\gamma-1)^{\varrho}}\right)^{2}+\frac{\varrho(\varrho-1) \delta g^{\varrho-2}}{c(\gamma-1) \varrho}\right]
\end{gathered}
$$




$$
\begin{gathered}
v_{y}=\omega L^{\nu}=\frac{1}{c} ; v_{y y}=\frac{\omega \nu L^{1+\nu}}{y^{2}}=\frac{\nu}{y c} \\
w_{g}=\frac{\beta}{1-\beta} \frac{1}{1+g} ; w_{g g}=\frac{-\beta}{1-\beta} \frac{1}{(1+g)^{2}}
\end{gathered}
$$

Second Order approximation of individual components of the welfare function is given by:

$$
\begin{gathered}
u_{t}=\bar{u}+y u_{y} \frac{d y_{t}}{y}+(1+g) u_{g} \frac{d g_{t+1}}{1+g}+y(1+g) \frac{d y_{t}}{y} \frac{d g_{t+1}}{1+g}+\frac{y^{2}}{2} u_{y y}\left(\frac{d y_{t}}{y}\right)^{2}+\frac{(1+g)^{2}}{2} u_{g g}\left(\frac{d g_{t+1}}{1+g}\right)^{2}+\text { h.o.t. } \\
v_{t}=\bar{v}+y v_{y} \frac{d y_{t}}{y}+\frac{y^{2}}{2} v_{y y}\left(\frac{d y_{t}}{y}\right)^{2}+\text { h.o.t. } \\
w_{t}=\bar{w}+(1+g) w_{g} \frac{d g_{t+1}}{1+g}+\frac{(1+g)^{2}}{2} w_{g g}\left(\frac{d g_{t+1}}{1+g}\right)^{2}+\text { h.o.t. }
\end{gathered}
$$

Using the Taylor approximation result that

$$
\frac{d x}{x}=\hat{x}+\frac{1}{2} \hat{x}^{2}
$$

where $\hat{x}=\log (x)-\log \left(x_{s s}\right)$, we can write down the quadtraic approximation as :

$$
\begin{gathered}
u_{t}=y u_{y}\left[\hat{y}_{t}+\frac{1}{2} \hat{y}_{t}^{2}\right]+(1+g) u_{g}\left[\hat{g}_{t+1}+\frac{1}{2} \hat{g}_{t+1}^{2}\right]+y(1+g) \hat{y}_{t} \hat{g}_{t+1}+\frac{y^{2}}{2} u_{y y} \hat{y}_{t}^{2}+\frac{(1+g)^{2}}{2} u_{g g} \hat{g}_{t+1}^{2}+\text { h.o.t. }+ \text { t.i.p. } \\
v_{t}=y v_{y}\left[\hat{y}_{t}+\frac{1}{2} \hat{y}_{t}^{2}\right]+\frac{y^{2}}{2} v_{y y} \hat{y}_{t}^{2}+\text { h.o.t. }+ \text { t.i.p. } \\
w_{t}=(1+g) w_{g}\left[\hat{g}_{t+1}+\frac{1}{2} \hat{g}_{t+1}^{2}\right]+\frac{(1+g)^{2}}{2} w_{g g} \hat{g}_{t+1}^{2}+\text { h.o.t. }+ \text { t.i.p. }
\end{gathered}
$$

where $\hat{y}_{t}=\log y_{t}-\log y$, and $\hat{g}_{t+1}=\log \left(1+g_{t+1}\right)-\log (1+g)$.

Combining the three components, per period welfare function can be expressed as:

$$
\begin{aligned}
W_{t}= & {\left[y u_{y}-y v_{y}\right] \hat{y}_{t}+\left[(1+g) u_{g}+(1+g) w_{g}\right] \hat{g}_{t+1}+y(1+g) u_{y g} \hat{y}_{t} \hat{g}_{t+1} } \\
& +\frac{1}{2}\left[y u_{y}+y^{2} u_{y y}-y v_{y}-y^{2} v_{y y}\right] \hat{y}_{t}^{2} \\
& +\frac{1}{2}\left[(1+g) u_{g}+(1+g)^{2} u_{g g}+(1+g) w_{g}+(1+g)^{2} w_{g g}\right] \hat{g}_{t+1}^{2} \\
& + \text { h.o.t. }+ \text { t.i.p. }
\end{aligned}
$$

note that following relations hold true at the efficient steady state

$$
y u_{y}=y v_{y} ; \quad(1+g) u_{g}+(1+g) w_{g}=0 ; \quad y(1+g) u_{y g}=\frac{y}{c} \frac{\beta}{1-\beta}
$$




$$
\begin{gathered}
y u_{y}+y^{2} u_{y y}-y v_{y}-y^{2} v_{y y}=-\frac{y}{c}\left[\frac{y}{c}+\nu\right] \\
(1+g) u_{g}+(1+g)^{2} u_{g g}+(1+g) w_{g}+(1+g)^{2} w_{g g}=-\left[\frac{\beta}{1-\beta}+\left(\frac{\beta}{1-\beta}\right)^{2}+\frac{\varrho(\varrho-1) \delta(1+g)^{2} g^{\varrho-2}}{c(\gamma-1)^{\varrho}}\right]
\end{gathered}
$$

Using these into the quadratic approximation of $W_{t}$ and completing the squares we get

$$
\begin{aligned}
W_{t}= & -\frac{1}{2} \frac{y}{c}\left(\nu+\frac{y}{c}\right)\left[\left(\hat{y}_{t}-\hat{y}_{t}^{*}\right)-\frac{\beta}{1-\beta} \frac{1}{\nu+\frac{y}{c}}\left(\hat{g}_{t+1}-\hat{g}_{t+1}^{*}\right)\right]^{2} \\
& -\frac{1}{2} \frac{\beta}{1-\beta}\left[\frac{\nu}{\nu+\frac{y}{c}} \frac{\beta}{1-\beta}+\left[(\varrho-1) \eta_{g}+1\right]\right]\left(\hat{g}_{t+1}-\hat{g}_{t+1}^{*}\right)^{2}+\text { h.o.t. }+ \text { t.i.p. }
\end{aligned}
$$

the term in the first bracket is the labor wedge.

Lemma 2. Labor Wedge is given by

$$
\nu\left(\hat{L}_{t}-\hat{L}_{t}^{*}\right)+\left(\hat{c}_{t}-\hat{c}_{t}^{*}\right)-\left(\hat{w}_{t}-\hat{w}_{t}^{*}\right)=\left(\hat{y}_{t}-\hat{y}_{t}^{*}\right)-\frac{\beta}{1-\beta} \frac{1}{\nu+\frac{y}{c}}\left(\hat{g}_{t+1}-\hat{g}_{t+1}^{*}\right)
$$

Proof. Use equations 40, 41 and 43 from definition A.3 to substitute for $\hat{L}_{t}, \hat{c}_{t}$ and $\hat{w}_{t}$. Finally note that under efficient allocation, the labor wedge is zero, that is, $\nu \hat{L}_{t}^{*}+\hat{c}_{t}^{*}-\hat{w}_{t}^{*}=0$.

Corollary (Corollary 1: Importance of Growth Stabilization). The relative weight on growth rate gap is higher than the relative weight on labor efficiency wedge if

$$
\frac{\beta}{1-\beta}>\frac{y}{c}\left(\nu+\frac{y}{c}\right)
$$

Proof. If $\frac{\beta}{1-\beta}>\frac{y}{c}\left(\nu+\frac{y}{c}\right)$, then it follows directly that:

$$
\frac{\beta}{1-\beta}\left[\frac{\nu}{\nu+\frac{y}{c}} \frac{\beta}{1-\beta}+(\varrho-1) \eta_{g}+1\right]>\frac{y}{c}\left(\nu+\frac{y}{c}\right)
$$

since all the terms in the square bracket on the LHS are positive and add to more than 1.

Proposition (Proposition 4: Optimal Policy away from ZLB). Given a process for liquidity demand and monetary policy shocks, optimal policy under sticky wage allocation tracks the natural rate of interest when the Zero Lower Bound constraint is slack.

Proof. When the nominal interest rate is set equal to the natural interest rate (and is non-negative), the unique solution to the competitive equilibrium is

$$
\hat{y}_{t}=0 ; \quad \hat{c}_{t}=0 ; \quad \hat{\pi}_{t}^{w}=0 ; \quad \hat{g}_{t+1}=0
$$

which corresponds to the first-best allocation as shown in proof of Proposition 4. 
Corollary (Corollary 2). When the ZLB is slack, the time series of output under optimal policy is a trend stationary process (integrated of order zero), that is,

$$
\log Y_{t}=a+b * t
$$

where $a=\log Y_{0}$ is the initial level of output, and $b=\log \left(1+g_{s s}\right)$ is the steady state productivity growth rate.

Proof. Under optimal policy, the productivity growth rate does not deviate from the steady state growth rate. Hence the series of output can be expressed as:

$$
\log Y_{T}=\log Y_{0}+\sum_{k=0}^{T-1}\left(1+g_{s s}\right)=\log Y_{0}+(T-1)\left(1+g_{s s}\right) ; \quad \forall t \geq 1
$$

\section{E.1 Optimal Policy at the Zero Lower Bound}

\section{E.1.1 Optimal Commitment Solution at the ZLB}

$$
\mathcal{L}_{0}=\mathbb{E}_{0} \sum_{t=0}^{\infty} \beta^{t}\left\{\begin{array}{l}
\frac{1}{2}\left[\lambda_{1}\left(\hat{y}_{t}-\tilde{\chi} \hat{g}_{t+1}\right)^{2}+\lambda_{2} \hat{g}_{t+1}^{2}+\left(\hat{\pi}_{t}^{w}\right)^{2}\right] \\
+\phi_{1 t}\left[\hat{c}_{t}-\hat{c}_{t+1}-\hat{\pi}_{t+1}^{w}-\hat{r}_{t}^{n}\right] \\
+\phi_{2 t}\left[\hat{\pi}_{t}^{w}-\beta \hat{\pi}_{t+1}^{w}-\kappa_{w}\left(\hat{c}_{t}+\nu \hat{y}_{t}\right)\right] \\
+\phi_{3 t}\left[-\left(\mathbb{E}_{t} \hat{c}_{t+1}-\hat{c}_{t}+\hat{g}_{t+1}\right)+\mathbb{E}_{t} \hat{V}_{t+1}-(\varrho-1) \eta_{g} \hat{g}_{t+1}\right] \\
+\phi_{4 t}\left[\frac{c}{y} \hat{c}_{t}+\frac{r d}{y} \varrho \eta_{g} \hat{g}_{t+1}-\hat{y}_{t}\right] \\
+\phi_{5 t}\left[-\hat{V}_{t}+\eta_{y} \hat{y}_{t}-\eta_{z} \hat{g}_{t+1}-\eta_{q}\left(\mathbb{E}_{t} \hat{c}_{t+1}-\hat{c}_{t}+\hat{g}_{t+1}\right)+\eta_{V} \mathbb{E}_{t} \hat{V}_{t+1}\right]
\end{array}\right.
$$

First Order conditions:

$$
\begin{gathered}
\phi_{1 t}-\kappa_{w} \phi_{2 t}+\phi_{3 t}+\frac{c}{y} \phi_{4 t}+\eta_{q} \phi_{5 t}-\beta^{-1}\left[\phi_{1 t-1}+\phi_{3 t-1}+\eta_{q} \phi_{5 t-1}\right]=0 \\
\lambda_{1}\left(\hat{y}_{t}-\tilde{\chi} \hat{g}_{t+1}\right)-\phi_{2 t} \kappa_{w} \nu-\phi_{4 t}+\phi_{5 t} \eta_{y}=0 \\
-\lambda_{1} \tilde{\chi}\left(\hat{y}_{t}-\tilde{\chi} \hat{g}_{t+1}\right)+\lambda_{2} \hat{g}_{t+1}-\left[(\varrho-1) \eta_{g}+1\right] \phi_{3 t}+\frac{r d}{y} \varrho \eta_{g} \phi_{4 t}-\left(\eta_{z}+\eta_{q}\right) \phi_{5 t}=0 \\
\hat{\pi}_{t}^{w}+\phi_{2 t}-\phi_{2 t-1}-\beta^{-1} \phi_{1 t-1}=0 \\
-\phi_{5 t}+\beta^{-1}\left[\phi_{3 t-1}+\eta_{V} \phi_{5 t-1}\right]=0 \\
\phi_{1 t} \geq 0, \quad i_{t} \geq 0, \quad \phi_{i t} i_{t}=0
\end{gathered}
$$




\section{E.1.2 Optimal Discretionary Solution at the ZLB}

Following is the Lagrangian for the Discretion policy

$$
\mathcal{L}_{0}=\mathbb{E}_{0} \sum_{t=0}^{\infty} \beta^{t}\left\{\begin{array}{l}
\frac{1}{2}\left[\lambda_{1}\left(\hat{y}_{t}-\tilde{\chi} \hat{g}_{t+1}\right)^{2}+\lambda_{2} \hat{g}_{t+1}^{2}+\left(\hat{\pi}_{t}^{w}\right)^{2}\right] \\
+\phi_{1 t}\left[\hat{c}_{t}-\hat{c}_{t+1}^{e}-\hat{\pi}_{t+1}^{w e}-\hat{r}_{t}^{n}\right] \\
+\phi_{2 t}\left[\hat{\pi}_{t}^{w}-\beta \hat{\pi}_{t+1}^{w e}-\kappa_{w}\left(\hat{c}_{t}+\nu \hat{y}_{t}\right)\right] \\
+\phi_{3 t}\left[-\left(\hat{c}_{t+1}^{e}-\hat{c}_{t}+\hat{g}_{t+1}\right)+\hat{V}_{t+1}^{e}-(\varrho-1) \eta_{g} \hat{g}_{t+1}\right] \\
+\phi_{4 t}\left[\frac{c}{y} \hat{c}_{t}+\frac{r d}{y} \varrho \eta_{g} \hat{g}_{t+1}-\hat{y}_{t}\right] \\
+\phi_{5 t}\left[-\hat{V}_{t}+\eta_{y} \hat{y}_{t}-\eta_{z} \hat{g}_{t+1}-\eta_{q}\left(\hat{c}_{t+1}^{e}-\hat{c}_{t}+\hat{g}_{t+1}\right)+\eta_{V} \hat{V}_{t+1}^{e}\right]
\end{array}\right.
$$

$\lambda_{1}=\kappa_{w}\left(\nu+\frac{y}{c}\right) \frac{\lambda_{w}}{1+\lambda_{w}}, \tilde{\chi}=\frac{\beta}{1-\beta} \frac{1}{\nu+\frac{y}{c}}$, and $\lambda_{2}=\kappa_{w} \frac{c}{y} \frac{\beta}{1-\beta}\left[\frac{\nu}{\nu+\frac{y}{c}} \frac{\beta}{1-\beta}+\left[(\varrho-1) \eta_{g}+1\right]\right] \frac{\lambda_{w}}{1+\lambda_{w}}$

First Order conditions:

$$
\begin{gathered}
\phi_{1 t}-\kappa_{w} \phi_{2 t}+\phi_{3 t}+\frac{c}{y} \phi_{4 t}+\eta_{q} \phi_{5 t}=0 \\
\lambda_{1}\left(\hat{y}_{t}-\tilde{\chi} \hat{g}_{t+1}\right)-\phi_{2 t} \kappa_{w} \nu-\phi_{4 t}+\phi_{5 t} \eta_{y}=0 \\
-\lambda_{1} \tilde{\chi}\left(\hat{y}_{t}-\tilde{\chi} \hat{g}_{t+1}\right)+\lambda_{2} \hat{g}_{t+1}-\left[(\varrho-1) \eta_{g}+1\right] \phi_{3 t}+\frac{r d}{y} \varrho \eta_{g} \phi_{4 t}-\left(\eta_{z}+\eta_{q}\right) \phi_{5 t}=0 \\
\hat{\pi}_{t}^{w}+\phi_{2 t}=0 \\
\phi_{5 t}=0 \\
\phi_{1 t} \geq 0, \quad i_{t} \geq 0, \quad \phi_{i t} i_{t}=0
\end{gathered}
$$

Proposition (Proposition 7: Optimal Discretionary Policy at the ZLB). If Assumptions A1 and A2 hold and for a given level of productivity at time $0, A_{0}$, the Markov equilibrium is characterized by:

$$
\log A_{1}=\log A_{0}+\log \left(1+g_{s s}\right)
$$

for $0<t<T^{e}$

$$
\begin{gathered}
\hat{y}_{t}=\psi_{y} r_{S}^{n}<0 ; \hat{\pi}_{t}^{w}=\psi_{p} r_{S}^{n}<0 ; \hat{g}_{t}=\psi_{g} r_{S}^{n}<0 \\
\log A_{t+1}=\log A_{t}+\psi_{g} r_{S}^{n}
\end{gathered}
$$

and when $t \geq T^{e}$

$$
\hat{y}_{t}=\hat{\pi}_{t}^{w}=\hat{g}_{t}=0
$$

$$
\log A_{t+1}=\log A_{t+1}^{*}+\left(T^{e}-1\right) \psi_{g} r_{S}^{n}<\log A_{t+1}^{*}
$$

where $\psi_{y}=\frac{1-\beta \mu}{(1-\beta \mu)(1-\mu) \eta_{C}-\kappa_{w}\left(\nu+\eta_{C}\right) \mu}>0, \psi_{p}=\frac{\kappa_{w}\left(\nu+\eta_{C}\right)}{1-\mu \beta} \psi_{y}>0$, and $\psi_{g}=\frac{1-\frac{c}{y} \eta_{C}}{\frac{r d}{y} \varrho \eta_{g}} \psi_{y}>0 . A_{t+1}^{*}$ is the 
(time-0) first-best output at time $t+1$.

Proof. First note that the policymaker sets the policy rate to the unconstrained optimal policy rate as soon as the zero lower bound stops binding that is for $t \geq T^{e}$. The discretionary policy (MPE) taking into account the ZLB constraint is defined by the first order conditions derived above and the structural relations. The optimal policy when the ZLB stops binding involves setting $\phi_{i t}$, the Lagrange multiplier on the zero lower bound constraint, to 0 . This reduces the system of equations to the familiar unconstrained policy of setting interest rate equal to the natural interest rate such that output and inflation are back to the (unconstrained) steady state. This constitutes a unique bounded solution and proves that there is no inertia in the discretionary policy. Remains to show that under the zlb, it is optimal to set interest rate to 0. Suppose it is not then, as discussed above, the Lagrange multiplier on ZLB constraint must be 0 and thus output and inflation must be at the steady state. But this leads to a violation of the AD equation, which is not satisfied. Next we solve for the values of endogenous variables. Under the assumed Eggertsson and Woodford two-state Markov Chain, the system at time $t<T^{e}$ is in state $S$ (short run) and can be expressed as:

$$
\begin{gathered}
(1-\mu) \hat{c}_{S}=\mu \hat{\pi}_{S}^{w}+\hat{r}_{S} \\
(1-\beta \mu) \hat{\pi}_{S}^{w}=\kappa_{w}\left(\hat{c}_{S}+\nu \hat{y}_{S}\right) \\
{\left[(\varrho-1) \eta_{g}+1\right] \hat{g}_{S}=\mu \hat{V}_{S}+(1-\mu) \hat{c}_{S}} \\
\frac{r d}{y} \varrho \eta_{g} \hat{g}_{S}=\hat{y}_{S}-\frac{c}{y} \hat{c}_{S} \\
\hat{V}_{S}=\frac{1}{1-\eta_{V} \mu}\left[\eta_{V} \hat{y}_{S}+\eta_{q}(1-\mu) \hat{c}_{S}-\left(\eta_{z}+\eta_{q}\right) \hat{g}_{S}\right]
\end{gathered}
$$

We can solve the last three equations to find a relationship between $c$ and $y$ :

$$
\hat{c}_{S}=\eta_{C} \hat{y}_{S} ; \quad \eta_{C} \equiv \frac{\frac{1-\eta_{V} \mu}{\mu} \frac{(\varrho-1) \eta_{g}+1}{\frac{r d}{y} \varrho \eta_{g}}+\frac{\eta_{z}+\eta_{q}}{\frac{r d}{Y} \varrho \eta_{g}}-\eta_{Y}}{\left[\frac{1-\eta_{V} \mu}{\mu} \frac{(\varrho-1) \eta_{g}+1}{\frac{r d}{y} \varrho \eta_{g}} \frac{c}{y}+(1-\mu)\right]+\frac{\eta_{z}+\eta_{q}}{\frac{r d}{y} \varrho \eta_{g}} \frac{c}{y}+\eta_{q}(1-\mu)}<1
$$

We can solve the system for $t<T^{e}$ :

$$
\hat{y}_{t}=\psi_{y} r_{S}^{n}<0 ; \hat{\pi}_{t}^{w}=\psi_{p} r_{S}^{n}<0 ; \hat{g}_{t}=\psi_{g} r_{S}^{n}<0
$$

where $\psi_{y}=\frac{(1-\beta \mu) \eta_{C}^{-1}}{(1-\beta \mu)(1-\mu)-\kappa_{w}\left(\nu+\eta_{C}\right) \mu \eta_{C}^{-1}}>0, \psi_{p}=\frac{\kappa_{w}\left(\nu+\eta_{C}\right)}{1-\mu \beta} \psi_{y}>0$, and $\psi_{g}=\frac{1-\frac{c}{y} \eta_{C}}{\frac{r d}{y} \varrho \eta_{g}} \psi_{y}>0$. We assume (by A2 in the main text) the system is locally determinate around the state $\mathrm{S}$ equilibrium defined above. Therefore by the law of motion of productivity, we can derive that:

$$
\log A_{t+1}=\log A_{t}+\psi_{g} r_{S}^{n} ; \quad \forall 0<t<T^{e}
$$


Second part of the proposition (when $t \geq T^{e}$ ) follows from Proposition 6 .

\section{E.2 consumption-equivalent welfare loss}

We derive the consumption equivalent welfare loss relative to the (time-0) first best allocation as follows:

We discussed above in the Appendix D.2 that the lifetime welfare function can be re-written as :

$$
\mathbb{W}_{0}=\sum_{s=0}^{\infty} \beta^{s}\left[\log c_{s}-v\left(L_{s}\right)+\frac{\beta}{1-\beta} \log \left(1+g_{s+1}\right)\right]
$$

Assuming a permanent gain in consumption $b \geq 0$ percent, the welfare at the efficient allocation is given by:

$$
\mathbb{W}_{0}^{*}(b)=\sum_{s=0}^{\infty} \beta^{s}\left[\log \left(c_{s}(1+b)\right)-v\left(L_{s}\right)+\frac{\beta}{1-\beta} \log \left(1+g_{s+1}\right)\right]=\mathbb{W}_{0}^{*}(b=0)+\frac{1}{1-\beta} \log (1+b)
$$

Equating this to the welfare under the sticky wage allocation:

$$
\begin{aligned}
& \mathbb{W}_{0}=\mathbb{W}_{0}^{*}(b) \\
\Longleftrightarrow & (1-\beta)\left(\mathbb{W}_{0}-\mathbb{W}_{0}^{*}(b=0)\right)=\log (1+b) \approx b
\end{aligned}
$$

Further we derived the quadratic approximation of the welfare relative to the first-best allocation above in Appendix D:

$$
\frac{\mathbb{W}_{0}-\mathbb{W}_{0}^{*}(b=0)}{U_{c_{s s}} y_{s s}}
$$

Thus, the consumption equivalent welfare loss :

$$
b=U_{c_{s s}} y_{s s}(1-\beta)\left[\frac{\mathbb{W}_{0}-\mathbb{W}_{0}^{*}(b=0)}{U_{c_{s s}} y_{s s}}\right]<0
$$

where the term in square brackets is the quadratic approximation we derived above in Proposition 4 and the welfare terms are the conditional welfare gains or losses, starting at the efficient steady state at $t=0$.

Under monetary policy shocks, liquidity demand shocks and wage markup shocks, the first-best allocation corresponds with the no-fluctuations allocation. Hence the consumption-equivalent welfare loss is relative to the Balanced Growth Path. However under productivity shocks, the first-best allocation departs from the Balanced Growth path and the consumption equivalent welfare loss derived above is non-standard. 


\section{E.3 Simple targeting rules}

We follow Chung, Herbst and Kiley (2015) in implementing a simple version of operational rules. Simple nominal wage level targeting takes the form:

$$
\hat{w}_{t}+\hat{y}_{t}-\hat{y}_{t}^{f}=0
$$

where $w_{t}=\frac{W_{t}}{A_{t}}$ is the normalized wage level, $y_{t}=\frac{Y_{t}}{A_{t}}$ is normalized output, hats refer to log deviations from steady state and superscript $f$ denotes the corresponding variable under flexible wage allocation. Simple hysteresis targeting rule is

$$
h_{t+1}+\hat{y}_{t}-\hat{y}_{t}^{f}=0
$$

where $h_{t+1}$ is the hysteresis term defined as a sum of productivity growth rate deviations (from steady state) because of the history of shocks realized until time $t$. Wage $\times \mathrm{Y}$ target (equivalent of Nominal GDP target) is implemented as combination of wage level targeting and hysteresis targeting:

$$
\begin{gathered}
\hat{w}_{t}+h_{t+1}+\hat{y}_{t}-\hat{y}_{t}^{f}=0 . \\
\text { wage }+h-h \text { flex }+y-y \text { flex }=0
\end{gathered}
$$

\section{F Fiscal Policy Multipliers at the ZLB}

The results echo the findings of Eggertsson (2011). The kew insight here is that the policy has long-run implications. We here present the analytical solution for investment subsidy for research spending. Results on paradox of toil, paradox of thrift, and expansionary government spending can be derived similarly.

To analyze fiscal policy, we allow government to run budget deficits, by issuing the nominal risk-free bond $B_{t+1}$, which is not in net zero supply anymore. ${ }^{\dagger}$

$$
P_{t} T_{t}+B_{t+1}=-\tau^{p} \int_{0}^{1} p_{i t} x_{i t} d i+\tau_{t}^{r} P_{t} R_{t}-\tau^{w} \int_{0}^{1} W_{t}(h) L_{t}(h)+\left(1-\tau_{t}^{b}\right)\left(1+i_{t-1}\right) B_{t}
$$

And the following transversality condition on government debt holds

$$
\lim _{T \rightarrow \infty} \mathbb{E}_{t} \frac{B_{T}}{P_{T}\left(1+\tau_{T}^{b}\right)} u_{c}\left(C_{T}\right)=0
$$

Further we assume that following bounds on $\mu$ hold:

$$
\mu<\frac{\left((\varrho-1) \eta_{g}+1\right)(\gamma-1)}{\beta \gamma}
$$

\footnotetext{
${ }^{\dagger}$ Since Ricardian Equivalence holds, it does not matter if the government finances expenditure by running a balanced budget or via deficit financing.
} 


$$
(1-\beta \mu)(1-\mu)-\kappa_{w}\left(\nu+\eta_{C}\right) \mu \eta_{C}^{-1}>0
$$

\section{F.1 R\&D Investment Subsidy}

Assume a temporary research subsidy is implemented $\hat{\tau}_{S}^{r}>0$ for $S \in\left[1, T^{e}\right)$. Under Eggertsson and Woodford

(2003)'s two-state Markov Chain assumption, the system at time $t<T^{e}$ is in state $S$ (short run) and can be expressed as:

$$
\begin{gathered}
(1-\mu) \hat{c}_{S}=\mu \hat{\pi}_{S}^{w}+\hat{r}_{S} \\
(1-\beta \mu) \hat{\pi}_{S}^{w}=\kappa_{w}\left(\hat{c}_{S}+\nu \hat{y}_{S}\right) \\
{\left[(\varrho-1) \eta_{g}+1\right] \hat{g}_{S}-\hat{\tau}_{S}^{r}=\mu \hat{V}_{S}+(1-\mu) \hat{c}_{S}} \\
\frac{r d}{y} \varrho \eta_{g} \hat{g}_{S}=\hat{y}_{S}-\frac{c}{y} \hat{c}_{S} \\
\hat{V}_{S}=\frac{1}{1-\eta_{V} \mu}\left[\eta_{V} \hat{y}_{S}+\eta_{q}(1-\mu) \hat{c}_{S}-\left(\eta_{z}+\eta_{q}\right) \hat{g}_{S}\right]
\end{gathered}
$$

We can solve the last three equations to find a relationship between $c$ and $y$ :

$$
\begin{gathered}
\hat{c}_{S}=\eta_{C} \hat{y}_{S}-\eta_{x} \hat{\tau}_{S}^{r} ; \quad \eta_{C} \equiv \frac{\frac{1-\eta_{V} \mu}{\mu} \frac{(\varrho-1) \eta_{g}+1}{\frac{r d}{y} \varrho \eta_{g}}+\frac{\eta_{z}+\eta_{q}}{\frac{r d}{y} \varrho \eta_{g}}-\eta_{Y}}{\left[\frac{1-\eta_{V} \mu}{\mu} \frac{(\varrho-1) \eta_{g}+1}{\frac{r d}{y} \varrho \eta_{g}} \frac{c}{y}+(1-\mu)\right]+\frac{\eta_{z}+\eta_{q}}{\frac{r d}{y} \varrho \eta_{g}} \frac{c}{y}+\eta_{q}(1-\mu)}<1 \\
\eta_{x}=\frac{1}{\left[\frac{1-\eta_{V} \mu}{\mu} \frac{(\varrho-1) \eta_{g}+1}{\frac{r d}{y} \varrho \eta_{g}} \frac{c}{y}+(1-\mu)\right]+\frac{\eta_{z}+\eta_{q}}{\frac{r d}{y} \varrho \eta_{g}} \frac{c}{y}+\eta_{q}(1-\mu)}>0
\end{gathered}
$$

Using this, the resulting AD-AS system can be expressed as:

$$
\begin{aligned}
& (1-\mu) \eta_{c} \hat{y}_{S}=\mu \hat{\pi}_{S}^{w}+(1-\mu) \eta_{x} \hat{\tau}_{S}^{r}+\hat{r}_{S} \\
& (1-\beta \mu) \hat{\pi}_{S}^{w}=\kappa_{w}\left(\eta_{c}+\nu\right) \hat{y}_{S}-\kappa_{w} \eta_{x} \hat{\tau}_{S}^{r}
\end{aligned}
$$

We can solve the system for $t<T^{e}$ :

$$
\begin{gathered}
\hat{y}_{t}=\psi_{y} r_{S}^{n}+\psi_{\tau}^{y} \hat{\tau}_{S}^{r} \\
\hat{\pi}_{t}^{w}=\psi_{p} r_{S}^{n}+\psi_{\tau}^{p} \hat{\tau}_{S}^{r} \\
\hat{g}_{t+1}=\psi_{g} r_{S}^{n}+\psi_{\tau}^{g} \hat{\tau}_{S}^{r}
\end{gathered}
$$

where $\psi_{y}=\frac{(1-\beta \mu) \eta_{C}^{-1}}{(1-\beta \mu)(1-\mu)-\kappa_{w}\left(\nu+\eta_{C}\right) \mu \eta_{C}^{-1}}>0$,

$\psi_{\tau}^{y}=\frac{1}{\frac{1-\eta_{V} \mu}{\mu} \frac{(\varrho-1) \eta_{g}+1}{\frac{R}{Y} \varrho \eta_{g}}+\frac{\eta_{z}+\eta_{q}}{\frac{r d}{y} \varrho \eta_{g}}-\eta_{Y}} \frac{(1-\beta \mu)(1-\mu)-\kappa_{w} \mu}{(1-\beta \mu)(1-\mu)-\kappa_{w}\left(\nu+\eta_{C}\right) \mu \eta_{C}^{-1}}>0$

$\psi_{p}=\frac{\kappa_{w}\left(\nu+\eta_{C}\right)}{1-\mu \beta} \psi_{y}>0$, and $\psi_{g}=\frac{1-\frac{c}{y} \eta_{C}}{\frac{r d}{y} \varrho \eta_{g}} \psi_{y}>0$ 
$\psi_{\tau}^{p}=\frac{\kappa_{w}}{1-\mu \beta}\left[\frac{\left(1+\nu \eta_{c}^{-1}\right)\left((1-\beta \mu)(1-\mu)-\kappa_{w} \mu\right)}{(1-\beta \mu)(1-\mu)-\kappa_{w}\left(\nu+\eta_{C}\right) \mu \eta_{C}^{-1}}-1\right]>0$.

$\psi_{g}=\frac{1-\frac{c}{y} \eta_{C}}{\frac{r d}{y} \varrho \eta_{g}} \psi_{y}>0$

$\psi_{\tau}^{g}=\frac{1-\frac{c}{y} \eta_{C}}{\frac{r d d}{y} \varrho \eta_{g}} \psi_{\tau}^{y}-\frac{\frac{c}{y}}{\frac{r d}{y} \varrho \eta_{g}} \eta_{x}=\frac{1}{\frac{r d}{y} \varrho \eta_{g}}\left[\psi_{\tau}^{y}-\frac{c}{y} \eta_{x}\left[\frac{\left((1-\beta \mu)(1-\mu)-\kappa_{w} \mu\right)}{(1-\beta \mu)(1-\mu)-\kappa_{w}\left(\nu+\eta_{C}\right) \mu \eta_{C}^{-1}}-1\right]\right]>0$.

Hence research tax subsidy is expansionary at the ZLB. This is equivalent to the investment tax credit studied by Eggertsson (2011). Note that a supply side expansionary policy is contractionary at the ZLB if it reduces expectations of inflation. Here, this supply side policy increases the potential output of the economy without inducing the corresponding deflationary pressures. Instead the expectations of increased demand for research spending boosts inflation. Hence, a tax subsidy for non-tangible investment can be expansionary at the ZLB.

The Long-run Output is given by:

$$
\log Y_{t+1}=\log Y_{t+1}^{*}+\left(T^{e}-1\right) \psi_{g} r_{S}^{n}+\left(T^{e}-1\right) \psi_{\tau}^{g} \hat{\tau}_{S}^{r} ; \quad \forall t \geq T^{e}
$$

The Long-run output is higher by the increase in productivity growth rate achieved by higher research subsidies duirng the binding ZLB. Thus the long-run output multiplier for research subsidy is given by:

$$
\frac{\partial Y_{L}}{\partial \hat{\tau}_{S}^{r}}=\left(T^{e}-1\right) \psi_{\tau}^{g}>0
$$

\section{G Quantitative Evaluation}

So far, we advanced a channel for hysteresis by allowing monetary policy to have an effect on R\&D investments and hence TFP growth. Second, we solved for optimal policy at ZLB assuming a liquidity demand shock. Our analysis raises two questions: (i) does monetary policy influence productivity enhancing investments and the level of TFP in the data, and (ii) can a realistically calibrated liquidity demand shock generate a sizable recession. We answer both questions in the affirmative. We show empirical evidence consistent with key model predictions regarding monetary policy shocks. Contractionary monetary policy temporarily reduces $R \& D$ investment, firm entry, and has a persistent effect on TFP. Further, we conduct numerical exercises using a medium scale version of our model. A one time increase in liquidity demand, calibrated to match the increase in premium associated with very liquid assets during the financial crisis, can explain a third of the drop in output observed in the data during the Great Recession.

\section{G.1 Empirical Evidence}

We estimate dynamic causal impacts of monetary policy on R\&D investment, firm-entry and aggregate TFP. We interpret firm entry as an indicator for productivity enhancing investment for two reasons. First, we observe R\&D investment for large firms in the data. These firms may not be significant drivers of TFP growth. Second, Decker et al. (2014), among others, have shown that firm entry is a significant driver of 
TFP growth. Consistent with the creative destruction literature, we interpret the number of innovating sectors in our model as counterpart of net firm entry in the data. The estimated impulse responses lend support for key predictions of our model: a contractionary monetary policy shock has a transitory negative effect on R\&D investment and firm entry, and a persistent negative effect on TFP.

\section{Empirical Strategy}

Our empirical strategy is based on the recent literature (Jordà, Schularick and Taylor 2019, Ramey and Zubairy 2017, and Barnichon and Brownlees 2016) that combines the instrumental variables with the local projections (LP-IV) approach to directly estimate the structural IRFs. The series of (narratively- and high frequency-) identified monetary surprises $e_{t}^{m}$ are treated as proxy for the true shocks $\epsilon_{t}^{m}$. In the first-stage, we instrument a policy indicator (fed funds rate) with the relevant proxy. ${ }^{\dagger}$ In the second stage, we run a sequence of predictive regressions of the dependent variable on the instrumented policy indicator for different prediction horizons. The estimated sequence of regression coefficients of the instrumented policy indicator are then the impulse responses.

More specifically, we estimate the following second-stage LP specification for horizons $\mathrm{h} \in 0, \ldots, \mathrm{H}$ :

$$
y_{t+h}=\alpha^{h}+\beta^{h} \hat{f} \hat{f} r_{t}+\sum_{p} \theta^{p h} Z_{t-p}+\nu_{t+h}
$$

$f \hat{f} r_{t}$ is the predicted policy instrument from the first-stage regression using identified monetary policy instruments $e_{t}^{m}$. The set $Z_{t}$ includes lags of dependent variable, the policy indicator, the policy instrument, and the current and lagged conditioning variables that identify exogenous fluctuations in the monetary policy instrument and improve precision of standard errors (see Stock and Watson 2017). The conditioning variables are log real GDP and log GDP deflator. The dynamic coefficients of interest are, therefore, the estimates of $\beta^{h}$ for $h=0,1, \ldots, H$. We compute standard errors based on heteroskedasticity and autocorrelation robust covariance matrix (Newey-West) estimators. The impulse responses for R\&D investment at the firm-level are estimated in a similar manner, by conditioning on time-invariant firm-fixed effects, an aggregate time trend as well as two lags of time-varying firm-level controls (assets, cash holdings, short-term debt, and annual employment). The standard errors, in this case, are clustered at the firm-level.

\section{Data: Instruments and Variables of Interest}

We obtain two sequences of monetary policy surprises identified in the empirical literature. One is narratively-identified series from Romer and Romer (2004) (RR). They decompose changes in the intended federal funds rate at the FOMC meetings into a systematic and a residual shock component. The residual shock is extracted from unexplained variation in a regression of target funds rate changes on changes

\footnotetext{
${ }^{\dagger}$ The use of external instruments or proxy SVAR was developed by Stock (2008), and extended by Stock and Watson (2012) and Mertens and Ravn (2013). Gertler and Karadi (2015) combine high-frequency identification and proxy SVARs to estimate monetary policy impulse responses. Stock and Watson (2017) discuss connections between proxy SVAR and LP-IV approaches.
} 
Figure 8: Policy Indicator and Monetary Policy Surprises
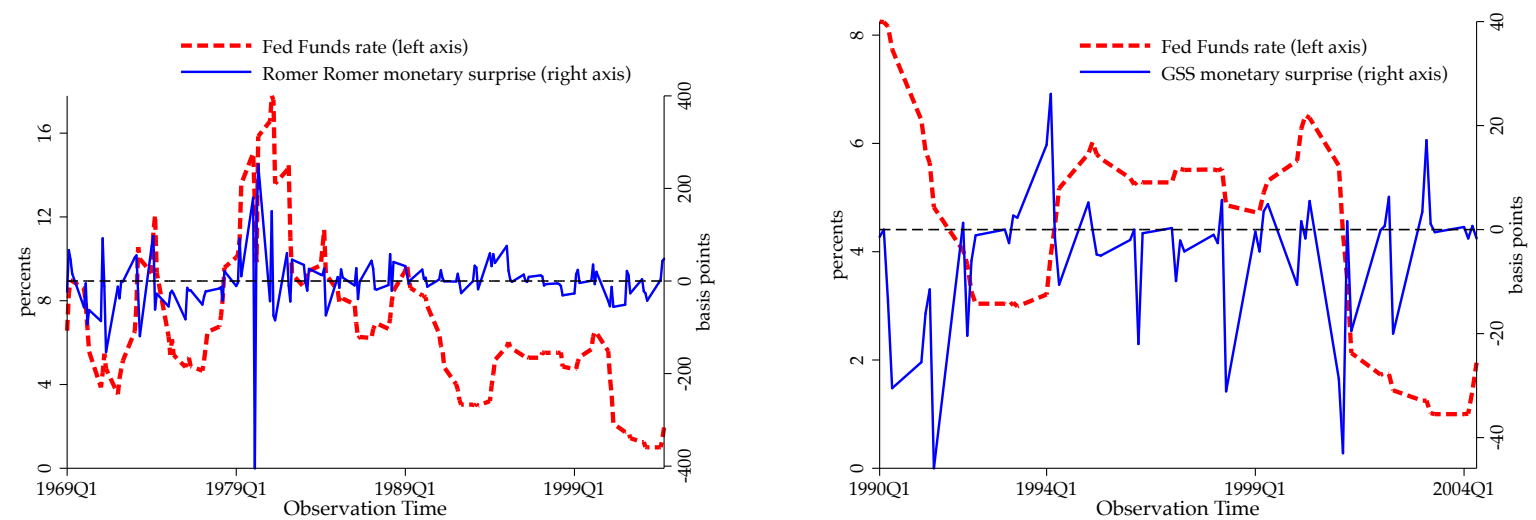

Note: The figure plots the Federal Funds rate against the monetary surprises. Two measures of monetary surprises are used in the main text. On the left, we plot the Romer \& Romer (2004) narrative-identified monetary policy instruments. On the right, we plot the changes in current-month federal funds rate futures in a narrow 30 minute window around FOMC meeting announcements. These daily indicators are aggregated to the monthly frequency by adjusting for number of days left in the month. Monthly monetary surprises are summed to get the quarterly frequency aggregates. We take the FOMC days' announcement surprises from Gürkaynak, Sack and Swanson (2005)

in Greenbook forecasts of inflation, output growth and unemployment. The original monthly series from 1969-1996 has been recently extended by Wieland and Yang (2016) until 2007. The second set of surprises are measured using high-frequency data on the federal funds futures contracts. The rates on these contracts reflect market expectations of the average federal funds rate during that month. To identify the exogenous part of announced changes in monetary policy, Gürkaynak, Sack and Swanson (2005) (GSS) calculate changes in the traded rate in a narrow 30 minutes window around the FOMC press releases. We obtain this series for 1990-2007 by combining the data from GSS with that extended by Gorodnichenko \& Weber (2016). We sum up both the series to get a quarterly series of surprises, as in Ottonello and Winberry (2017) and Wong (2015). Figure 8 plots series of obtained shocks against the effective federal funds rate. We use information on surprises until 2005Q4, with response variables measured up to three years later (2008Q4), before the financial crisis. ${ }^{\dagger}$

As measures for R\&D investment, we use two quarterly data series (denoting sample lengths used in parentheses): (i) $\log$ R\&D investment deflated by GDP deflator available from NIPA (1969-2007), and (ii) firm-level R\&D investment constructed from COMPUSTAT database (1990-2007). The construction of firm-level R\&D investment data is described in the Appendix and follows the methodology common in the literature (Brown, Fazzari, and Petersen 2009, Terry 2017). ${ }^{\dagger}$ As measures of firm entry, we obtain two aggregate data series: (1) log number of business incorporations, and (2) log number of (net) establishment births. The first series is aggregated to quarterly level from a monthly Survey of Current Business produced until 1994 run by the Bureau of Labor and Statistics (BLS). The second series comes from a quarterly National Private Sector Business Employment Dynamics Data of BLS available 1993 onwards. Finally, log

\footnotetext{
${ }^{\dagger}$ We exclude the rate cut of September 2001, to avoid the noise in the rates caused by the terrorist attacks.

${ }^{\dagger}$ To provide a broad picture, the firm-level R\&D sample data in year 2000 contained 3441 firms for which R\&D investment information was available. These firms collectively employed 9.7\% of total US Employment (Fred code: PAYEMS), spent $86 \%$ of total private R\&D measured by NIPA and had sales worth $26 \%$ of US nominal GDP. Data construction discussed in Appendix H.
} 
utilization-adjusted TFP and non-adjusted TFP measures are constructed by cumulating the respective TFP growth rate series obtained from (Fernald, 2014b) over 1969-2007. For brevity, we leave the discussion on data-selection, sample end-points and other robustness checks to the appendix.

\section{Results}

Figures 9 and 10 report our main empirical results using the GSS and RR instruments over different sample lengths. We report deviations from a constant trend following a 100 bps increase in federal funds rate. The shaded areas represent the $95 \%$ confidence intervals. We report the F-statistics for respective IRFs in the figures to verify instrument relevance. In most cases, the F statistic is above 23, a threshold for ten percent level constructed by Montiel-Olea and Pflueger (2013). Because of the shorter sample length, the GSS instrument does suffer from the weak-instrument issue.

Figure 9: Response of utilization adjusted TFP and TFP to 100 bps increase in Federal Funds Rate

1969Q1 - 1999Q4

$\log$ adjusted TFP

$\log \mathrm{TFP}$

1969Q1 -1999Q4

$\log$ adjusted TFP

$\log$ TFP

Romer and Romer Surprises

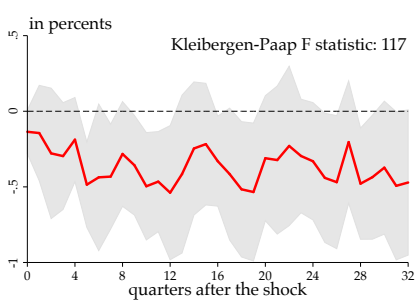

1990Q1 - 2004Q4

$\log$ adjusted TFP

Gürkaynak, Sack and Swanson Surprises
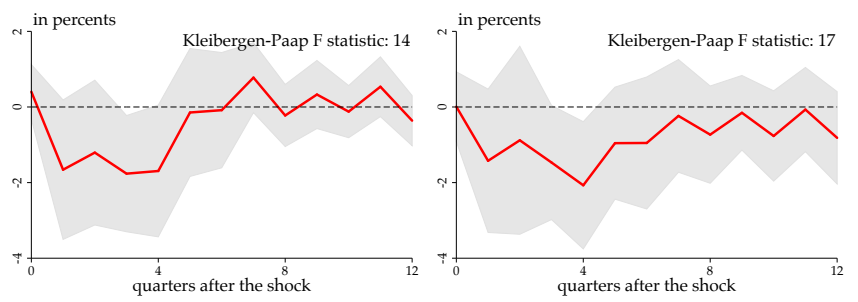
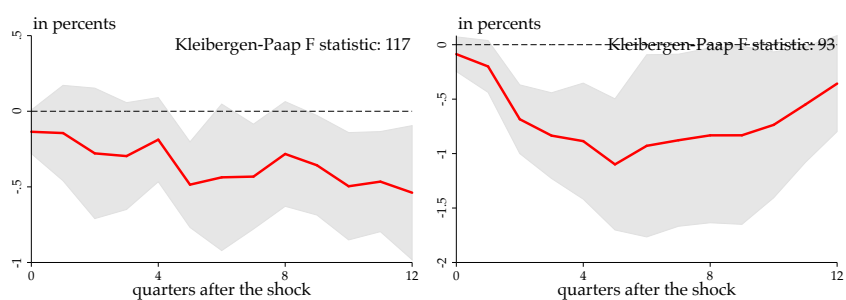

1969Q1 - 2004Q4 $\log$ TFP $\log$ adjusted TFP

Romer and Romer Surprises

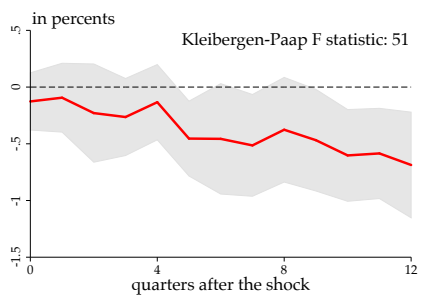

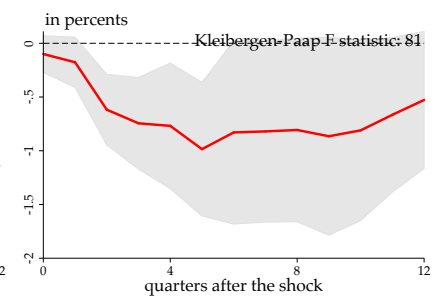

Notes: The figure plots the estimated impulse response functions for log utilization adjusted TFP and non-adjusted TFP. Time is in quarters. Sample length, and instrument used are denoted at the top of each row. IRFs are computed using a local-projections IV approach. Current and two past-lagged values of log real GDP and inflation rate are used as conditioning variables. Regressions also are reported in the figures. The standard errors are calculated using HAR-Newey-West standard errors. The shaded areas denote $95 \%$ confidence intervals.

In figure 9, we plot the IRFs for utilization-adjusted TFP and raw TFP. Consistent with the dynamics of the model, the utilization-adjusted TFP declines gradually after a monetary policy shock. The IRFs for raw TFP decline by more than the fall in adjusted TFP because of higher fluctuations in factor utilizations induced by monetary policy shocks. The leveling off of the decline in raw TFP is consistent with the persistent decline in adjusted TFP. This decline in TFP reaches $-0.4 \%$ after 32 quarters (estimated on data 
from 1969-1999). Recently, Moran and Queraltó (2018) identify monetary policy shocks using a Cholesky ordering and find that a shock which increases the federal funds rate by 70 basis points, permanently reduces adjusted-TFP by $0.25 \%$. With a non-parametric estimation strategy, we reach similar results. ${ }^{\dagger}$

Figure 10: Response of Firm Entry, Aggregate R\&D and Firm-level R\&D to 100 bps increase in Federal Funds Rate
1969Q1 - 1991Q4
1969Q1 - 2004Q4
1990Q1- 2004Q4

$(\log )$ no. of new incorp.

Aggregate R\&D

Firm-level R\&D

Romer and Romer Surprises

Romer and Romer Surprises

Gürkaynak, Sack and Swanson Surprises
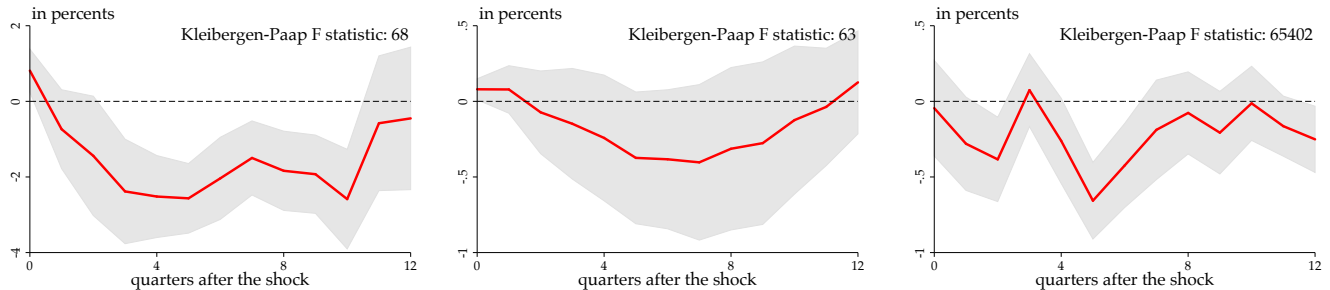

1993Q1 - 2004Q4

1990Q1 - 2004Q4

1990Q1 - 2008Q4

(log) Net Establishment Births

Aggregate R\&D

Firm-level R\&D

Gürkaynak, Sack and Swanson Surprises
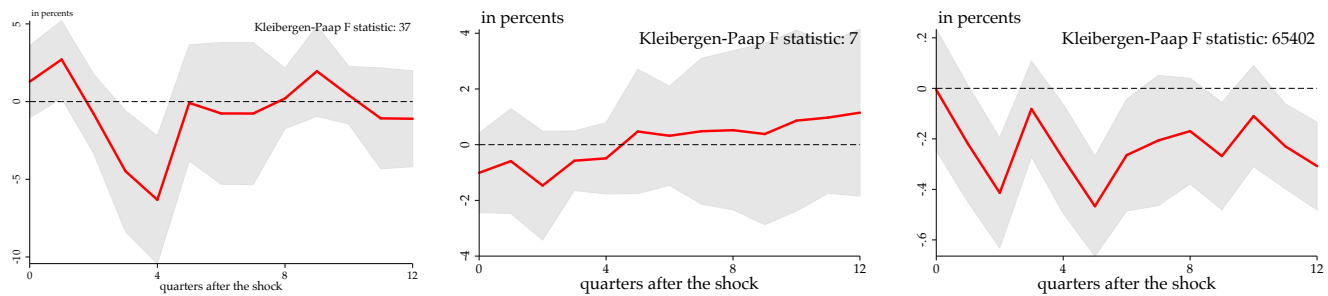

Notes: The figure plots the estimated impulse response functions for firm entry, aggregate R\&D and firm-level R\&D. Two indicators for firm-level R\&D are used: (1) log number of new incorporations available over 1969-994, and (2) log number of net establishment births available since 1993. Time is in quarters. Sample length, and instrument used are denoted at the top of each row. IRFs are computed using a local-projections IV approach. Current and two past-lagged values of log real GDP and inflation rate are used as conditioning variables. Regressions also include past values of the proxy, the federal funds rate, and the dependent variable. Kleibergen-Paap $\mathrm{F}$ statistic for weak instruments are reported in the figures. The standard errors are calculated using HAR-Newey-West standard errors.

The shaded areas denote $95 \%$ confidence intervals. Firm -level R\&D regressions also include two lags of assets, short debt, cash, employment, and firm-fixed effects. The standard errors are robust clustered at the firm-level.

In Figure 10, we plot the response of the number of new incorporations, establishment births, aggregate R\&D and firm-level R\&D investments. Contractionary monetary policy shocks are found to have a temporary effect on these indicators. There is a delayed negative effect on R\&D investment, which is not statistically significant for aggregate R\&D but is statistically significant at the firm-level. Our benchmark model does not feature adjustment costs or frictions in $R \& D$ investment. As a result, the benchmark model exhibited a linear response of $R \& D$ investment to monetary policy shocks. In the medium scale model, we introduce adjustment costs in order to generate the curvature in the $R \& D$ response. The empirical findings align with the key predictions of our model: monetary policy influences long-run level of TFP. We next use these empirical findings to assess the quantitative relevance of our model.

\footnotetext{
${ }^{\dagger}$ In the appendix, we show the IRFs for log real GDP and the implicit price deflator. The responses are similar to those documented by Ramey (2016). We confirm that the real GDP traces the response of raw TFP and levels off after 32 quarters to match the permanent decline in TFP. The permanent effect is, however, statistically indistinguishable from zero.
} 


\section{G.2 Medium Scale DSGE Model with Schumpeterian growth}

\section{G.2.1 Model}

For brevity, we sketch the additional features introduced into the benchmark model and leave the detailed model discussion to appendix I. Capital is introduced in the production of intermediate good, following Howitt and Aghion (1998). Households own and accumulate capital subject to investment adjustment costs and rent it out to the intermediate good monopolists. The specification for investment adjustment costs follows the new Keynesian literature (Christiano, Eichenbaum and Evans, 2005). We append price-rigidity by introducing a retail sector that sells the final good produced by the perfectly competitive producer. Monopolistically competitive retailers set prices on a staggered basis following Calvo (1983). Further, we allow for variable capital utilization, and (internal) habits in consumption. Relative to the existing new Keynesian literature, we introduce adjustment costs in $R \& D$ expenditure. A particular functional form we use is $S^{r d}=\frac{\varkappa}{2}\left(\frac{R_{t}}{\left(1+g_{s s}\right) R_{t-1}}-1\right)^{2}$, which the entrepreneur takes as given while making her R\&D investment decision. This feature helps the model match the curvature in $R \& D$ responses that is found in empirical IRFs (see Figure 10 discussed above, as well as Moran and Queraltó 2018).

\section{G.2.2 Calibration}

We calibrate the model at a quarterly frequency. Table 5 reports the calibrated values of parameters, that we discuss next:

\section{Steady State Parameters}

Steady state labor supply is normalized to 1 . Six parameters are set to match six steady state targets. Table 6 reports the steady state moments targeted by the model. We set $\beta$ to 0.9990 , to match an annualized real interest rate of $2.40 \%$, along with (annualized) steady state output growth rate of $2 \%$. Innovation step size $\gamma$ is set to 1.55 to match the creative destruction rate of $3.6 \%$. Howitt (2000) selects this value as it matches the empirical finding that a non-innovating U.S. company loses value at a 3.6-percent annual rate. Capital depreciation rate is set to an annual rate of $10 \%$ and steady state price markup is set to $15 \%$. These are commonly used values in the business cycle literature. We calibrate $\alpha, \delta$, and $\varrho$ such that model replicates following (annual) steady state targets: Gross Private Domestic investment to GDP ratio of $17.2 \%$, growth rate of $2 \%, \mathrm{R} \& \mathrm{D}$ to GDP ratio of $2 \%$, and Profits to GDP ratio of $6.2 \%$. These are calculated from quarterly NIPA tables over 1947-2007.

We consider two variants of the model to vary the innovation sensitivity. Under first calibration, following Benigno and Fornaro (2018), we introduce an exogenous probability of patent loss $\mu=11.4 \%$. This implies that value of owning an intermediate goods' patent defined in equation 11 is modified to:

$$
V_{t}=\Gamma_{t}+\left(1-z_{i t}-\mu\right) \mathbb{E}_{t} Q_{t, t+1} V_{t+1}
$$


Table 5: Parameters

\begin{tabular}{|c|c|c|c|c|c|}
\hline \multicolumn{6}{|c|}{ Steady State Parameters } \\
\hline & $\beta$ & $\lambda_{p}$ & $\delta_{k}$ & $\alpha$ & $\gamma$ \\
\hline & $\begin{array}{l}\text { Discount } \\
\text { factor }\end{array}$ & $\begin{array}{c}\text { Price s.s. } \\
\text { markup }\end{array}$ & $\begin{array}{l}\text { Capital } \\
\text { depreciation } \\
\text { rate }\end{array}$ & $\begin{array}{l}\text { Capital } \\
\text { share }\end{array}$ & $\begin{array}{l}\text { Innovation } \\
\text { step size }\end{array}$ \\
\hline & 0.999 & 0.15 & 0.025 & 0.28 & 1.55 \\
\hline Calibrations & & $\underset{\substack{\text { Inverse } \\
\text { innovation } \\
\text { elasticity }}}{\varrho}$ & $\begin{array}{c}\delta \\
\begin{array}{c}\text { Innovation } \\
\text { cost } \\
\text { parameter }\end{array}\end{array}$ & $\begin{array}{c}\mu \\
\begin{array}{c}\text { Probability of } \\
\text { patent loss }\end{array}\end{array}$ & \\
\hline 1. low $\varrho$ & & 1.07 & 5.88 & 0.0285 & \\
\hline 2. high $\varrho$ & & 3.08 & $7.47 \times 10^{4}$ & 0.0 & \\
\hline \multicolumn{6}{|c|}{ Parameters Characterizing the Dynamics } \\
\hline$\nu$ & $\lambda_{w}$ & $\theta_{p}$ & $\theta_{w}$ & $h$ & $\frac{a^{\prime \prime}(1)}{a^{\prime}(1)}$ \\
\hline $\begin{array}{l}\text { Inverse } \\
\text { Frissch } \\
\text { elasticity }\end{array}$ & $\begin{array}{l}\text { Wage s.s. } \\
\text { markup }\end{array}$ & $\begin{array}{l}\text { Price Calvo } \\
\text { probability }\end{array}$ & $\begin{array}{l}\text { Wage Calvo } \\
\text { probability }\end{array}$ & $\begin{array}{c}\text { (Internal) } \\
\text { habit }\end{array}$ & $\begin{array}{c}\text { Capital } \\
\text { utilization } \\
\text { cost }\end{array}$ \\
\hline 1.00 & 0.15 & 0.750 & 0.750 & 0.5 & 4 \\
\hline$\varkappa$ & $S^{\prime \prime}(1)$ & $\phi_{\pi}$ & $\phi_{y}$ & $1-\frac{1}{\lambda_{a}}$ & \\
\hline $\begin{array}{c}R \& D \\
\text { adjustment } \\
\text { cost } \\
0.768\end{array}$ & $\begin{array}{c}\text { Investment } \\
\text { adjustment } \\
\text { cost } \\
0.75\end{array}$ & $\begin{array}{c}\text { Taylor rule } \\
\text { inflation } \\
\text { response } \\
1.50\end{array}$ & $\begin{array}{l}\text { Taylor rule } \\
\text { (normalized) output } \\
\text { response } \\
0.125\end{array}$ & $\begin{array}{c}\text { Government } \\
\text { spending } \\
\text { share } \\
0.20\end{array}$ & \\
\hline
\end{tabular}

Notes: The table shows the parameter values of the model for the baseline calibration.

Table 6: Targets and Model-Implied Values in Calibration of Steady State Parameters

\begin{tabular}{lcccccc} 
Targets & GDP growth rate & $\begin{array}{c}\text { Creative } \\
\text { Destruction rate }\end{array}$ & Real rate & $\begin{array}{c}\text { Investment/GDP } \\
\text { Ratio }\end{array}$ & $\begin{array}{c}\text { R\&D/GDP } \\
\text { Ratio }\end{array}$ & $\begin{array}{c}\text { Profits/GDP } \\
\text { Ratio }\end{array}$ \\
\hline Data & 2 & 3.6 & 2.40 & 17.18 & 2 & 6.50 \\
Model & 2 & 3.6 & 2.40 & 17.18 & 2 & 6.59
\end{tabular}

Notes: The table shows the empirical targets and the model-implied values in the calibration of the six steady state parameters. The sample used to compute the data counterparts of the targets is 1948Q1-2007Q4.

$\mu$ is chosen in order to match the (annual) $\mathrm{R} \& \mathrm{D}$ depreciation rate of $15 \%$. An exogenous probability of patent loss reduces profitability from successful innovation, and in turn reduces $R \& D$ investment. Ceteris paribus, a higher exogenous patent loss probability requires higher returns from $R \& D$ investment, and thus lower $\varrho$. As a result, we find $\varrho=1.07$. Schumpeterian growth literature following Aghion and Howitt (1992) has largely focused on the analytically tractable case of $\varrho=1$ (cf. Nuño 2011). There is an extensive empirical literature that estimates this parameter (surveyed in Hall, Mairesse and Mohnen 2010) and finds a relatively wide range $\varrho \in(1.10,5)$. Low $\varrho$ implies higher sensitivity of innovation probability to $\mathrm{R} \& \mathrm{D}$ investment, which invariably allows the model to generate large growth rate fluctuations. ${ }^{\dagger}$ Additionally, we recalibrate the model without the exogenous patent loss to get a calibration with higher $\varrho=3.08$.

\section{Parameters characterizing Endogenous Propagation}

Remaining set of parameters are chosen from the standard business cycle literature, and we closely follow Del Negro et al. (2017) in calibrating these parameters. Inverse Frisch elasticity of labor supply is set to 1, wage markup is set to steady state markup of $15 \%$ to mirror the degree of monopolistic competition assumed

\footnotetext{
${ }^{\dagger}$ The marginal probability of success is decreasing in $\varrho$, keeping fixed the profitability upon successful innovation. Exogenous patent loss reduces the profitability of successful innovation, for a given probability of success.
} 
in the product market $\left(\lambda_{w}=0.15\right)$. Nominal rigidities parameters are chosen, following the empirical evidence of Nakamura and Steinsson (2008) who find an average duration of price and wage contracts to be 4 quarters $\left(\theta_{p}=\theta_{w}=0.75\right)$. We calibrate habits parameter at $h=0.5$. Varying these parameters to ranges considered in the literature does not significantly change our results. Investment adjustment cost parameter $S^{\prime \prime}(1)$ is set to 0.75 , consistent with the estimates of price elasticity of investment (in the range of $1.22-1.36$ ) in Eberly (1997) as well as Christiano and Fisher (1998).

As discussed above, we introduce curvature in $R \& D$ investment in order to replicate the curvature in the estimated impulse responses. Brown, Fazzari and Petersen (2009) estimate an Euler equation model for $R \& D$ investment at the firm level using Compustat data and find a baseline estimate for $\frac{\varkappa}{2}=0.384$. Consequently, we set $\varkappa=0.768 .^{\dagger}$

\section{Policy Rule parameters and Exogenous shocks}

We set the feedback coefficient on inflation and (normalized) output at 1.50 and 0.125 respectively (Taylor, 1993). Steady state government spending share $\left(1-\frac{1}{\lambda_{g}}\right)$ is set to 0.20 . We discuss the persistence of shocks in the next exercises.

\section{G.2.3 Quantitative Assessment}

\section{Impulse Response Functions}

We shock the economy with a monetary policy shock that generates a 100 basis point (annualized) increase in nominal interest rate on impact. This is the same shock we used in the estimation in section G.1, so that the results are comparable. We choose the persistence of monetary policy shock equal to 0.9 , a commonly used estimate in the literature. We report the model IRFs in percent deviations from steady state at time 0. Figure 11 plots the IRFs for two calibrations of the model against the estimated IRFs for R\&D investment, average firm entry, and utilization-adjusted as well as raw TFP. ${ }^{\dagger}$ While we do not explicitly model firm entry, we interpret probability of innovation $z_{t}$ as the average firm entry in the following period consistent with the creative destruction aspect of our framework. The monetary policy shocks induce a negative transitory response for R\&D investment, average firm entry and a permanent effect on TFP. Because of the presence of adjustment costs in $R \& D$ investment, $R \& D$ impulse response exhibits an U-shaped response, as seen in the estimated IRFs. R\&D investment and firm entry are important sources of TFP growth in the model. While firm entry and R\&D investment decline immediately, endogenous slow TFP growth results in a permanently lower level of TFP. Because of absence of technology adoption, TFP monotonically declines to a permanently lower level. As in the data, initial decline in raw TFP exceeds that of the adjusted TFP because of variability

${ }^{\dagger}$ They estimate the following equation for firm $j$, investing $\mathrm{R} \& \mathrm{D} r d_{j, t}$ at time $t$ :

$$
r d_{j, t}=\beta_{1} r d_{j, t-1}+\beta_{2} r d_{j, t-1}^{2}+\text { controls }+ \text { fixed effects }+ \text { error }_{j, t}
$$

We interpret $\beta_{2}$ to be our model equivalent of $\frac{\varkappa}{2}$.

${ }^{\dagger}$ In the model, we define raw TFP as sum of two terms (1) deviations in capital utilization from steady state, and (2) deviations in log TFP (pure) from its deterministic trend at time 0. 
in factor utilizations. Overall, the model replicates the estimated dynamic impacts.

Figure 11: Response of Firm Entry, Aggregate R\&D and Firm-level R\&D to 100 bps increase in Federal Funds Rate
1969Q1 - 2004Q4
1969Q1 - 2004Q4
$\log$ adjusted TFP
$\log$ TFP

Romer and Romer Surprises

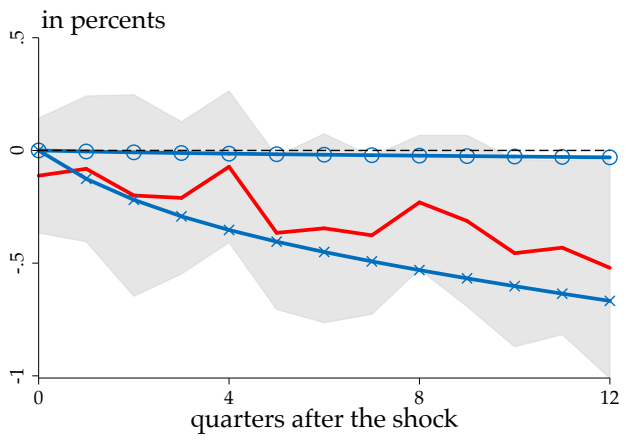

1990Q1- 2004Q4

Firm-level R\&D

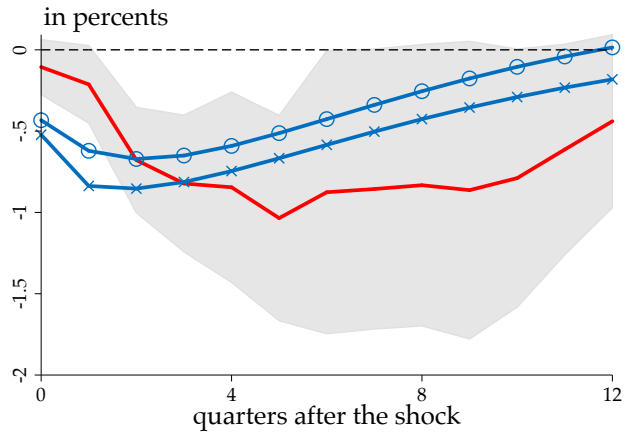

1993Q1 - 2004Q4

Gürkaynak, Sack and Swanson Surprises
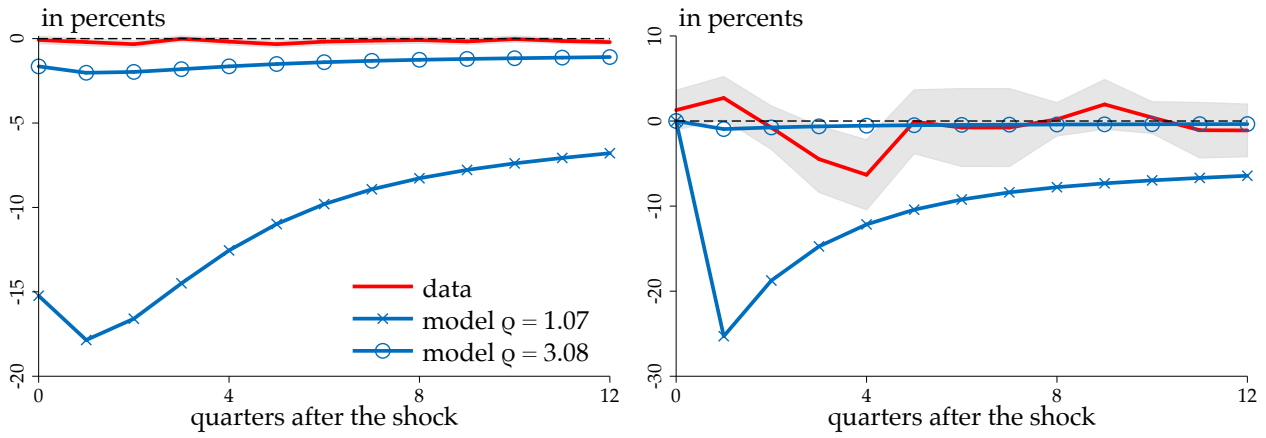

Notes: The figure compares model-implied IRFs to the estimated impulse response functions for utiltization adjusted TFP, raw TFP, firm-level R\&D and net establishment births. Time is in quarters. Sample length, and instrument used are denoted at the top of each row. IRFs are computed using a local-projections IV approach. Current and two past-lagged values of log real GDP and inflation rate are used as conditioning variables. Regressions also include past values of the proxy, the federal funds rate, and the dependent variable. Kleibergen-Paap F statistic for weak instruments are reported in the figures. The standard errors are calculated using HAR-Newey-West standard errors. The shaded areas denote $95 \%$ confidence intervals. Firm -level R\&D regressions also include two lags of assets, short debt, cash, employment, and firm-fixed effects. The standard errors are robust clustered at the firm-level. The model impulse responses are extracted from two calibrations with $\varrho=1.07$ and $\varrho=3.08$. In the mode, IRFs are traced following a one-time exogenous shock in the federal funds rate of $100 \mathrm{bps}$ (annualized).

Importantly, the impulse response comparisons highlight a tradeoff in calibrating a value for $\varrho$. Lower $\varrho$ implies higher sensitivity of R\&D investment and hence a significant innovation gap emerges. The model, however, is unable to match the empirical response of R\&D. Even for the extreme value of $\varrho=3.08$, the model predicts a larger fall in R\&D investment relative to that observed in the data. On the other hand, the model with low $\varrho$ closely replicates the empirical impulse responses for TFP. Given the low responsiveness of R\&D investment in the data, the model tends to fit the data under a firm entry interpretation. To the extent firm entry and other forms of investment are significant drivers of TFP growth, there is little reason to treat R\&D expenditure in the model solely as the R\&D expenditure incurred by publicly-traded firms. 
Another takeaway we emphasize is that there is lack of a clear disciplining device for calibrating the value for $\varrho$ without making an assumption on the drivers of TFP growth. As a result, we will show results for both parameter calibrations. $^{\dagger}$

\section{Simulating the Great Recession}

We now simulate the model with a liquidity demand shock to study its ability to explain the Great Recession episode. In the model, the liquidity demand shock is characterized by the rise in premium for holding Treasuries - referred to as the convenience yield (Krishnamurthy and Vissing-Jorgensen, 2012). The size of the liquidity demand shock is calibrated to generate a rise in the liquidity premium of 180 basis points. This is the preferred parameter choice of Del Negro, Eggertsson, Ferrero and Kiyotaki (2017), who estimate the convenience yield using financial market data. ${ }^{\dagger}$ We chose the persistence of the shock to equal 0.938 and 0.95 in two calibrations of $\varrho$. These are chosen in order to generate a ZLB episode with expected duration of six quarters. This expected duration lies within the range of estimates found in financial market surveys during 2009-2010.

Figure 12 plots the evolution of output, inflation and nominal interest rate to the calibrated liquidity demand shock and compares it with the data, for sixteen quarters starting in 2008Q3. Column 1 shows the changes in the data relative to 2008Q3 (Lehman Brother's bankruptcy). We report percentage change in output from a linear trend estimated from 2000Q1 to 2007Q4, normalized to zero in 2008Q3. Output is constructed as the log sum of consumption, and investment from the NIPA tables. For inflation, we report the deviation of the annualized percentage change in the GDP deflator from $1.6 \%$ annual inflation rate. We chose this number to get the model to match annualized nominal interest rate of $4 \%$. The nominal interest rate is the effective federal funds rate.

Given a relatively modest shock, the model can explain a significant component of the decline in output $(-2.6 \%$ in the model versus $-8.6 \%$ in the data). Furthermore, it implies a reduction in inflation of 0.9 percentage points following the shock, compared to an initial drop of $1 \%$ in the data. The nominal interest rate hits the zero lower bound, stays at zero for six quarters and sluggishly recovers back. We emphasize the close fit in the dynamics of the model with the data. The model implies no recovery to the 2000Q12007Q4 trend, as has been observed in the data. Calibrations of $\varrho=1.07$ and 3.08 imply a $1.25 \%$ and $0.08 \%$ permanently lower output respectively, relative to pre-recession trend. In figure 12 , we compare the evolution of consumption, investment and R\&D investment with the data. The model replicates the broad empirical pattern of generating more decline in investment relative to consumption. Moreover, it generates

${ }^{\dagger}$ The range of values for $\varrho$ considered is consistent with wide range of estimates found in aggregate and firm level studies (see Hall, Mairesse and Mohnen 2010). One of the commonly cited estimates come from Griliches (1990), who surveys the literature estimating relationship between $R \& D$ and patents (as an indicator of innovation output). Results differ on the estimation strategy: cross-sectional estimates of $\varrho$ lie in range of $1-1.67$, while within-firm time-series estimates are in the range of 1.5-3.3. Kortum (1993) reports estimates in the range of $(1.3,10)$. More recently, Bloom et al. (2017) emphasize that research effort has gone up, with declining research productivity suggesting an increasing $\varrho$ over time.

${ }^{\dagger}$ The results are qualitatively similar, but larger in magnitude, when we calibrated the shock to match rise in spread between AAA and 20 year Treasuries, or the spread between most recently used and older 10 year Treasury bonds of same maturity, called the on-the-run/ off-the-run spread. 
Figure 12: Response of Output, Inflation, and the Nominal Interest Rate to the Liquidity Shock
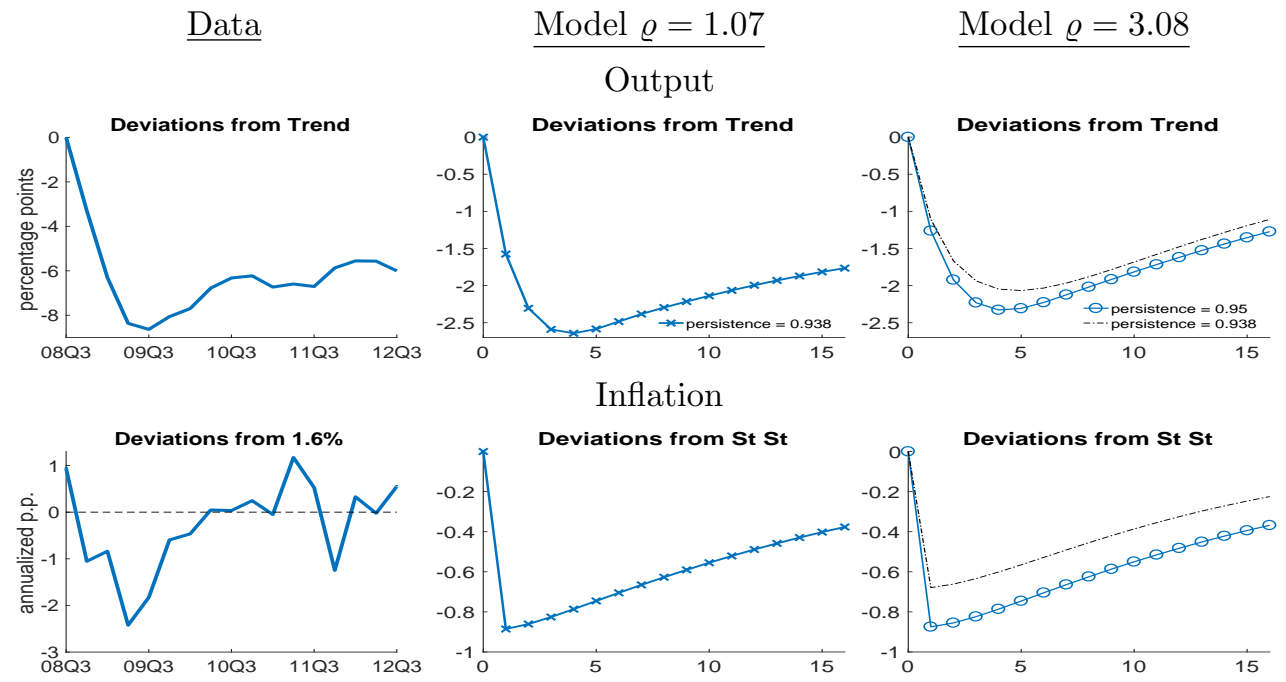

Federal Funds Rate
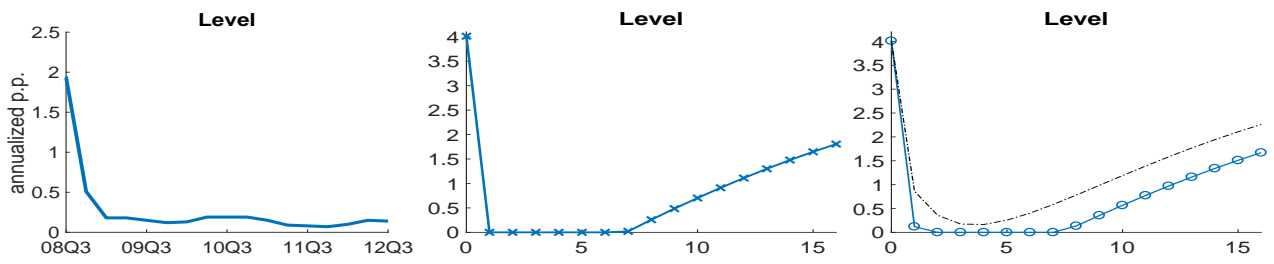

Notes: The figure compares the evolution of output, inflation, and the nominal interest rate in the data (left column) and in the two variants of the model in response to the calibrated liquidity shock (right columns). The data start in 2008Q3. Both data and model are plotted for 16 quarters. Output in the data (top-left) is the sum of consumption and investment, in percentage log-deviations from a linear trend estimated from 2000Q1 to 2007Q4, and is normalized to zero in 2008Q3. Inflation in the data (middle-left) is the annualized quarterly inflation rate of the GDP deflator minus $1.6 \%$. Value of $1.6 \%$ is chosen for the model to hit a steady state nominal interest rate of $4 \%$. The interest rate in the data (bottom-left) is the annualized effective Federal Funds Rate. Output in the model (top-right) is the log-deviation from steady state in percentage points. Inflation in the model (middle-right) is expressed in annualized percentage points. The interest rate in the model (bottom-right) is the annualized level of the nominal interest rate in percentage points (the horizontal line is its steady state value).

a persistent decline in consumption relative to investment. The model with low $\varrho$ (line with crosses) implies a more sluggish recovery in consumption relative to high $\varrho$ (line with circles). Because of higher sensitivity of R\&D investment, low $\varrho$ generates a counterfactually large response of R\&D investment. In the data, R\&D investment declined by $6 \%$, while low $\varrho$ implies a decline of $16 \%$. In contrast, the model with high $\varrho$ generates a $1.8 \%$ decline in $\mathrm{R} \& \mathrm{D}$ investment. ${ }^{\dagger}$

\section{Hysteresis targeting during the Great Recession}

How does a hysteresis targeting rule perform in a quantitative model? We assume that the central bank sets interest rate using the following hysteresis-augmented interest rate rule, with $\phi_{h}=0.5$ :

$$
\hat{i}_{t}=\max \left(-\frac{\bar{i}}{1+\bar{i}}, \phi_{\pi} \hat{\pi}_{t}^{w}+\phi_{y}\left(\hat{L}_{t}-\hat{L}_{t}^{f}\right)+\phi_{h} h_{t+1}+\hat{\varepsilon}_{t}^{i}\right)
$$

${ }^{\dagger}$ Note that persistence of the simulated shock is calibrated such that the expected duration of ZLB is six quarters. Consequently, the recession is less severe. In the Appendix I.10, we show that a more persistent shock where the ZLB is expected to bind for twelve quarters performs better at replicating the drop in output, inflation, consumption and investment in the data. Moreover, the drop in consumption is more persistent and less severe than output and investment. Because of pro-cyclicality of R\&D investment, a more severe recession, however, also implies a larger drop in R\&D. 
Figure 13: Response of Consumption, Investment, R\&D Investment, and Convenience Yield to the Liquidity Shock

Data

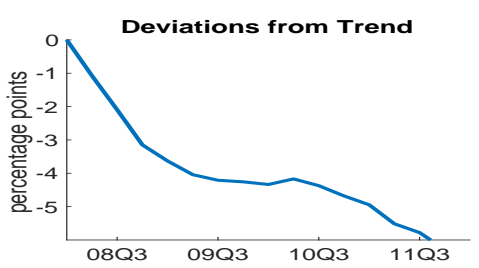

Consumption
Model

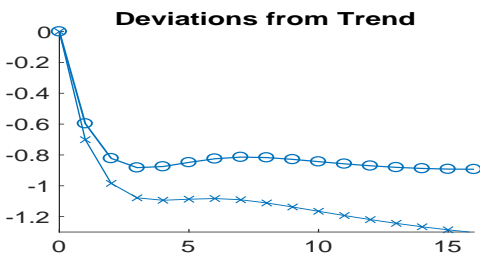

Convenience Yield
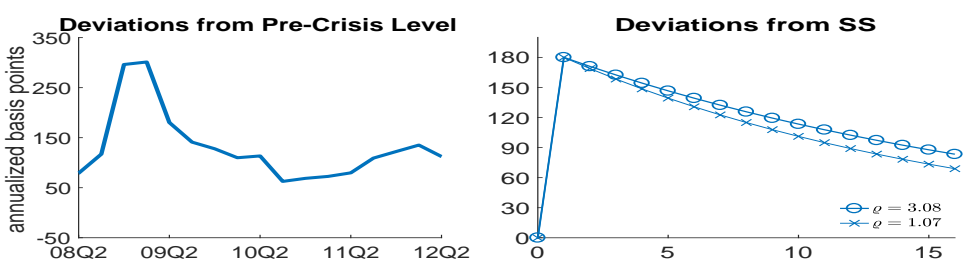

Data

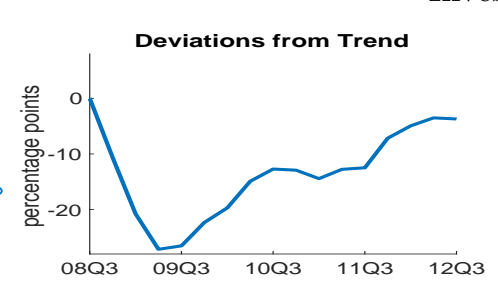

Model

Investment

Note: The figure compares the evolution of consumption, investment, R\&D investment, and convenience yield in the data (left column) and in the model in response to the calibrated liquidity shock (right column). The data start in 2008Q3. Both data and model are plotted for 16 quarters. Consumption in the data (top-left) is total consumption minus durable consumption. Investment in the data (top-middle-left) is investment plus durable consumption minus Intellectual Property Investment. R\&D Investment in the data (bottom-middle-left) is the Intellectual Property Investment. These three variables are expressed in percentage log-deviations from a linear trend estimated from 2000Q1 to 2007Q4, and are normalized to zero in 2008Q3. The convenience yield in the data (bottom-left) is in annualized basis points (produced by (Del Negro et al., 2017)). Consumption (top-right), investment (top-middle-right), and R\&D investment (bottom-middle-right) in the model are log-deviations from steady state in percentage points. The convenience yield in the model (bottom-right) is the annualized absolute deviation from steady state expressed in basis points.

where superscript $f$ denotes the flexible-price-wage allocation, hysteresis $h_{t+1}=h_{t}+\hat{g}_{t+1}^{f}$, where $g_{t+1}$ is determined by R\&D investments in period $t$.

Figure 14: Hysteresis Targeting: Response of Output, Inflation, and the Nominal Interest Rate to the Liquidity Shock
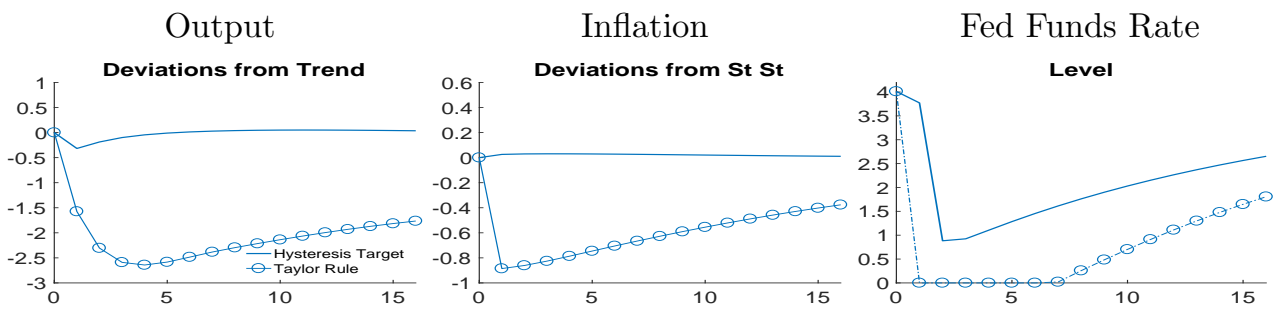

Notes: The figure compares the evolution of output, inflation, and the nominal interest rate under Hysteresis targeting rule and assumed Taylor rule in the model with $\varrho=1.07$ in response to the calibrated liquidity shock. All graphs are plotted for 16 quarters. Output in the model (top-right) is the log-deviation from steady state in percentage points. Inflation in the model (middle-right) is expressed in annualized percentage points, deviation from steady state value of $1.6 \%$. The interest rate in the model (bottom-right) is the annualized level of the nominal interest rate in percentage points (the horizontal line is its steady state value). Hysteresis targeting rule is implemented by adding an additional term called the hysteresis with a coefficient of 0.5. Hysteresis is defined as sum of all endogenous growth rate deviations induced by history of shocks at time t.

Figure 14 compares the evolution of output, inflation and interest rate under the above interest rate rule with $\phi_{h}=0.5$ (Hysteresis targeting) to rule with $\phi_{h}=0$ (Standard Taylor rule). We only plot the figures for the case of $\varrho=1.07$. The results are similar in the case of $\varrho=3.08$, although the permanent output shortfall is significantly smaller in that setting. Output falls by only $0.3 \%$ under hysteresis targeting compared to the $2.6 \%$ drop under Taylor rule. Inflation and federal funds rate are positive (in contrast to Taylor rule). An explicit commitment to targeting permanent output shortfalls creates inflationary expectations, which 
lowers the natural interest rate. Higher expected inflation provides more room for the central bank to offset declines in natural interest rates, as the central bank in this exercise has the power to reduce the impact of the shock by lowering the nominal interest rate. This example illustrates that the hysteresis bias embedded in a standard Taylor rule has quantitatively significant implications for the permanent level of output.

\section{H Data Appendix}

\section{H.1 Sources}

- Real GDP, GDP deflator, unemployment rate, RED Investment (1969 - present): St. Louis FRED database

- TFP (Quarterly, 1969 - present): Fernald (2014). We constructed the annualized TFP growth rates into a $\log$ TFP series.

- Number of new business incorporations (Monthly, 1969 - 1994): Survey of Current Business January/February 1996 supplement titled "Sources for Business Cycle Indicators" (discontinued) from the BEA website

- Quarterly net establishment births (Quarterly, 1993Q1 - present): National Private Sector Business Employment Dynamics Data, BLS

- RED Compustat (Monthly, 1969 - 2010): Quarterly and Annual COMPUSTAT database from WRDS, (Quarterly, 1990Q1 - present)

- Romer Romer shocks: Romer and Romer (2004), Wieland \& Yang (2016)

- High frequency shocks (Monthly, 1990 - 2010): Gorodnichenko \& Weber (2016) and Gurkayanak, Sack \& Swanson (2006).

\section{H.2 Firm level R\&D data construction}

We downloaded COMPUSTAT data from the US Fundamentals Quarterly file available through Wharton Research Data Services (WRDS). Annual employment data came from the US Fundamentals Annual file. We follow Terry (2017) and make the following sample restrictions:

- Nonmissing total assets atq, SIC code sic, book value of capital ppentq, GAAP earnings ibq, operating earnings before depreciation EBITDA oibdpq, total sales saleq, value of equity ceqq

- Positive levels of assets and book value of capital: atq, ppentq $>0$

- No utilities or financial firms as classified by SIC code: sic not in 6000's or 4900's 
In the baseline regression at horizon 0, the sample included 4271 unique gvkey and 90385 firm-quarter observations between 1992Q1 and 2004Q4. Nominal variables were deflated using the GDP deflator. R\&D investment is defined as the difference between $\log \mathrm{R} \& \mathrm{D}$ stock in two consecutive periods. Following Brown, Fazzari \& Petersen (2009), and Kabuckuoglu (2014), we construct R\&D stock using perpetual inventory method as follows:

$$
\mathrm{RD}_{i, t}^{\text {stock }}=\left(1-\delta^{R}\right) \mathrm{RD}_{i, t-1}^{\text {stock }}+\mathrm{XRDQ}_{i, t}
$$

where $\mathrm{XRDQ}_{i, t}$ represents the real $\mathrm{R} \& \mathrm{D}$ expenditures of firm $i$ at time $t ; \delta^{R}$ is the depreciation rate. We assume $\delta^{R}=15 \%$ (annualized), standard practice in the innovation literature.. Initial period R\&D stock is assumed to be $\frac{\mathrm{XRDQ}_{i, 0}}{\delta}$, where $\mathrm{XRDQ}_{i, 0}$ is the first observation of $\mathrm{R} \& \mathrm{D}$ expenditures for firm $i$. We define R\&D investment as:

$$
\Delta \mathrm{R} \& \mathrm{D}_{i, t}=\log \mathrm{RD}_{i, t+1}^{\text {stock }}-\log \mathrm{RD}_{i, t}^{\text {stock }}
$$

\section{H.3 Real GDP and Price level}

Figure 15: Response of Output, and Price level to 100 bps increase in Federal Funds Rate

$$
\text { 1969Q1 - 1999Q4 1990Q1 - 2004Q4 }
$$

log Real GDP per capita Implicit GDP Deflator log Real GDP per capita Implicit GDP Deflator

Romer and Romer Surprises

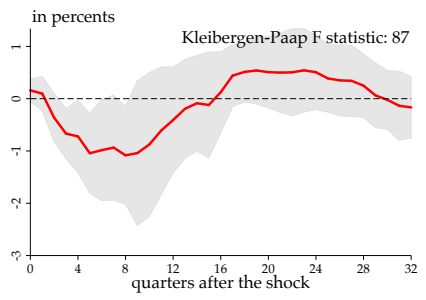

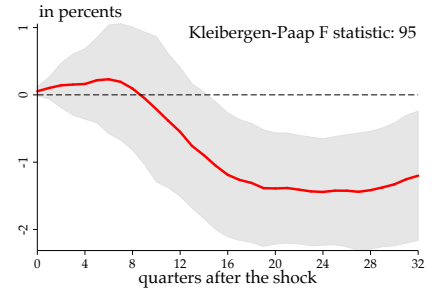

Gürkaynak, Sack and Swanson Surprises

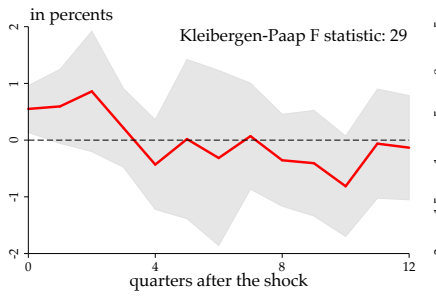

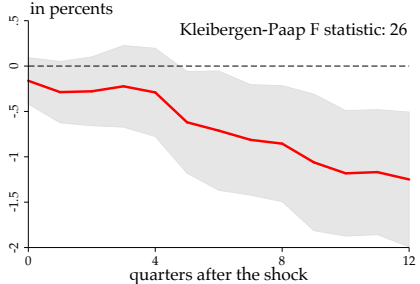

Notes: The figure plots the estimated impulse response functions for log real GDP and implicit GDP deflator. Time is in quarters. Sample length, and instrument used are denoted at the top of each row. IRFs are computed using a local-projections IV approach. Current and two past-lagged values of log real GDP and inflation rate are used as conditioning variables. Regressions also include past values of the proxy, the federal funds rate, and the dependent variable. Kleibergen-Paap F statistic for weak instruments are reported in the figures. The standard errors are calculated using HAR-Newey-West standard errors. The shaded areas denote $95 \%$ confidence intervals.

\section{H.4 Robustness: Sample endpoints, lags, and instruments}

In the IRFs reported in the main text of the paper, we cut the sample end point at 2004Q4 in order to trace out the IRF until 2008Q4. In Figure 16, we show robustness of our results to sample size adjustments, different instruments, and changing the number of lags for controls. The graphs are plotted for utilization adjusted TFP, and aggregate R\&D . For comparison, we also plot unadjusted TFP measure from Fernald. The IRFs for TFP and adjusted TFP plotted using the RR instrument are consistent with the results in the paper for different sample lengths as well as lags. The robust takeaway is that the the utilization adjusted TFP is found to exhibit a persistent response to a temporary contractionary monetary policy shocks 
identified by narrataive instruments. The results reported in the main text are robust to choosing reasonable sample start-date, end-date and number of lags of conditioning variables. But, those results are sensitive to the choice of instrument. These inconsistencies are under investigation and are part of active literature as surveyed by Ramey(2016).

Figure 16: LPIV: Robustness to sample endpoints, \# of lags

TFP UTIL TFP 1969Q1-1996Q4. 4 lags. RR

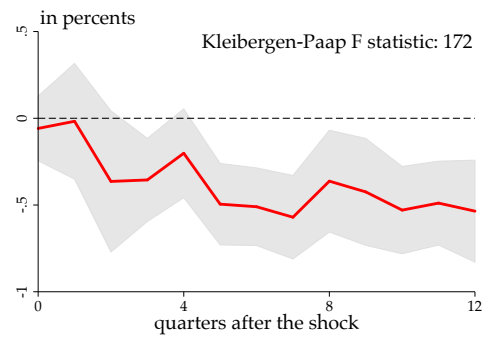

TFP UTIL

1994Q1-2004Q4, 2 lags, GSS

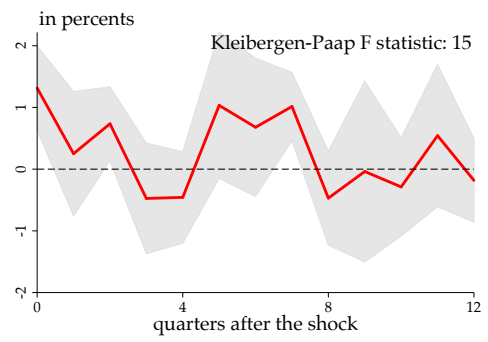

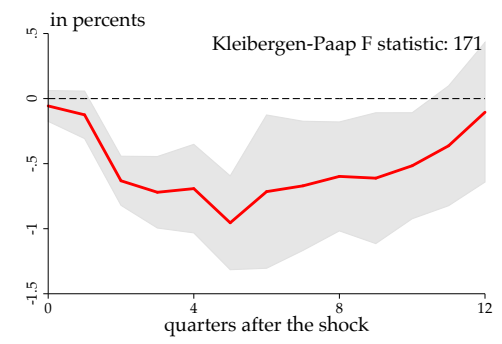

TFP UTIL

1994Q1-2007Q4, 2 lags, GSS

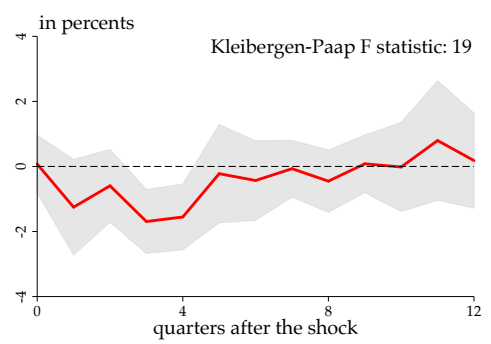

TFP UTIL

TFP

1969Q1-2004Q4. 8 lags. RR

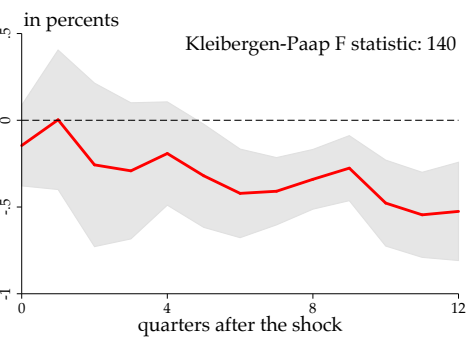

TFP UTIL

1990Q1-2004Q4, 2 lags, GSS

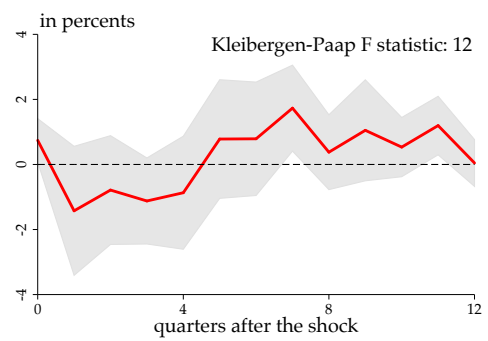

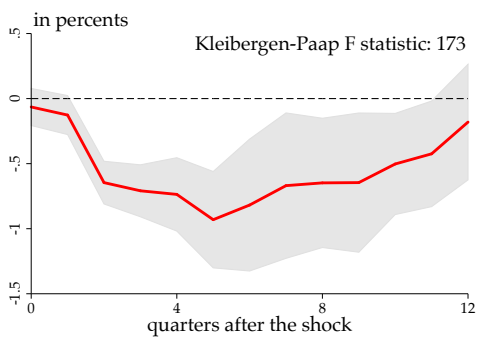

TFP UTIL

1990Q1-2007Q4, 2 lags, GSS

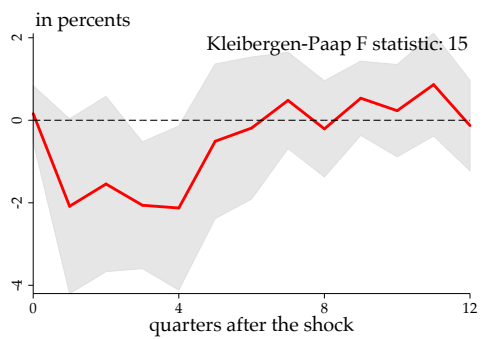

Note: The figure plots the structural impulse responses for TFP (utilization adjusted), and TFP (unadjusted). Time is in quarters. IRFs are computed using a local-projections instrumental variables approach. A policy indicator, federal funds rate, is instrumented with either narrative shocks identified by Romer \& Romer (RR) or high frequency surprises (GSS). Conditioning variables used are current and $p$ lagged values of : log real GDP, and GDP Price deflator index. Sample length, number of lags $p$, and the instrument type (RR or GSS) are indicated in titles above the graphs. 


\section{Derivation and details for the medium scale DSGE model}

We follow Howitt and Aghion (1998) and Aghion and Howitt (2008) in introducing capital in the endogenous growth framework. We however extend our model to allow for investment adjustment costs in sync with the New Keynesian literature following (Christiano, Eichenbaum and Evans, 2005), Smets and Wouters (2007) and Justiniano, Primiceri and Tambalotti (2013). The new ingredients are (i) a monopolistically competitive retail sector that sets prices in a staggered fashion, (ii) endogenous capital accumulation by households subject to investment adjustment costs, (iii) habit formation in consumption, (iv) variable capital utilization rate, and (v) partial indexation of prices and wages to the respective lagged inflation rates. We discuss these in turn:

\section{I.1 Monopolistically Competitive Retailers}

There is a continuum of monopolistically competitive retailers that sell the final good $Y_{t}(k)$. These goods can be aggregated into a Dixit-Stiglitz composite $Y_{t}$ as follows:

$$
Y_{t}=\left[\int_{0}^{1} Y_{t}(k)^{\frac{1}{1+\lambda_{p, t}}} d k\right]^{1+\lambda_{p, t}}
$$

where $\lambda_{p, t}>0$ is the (time-varying) price markup. We assume that $\lambda_{p, t}$ follows the exogenous ARMA process:

$$
\log \lambda_{p, t}=\left(1-\rho_{p}\right) \log \lambda_{p}+\rho_{p} \log \lambda_{p, t-1}+\epsilon_{t}^{p}-\mu_{p} \epsilon_{t-1}^{p} ; \quad \epsilon_{t}^{p} \sim N\left(0, \sigma_{p}\right)
$$

Each retailer $k$ purchases one unit of intermediate good composite $Y_{t}(k, m)$ at a given price of $P_{t}^{M}$ to package it into one unit of final good and is assumed to set prices on a staggered basis following Calvo (1983). With probability $\left(1-\theta_{p}\right)$, a retailer gets to reset its price. It solves the following problem:

$$
\max _{P_{t}(k)} \mathbb{E}_{t} \sum_{s=0}^{\infty}\left(\beta \theta_{p}\right)^{s} Q_{t, t+s}\left[P_{t}(k) \Pi_{t, t+s}-P_{t+s}^{M}\right] Y_{t+s}(k)
$$

subject to demand for its product

$$
Y_{t+s}(k)=\left(\frac{P_{t}(k) \Pi_{t, t+s}}{P_{t+s}}\right)^{-\frac{1+\lambda_{p, t+s}}{\lambda_{p, t+s}}}
$$

where the stochastic discount factor period $t+s$ is given by:

$$
Q_{t, t+s}=\beta \frac{\Lambda_{t+s}}{\Lambda_{t}} \frac{P_{t}}{P_{t+s}}
$$

where $\Lambda_{t}$ is the marginal utility of consumption defined later and

$$
\Pi_{t, t+s} \equiv \prod_{b=1}^{s}\left(\pi_{s s}^{1-\iota_{p}} \pi_{t+b-1}^{\iota p}\right)
$$

is the automatic adjustment that firms make to their price when they do not get to reset them, $\iota_{p} \in(0,1)$ is the indexation coefficient and $\pi_{s s}$ is the steady state price inflation rate. Let $\tilde{P}_{t}$ be the reset price at time $t$. The first order condition is :

$$
\mathbb{E}_{t} \sum_{s=0}^{\infty}\left(\beta \theta_{p}\right)^{s} Q_{t, t+s}\left[\tilde{P}_{t} \Pi_{t, t+s}-\left(1+\lambda_{p, t+s}\right) P_{t+s}^{M}\right] Y_{t+s}(k)=0
$$

The law of motion of the aggregate price index $P_{t}$ is given by:

$$
P_{t}^{\frac{1}{\lambda_{p, t}}}=\left(1-\theta_{p}\right)\left(\tilde{P}_{t}\right)^{\frac{1}{\lambda_{p, t}}}+\theta_{p}\left(\pi_{t-1}^{\iota p} \pi_{s s}^{1-\iota p} P_{t-1}\right)^{\frac{1}{\lambda_{p, t}}}
$$

\section{I.2 Perfectly Competitive Composite Good Production}

Each of the intermediate good composites is produced by a perfectly competitive firm that uses a CES composite of labor and secondary intermediate goods. ${ }^{\dagger}$ As a result, all intermediate good firms are identical and we omit the subscripts $(k, m)$ and simply denote the intermediate output at $Y_{t}^{m}$.

$$
Y_{t}^{m}=M_{t} L_{t}^{1-\alpha} \int_{0}^{1} A_{i t} x_{i t}^{\alpha} d i
$$

where each $x_{i t}$ is the flow of intermediate product $i$ used at time $t$, and the productivity parameter $A_{i t}$ reflects the quality of that product and $M_{t}$ is the aggregate (stationary) productivity shock which follows the process:

$$
\log M_{t}=\left(1-\rho_{m}\right) \log M_{t}+\rho_{m} \log M_{t-1}+\epsilon_{t}^{m} ; \quad \epsilon_{t}^{m} \sim N\left(0, \sigma_{m}\right)
$$

\footnotetext{
${ }^{\dagger}$ Such a convoluted market structure is assumed to introduce price -rigidity in a staggered fashion. Basically, there is a single consumption good that is produced by a perfectly competitive firm, but is retailed by monopolistically competitive retailers in different packaging.
} 
The composite good producer's maximization problem is is as follows

$$
\max _{L_{t},\left\{x_{i t}\right\}_{i \in[0,1]}}\left\{P_{t}^{m} M_{t} L_{t}^{1-\alpha} \int_{0}^{1} A_{i t} x_{i t}^{\alpha} d i-W_{t} L_{t}-\int_{0}^{1} p_{i t} x_{i t} d i\right\}
$$

Solving this gives the (inverse) factor demands:

$$
\begin{aligned}
& p_{i t}=\alpha P_{t}^{m} M_{t} L_{t}^{1-\alpha} A_{i t} x_{i t}^{\alpha-1} \\
& W_{t}=(1-\alpha) P_{t}^{m} \frac{Y_{t}^{m}}{L_{t}}
\end{aligned}
$$

\section{I.3 Monopolist Intermediate Good Producer}

Intermediate good producers are monopolists and use capital to produce one unit of intermediate good. Following Howitt and Aghion (1998), we assume the following production function for the intermediate good:

$$
x_{i t}=\frac{K_{i t}}{A_{i t}}
$$

The intermediate monopolistic firm sets prices flexibly every period in order to maximize profits:.

$$
\max _{p_{i t}}\left(1-\tau_{t}^{p}\right) p_{i t} x_{i t}-R_{t}^{K} K_{i t}
$$

subject to the demand for the intermediate good (eq I.1). $\tau_{t}^{p}$ is the sales tax/subsidy imposed on the monopolist's price. Further, we assume that there is a competitive fringe in every sector that faces a marginal cost of $\gamma^{1-\alpha} A_{i t} R_{t}^{K}$, where $\gamma$ is the step-size of innovation, discussed in following subsection. As a result, the intermediate monopolist cannot charge a price higher than $p_{i t}=\chi A_{i t} R_{t}^{K}$. In equilibrium, the monopolist charges a price given by:

$$
p_{i t}=\zeta A_{i t} R_{t}^{K} \equiv \min \left(\gamma^{1-\alpha}, \frac{1}{\left(1-\tau^{p}\right) \alpha}\right) A_{i t} R_{t}^{K}
$$

This yields

$$
x_{i t}=\frac{K_{t}}{A_{t}}=\left(\frac{\frac{\alpha}{\zeta} P_{t}^{m} M_{t} L_{t}^{1-\alpha}}{R_{t}^{K}}\right)^{\frac{1}{1-\alpha}}, \quad R_{t}^{K}=\frac{\alpha}{\zeta} \frac{P_{t}^{m} Y_{t}^{m}}{K_{t}}
$$

and profits are given by $\Gamma_{t}\left(A_{i t}\right)=(\zeta-1) \frac{\alpha}{\zeta} \frac{P_{t}^{m} Y_{t}^{m} A_{i t}}{A_{t}}$. Define aggregate productivity $A_{t} \equiv \int_{0}^{1} A_{i t} d i$. Substituting for the intermediate goods' production levels, we can rewrite the production function purely in the form of aggregates:

$$
Y_{t}^{m}=M_{t}\left(A_{t} L_{t}\right)^{1-\alpha} K_{t}^{\alpha}
$$

Define $k_{t}=\frac{K_{t}}{A_{t}}$ and $y_{t}^{m}=\frac{Y_{t}^{m}}{A_{t}}=M_{t} k_{t}^{\alpha} l_{t}^{1-\alpha}$.

\section{I.4 Innovation and research arbitrage}

There is a single entrepreneur in each sector who spends final output in research. The entrepreneur at time $t$ decides her research inputs and if successful, she gets to be the intermediate monopolist in the following period producing goods with productivity $A_{i t+1}=\gamma A_{i t}$. She is successful with probability $\Omega_{t} z_{i t}$, where $\Omega_{t}$ is the exogenous shock to innovation success and and is assumed to follow the following process:

$$
\log \Omega_{t}=\rho_{\Omega} \log \Omega_{t-1}+\epsilon_{t}^{\Omega} ; \quad \epsilon_{t}^{\Omega} \sim N\left(0, \sigma_{\Omega}\right)
$$

$z_{i t}$ is the innovation intensity chosen by the entrepreneur. In order to achieve this, she needs to spend the amount of final good ${ }^{\dagger}$

$$
R_{i t}=c\left(z_{i t}\right) A_{i t}+S^{r}\left(\frac{R_{t}}{\left(1+g_{s s}\right) R_{t-1}}\right) A_{t}
$$

in research, where $c\left(z_{t}\right) \equiv \delta z_{t}^{\varrho} ; \varrho>1 . S^{r}(\cdot)$ denote adjustment costs in R\&D that the entrepreneur takes as given. We assume $S^{r}(1)=0$ and $\frac{\partial S^{r}}{\partial R}(1)>0$. These adjustment costs generate a hump shape response for R\&D expenditure. These costs are similar to those considered by Aghion et al. (2010) since these enter additively and do not affect the first-order condition for entrepreneur. Entrepreneur maximizes the net expected profits from investing in research :

$$
\max _{z_{i t} \in[0,1]}\left\{\Omega_{t} z_{i t} Q_{t, t+1} V_{t+1}\left(\gamma A_{i t}\right)-\left(1-\tau_{t}^{r}\right) P_{t} R_{i t}\right\}
$$

where the lifetime discounted profits are given by the value function:

$$
V_{t}\left(A_{i t}\right)=\Gamma_{t}\left(A_{i t}\right)+\left(1-\Omega_{t} z_{i t}\right) \mathbb{E}_{t} Q_{t, t+1} V_{t+1}\left(A_{i t}\right)
$$

Because of the linearity of production function, as we showed above in the Appendix A, the Value function is also linear in productivity. Writing the normalized Value function as $\tilde{V}_{i t} \equiv \frac{V_{i t}}{P_{t} A_{i t}}$ and focusing on the symmetric equilibrium, we solve for

${ }^{\dagger}$ This could further be generalized to allow for adoption probability for this entrepreneur's technology in the next period, which would better match the data. Secondly, we can also add a financial frictions constraint to get more action. 
interior solution (where $z_{t}>0$ ):

$$
\varrho z_{t}^{\varrho-1}=\beta \frac{\Lambda_{t+1}}{\Lambda_{t}} \frac{\gamma \Omega_{t} \tilde{V}_{t+1}}{\left(1-\tau_{t}^{r}\right) \delta}
$$

Total amount of the final good used in research and innovation:

$$
R_{t}=\int_{0}^{1} R_{i t} d i=\left(c\left(z_{t}\right)+S^{r}\left(\frac{R_{t}}{\left(1+g_{s s}\right) R_{t-1}}\right)\right) A_{t}
$$

\section{I.5 Households \& Wage Setting}

\section{I.5.1 Households}

Each household supplies differentiated labor indexed by $j$. Household $j$ chooses consumption $C_{t}$, risk-free nominal bonds $B_{t}$, investment $I_{t}$ and capital utilization $u_{t}$ to maximize the utility function:

$$
\mathbb{E}_{t} \Sigma_{s=0}^{\infty} \beta^{j}\left[\log \left(C_{t+s}-h C_{t+s-1}\right)-\frac{\omega}{1+\nu} L_{t+s}(j)^{1+\nu}+\xi_{t} \frac{B_{t+1}}{P_{t}}\right]
$$

where $h$ is the degree of habit formation, $\nu>0$ is the inverse Frisch elasticity of labor supply, $\omega>0$ is a parameter that pins down the steady-state level of hours, the discount factor $\beta$ satisfies $0<\beta<1$ and $\xi_{t}$ is the liquidity demand shock. We assume that in the steady state $\xi=0$.We assume perfect consumption risk sharing across the households. As a result, household's budget constraint in period $t$ is given by

$$
P_{t} C_{t}+P_{t} I_{t}+B_{t+1}=B_{t}\left(1+i_{t}\right)+B_{t}^{S}(j)+\left(1+\tau^{w}\right) W_{t} L_{t}(j)+\Gamma_{t}+T_{t}+R_{t}^{K} u_{t} K_{t}^{u}-P_{t} a\left(u_{t}\right) K_{t}^{u}
$$

where $I_{t}$ is investment, $B_{t}^{S}(j)$ is the net cash-flow from household $j$ 's portfolio of state-contingent securities. Labor income $W_{t} L_{t}(j)$ is subsidized at a fixed rate $\tau_{w}$. Households own an equal share of all firms, and thus receive $\Gamma_{t}$ dividends from profits. Finally, each household receives a lump-sum government transfer $T_{t}$. Since households own the capital and choose the utilization rate, the amount of effective capital that the households rent to the firms at nominal rate $R_{t}^{K}$ is :

$$
K_{t}=u_{t} K_{t}^{u}
$$

The (nominal) cost of capital utilization is $P_{t} a\left(u_{t}\right)$ per unit of physical capital. As in the literature (SW 2007, JPT 2010) we assume $a(1)=0$ in the steady state and $a^{\prime \prime}>0$. Following CEE 2005, we assume investment adjustment costs in the production of capital. Law of motion for capital is as follows:

$$
K_{t+1}^{u}=v_{t}\left[1-S\left(\frac{I_{t}}{\left(1+g_{s s}\right) I_{t-1}}\right)\right] I_{t}+\left(1-\delta_{k}\right) K_{t}^{u}
$$

where $g_{s s}$ is the steady state growth rate of productivity, $\epsilon_{t}^{i}$ is a shock to the relative price of investment and In the steady state $S(1)=S^{\prime}(1)=0, S^{\prime \prime}>0$. JPT consider this as shock to marginal efficiency of investment (MEI) and is assumed to follow the following process:

$$
\log v_{t}=\rho_{v} \log v_{t-1}+\epsilon_{t}^{v} ; \quad \epsilon_{t}^{v} \sim N\left(0, \sigma_{v}\right)
$$

Utility maximization delivers the first order condition linking the inter-temporal consumption smoothing to the marginal utility of holding the risk-free bond

$$
1=\beta \mathbb{E}_{t}\left[\frac{\Lambda_{t+1}}{\Lambda_{t}}\left(1+i_{t}\right) \frac{P_{t}}{P_{t+1}}\right]+\Lambda_{t}^{-1} \xi_{t}
$$

The stochastic discount factor in period $t+1$ is given by:

$$
Q_{t, t+1}=\beta \frac{\Lambda_{t+1}}{\Lambda_{t}} \frac{P_{t}}{P_{t+1}}
$$

where $\Lambda_{t}$ is the marginal utility of consumption given by:

$$
\Lambda_{t}=\frac{1}{C_{t}-h C_{t-1}}-\frac{h \beta}{C_{t+1}-h C_{t}}
$$

The household does not choose hours directly. Rather each type of worker is represented by a wage union who sets wages on a staggered basis. Consequently the household supplies labor at the posted wages as demanded by firms.

We introduce capital accumulation through households. Solving household problem for investment and capital yields the Euler condition for capital:

$$
q_{t}=\beta \mathbb{E}_{t}\left[\frac{\Lambda_{t+1}}{\Lambda_{t}}\left(\frac{R_{t+1}^{K}}{P_{t+1}} u_{t+1}-a\left(u_{t+1}\right)+q_{t+1}\left(1-\delta_{k}\right)\right)\right]
$$

where the (relative) price of installed capital $q_{t}$ is given by

$q_{t} v_{t}\left[1-S\left(\frac{I_{t}}{\left(1+g_{s s}\right) I_{t-1}}\right)-S^{\prime}\left(\frac{I_{t}}{\left(1+g_{s s}\right) I_{t-1}}\right) \frac{I_{t}}{\left(1+g_{s s}\right) I_{t-1}}\right]+\beta \frac{\Lambda_{t+1}}{\Lambda_{t}} q_{t+1} v_{t+1} \frac{1}{\left(1+g_{s s}\right)}\left(\frac{I_{t+1}}{I_{t}}\right)^{2} S^{\prime}\left(\frac{I_{t+1}}{\left(1+g_{s s}\right) I_{t}}\right)=1$

Choice of capital utilization rate yields:

$$
\frac{R_{t}^{K}}{P_{t}}=a^{\prime}\left(u_{t}\right)
$$




\section{I.5.2 Wage Setting}

Wage Setting follows Erceg, Henderson and Levin (2000) and is relatively standard. Perfectly competitive labor agencies combine $j$ type labor services into a homogeneous labor composite $L_{t}$ according to a Dixit-Stiglitz aggregation:

$$
L_{t}=\left[\int_{0}^{1} L_{t}(j)^{\frac{1}{1+\lambda} w, t} d j\right]^{1+\lambda w, t}
$$

where $\lambda_{w, t}>0$ is the (time-varying) nominal wage markup. We assume that $\lambda_{w, t}$ follows the exogenous ARMA process:

$$
\log \lambda_{w, t}=\left(1-\rho_{w}\right) \log \lambda_{w}+\rho_{w} \log \lambda_{w, t-1}+\epsilon_{t}^{w}-\mu_{w} \epsilon_{t-1}^{w} ; \quad \epsilon_{t}^{w} \sim N\left(0, \sigma_{w}\right)
$$

Labor unions representing workers of type $j$ set wages on a staggered basis following Calvo (1983), taking given the demand for their specific labor input:

$$
L_{t}(j)=\left(\frac{W_{t}(j)}{W_{t}}\right)^{-\frac{1+\lambda w, t}{\lambda_{w, t}}} L_{t}, \quad \text { where } W_{t}=\left[\int_{0}^{1} W_{t}(j)^{\frac{-1}{\lambda_{w, t}}} d j\right]^{-\lambda_{w, t}}
$$

In particular, with probability $1-\theta$, the type- $j$ union is allowed to re-optimize its wage contract and it chooses $\tilde{W}$ to minimize the disutility of working for laborer of type $j$, taking into account the probability that it will not get to reset wage in the future. If a union is not allowed to optimize its wage rate, it adjusts wage at steady state wage inflation $\bar{\Pi}^{w}$ rate. Workers supply whatever labor is demanded at the posted wage. The first order condition for this problem is given by:

$$
\mathbb{E}_{t} \sum_{s=0}^{\infty}\left(\beta \theta_{w}\right)^{s} \Lambda_{t+s}\left[\left(1+\tau_{t}^{W}\right) \tilde{W} \Pi_{t, t+s}^{w}-\left(1+\lambda_{w, t}\right) \omega \frac{L_{t+s}^{\nu}(j)}{\Lambda_{t+s}}\right] L_{t+s}(j)=0
$$

where

$$
\Pi_{t, t+s}^{w} \equiv \prod_{b=1}^{s}\left(\pi_{s s}^{w}\right)
$$

By the law of large numbers, the probability of changing the wage corresponds to the fraction of types who actually change their wage. Consequently, the nominal wage evolves according to:

$$
W_{t}^{\frac{1}{\lambda_{w, t}}}=\left(1-\theta_{w}\right)\left(\tilde{W}_{t}\right)^{\frac{1}{\lambda w, t}}+\theta_{w}\left(\pi_{s s}^{w} W_{t-1}\right)^{\frac{1}{\lambda w, t}}
$$

where the nominal wage inflation and price inflation are related to each other :

$$
\pi_{t}^{w}=\frac{W_{t}}{W_{t-1}}=\frac{w_{t}}{w_{t-1}} \frac{1}{\pi_{t}} \frac{1}{1+g_{t}}
$$

where $\pi_{t} \equiv \frac{P_{t}}{P_{t-1}}$ is the inflation rate, $w_{t} \equiv \frac{W_{t}}{P_{t} A_{t}}$ is the productivity adjusted real wage and $g_{t}$ is the (endogenous) productivity growth rate.

\section{I.6 TFP and growth rate}

Aggregate (endogenous) productivity follows:

$$
A_{t}=\int_{0}^{1} A_{i t} d i=\int_{0}^{1}\left[\Omega_{t-1} z_{t-1} \gamma A_{i t-1}+\left(1-\Omega_{t-1} z_{t-1}\right) A_{i t-1}\right] d i=A_{t-1}+\Omega_{t-1} z_{t-1}(\gamma-1) A_{t-1}
$$

The growth rate of the productivity :

$$
g_{t}=\frac{A_{t}-A_{t-1}}{A_{t-1}}=\Omega_{t-1} z_{t-1}(\gamma-1)
$$

Measured TFP (total factor productivity) is given by product of stationary exogenous component and the non-stationary endogenous component :

$$
T F P_{t}=M_{t} \times A_{t}
$$

\section{I.7 Government}

The central bank follows a Taylor rule in setting the nominal interest rate. It responds to deviations in inflation, output and output growth rate from time-t natural allocations.

$$
\frac{1+i_{t}}{1+i_{s s}}=\left(\frac{\pi_{t}}{\pi_{s s}}\right)^{\phi_{\pi}}\left(\frac{Y_{t}}{Y_{t}^{f, t}}\right)^{\phi_{y}} \epsilon_{t}^{m p}
$$

where $i_{s s}$ is the steady state nominal interest rate, $Y_{t}^{f, t}$ is the time-t natural output, and $\epsilon_{t}^{m p} \sim N\left(0, \sigma_{r}\right)$ is an $\mathrm{AR}(1)$ monetary policy shock with persistence $\rho_{R}$.

We assume government balances budget every period:

$$
P_{t} T_{t}=\tau^{p} \int_{0}^{1} p_{i t} x_{i t} d i+\tau_{t}^{r} P_{t} R_{t}+\tau^{w} W_{t} L_{t}+P_{t} G_{t}
$$


where $G_{t}$ is the government spending, which is determined exogenously as as a fraction of GDP

$$
G_{t}=\left(1-\frac{1}{\lambda_{t}^{g}}\right) Y_{t}
$$

where the government spending shock follows the process:

$$
\log \lambda_{t}^{g}=\left(1-\rho_{g}\right) \lambda^{g}+\rho_{g} \log \lambda_{t-1}^{g}+\epsilon_{t}^{g} ; \quad \epsilon_{t}^{g} \sim N\left(0, \sigma_{g}\right)
$$

\section{I.8 Market Clearing}

$$
Y_{t}=C_{t}+I_{t}+R_{t}+a\left(u_{t}\right) K_{t}^{u}+G_{t}
$$

\section{I.9 Stationarizing the system}

We normalize the following variables:

$$
\begin{gathered}
y_{t}=Y_{t} / A_{t} \\
y_{t}^{m}=Y_{t}^{m} / A_{t} \\
c_{t}=C_{t} / A_{t} \\
k_{t}=K_{t} / A_{t} \\
k_{t}^{u}=K_{t}^{u} / A_{t-1} \\
\mathbb{I}_{t}=I_{t} / A_{t} \quad \text { capital investment } \\
\mathbb{R}_{t}=R_{t} / A_{t} \quad \text { R\&D investment } \\
\mathbb{G}_{t}=G_{t} / A_{t} \quad \text { Govt Spending } \\
w_{t}=W_{t} /\left(A_{t} P_{t}\right) \\
p_{t}^{m}=P_{t}^{m} / P_{t} \\
r_{t}^{k}=R_{t}^{k} / P_{t} \\
\lambda_{t}=\Lambda_{t} A_{t} \\
\xi_{t}^{\prime}=\xi_{t} A_{t} \\
\tilde{\Gamma}_{t} \equiv \frac{\Gamma_{t}}{P_{t} A_{t}}
\end{gathered}
$$

Further note that because of the linearity assumption in the production of final goods, the Value function is a linear function in productivity with which an entrepreneur enters the sector:

$$
\tilde{V}_{t} \equiv \frac{V_{t}\left(A_{i t}\right)}{P_{t} A_{i t}}=\tilde{\Gamma}_{t}+\left(1-z_{t}\right) \mathbb{E}_{t} \frac{\lambda_{t+1}}{\lambda_{t}} \tilde{V}_{t+1}
$$

where $\tilde{V}$ is normalized by the productivity with which the entrepreneur enters the sector.

\section{I.10 Matching the Great Recession: II}

In the main text, we choose a conservative persistence for the liquidity demand shock such that the ZLB is expected to bind for six quarters. Here, we choose a persistence such that the expected duration of the ZLB is 12 quarters, i.e 3 years. We show that the model is better able to match the empirical moments. Figure 17 plots the evolution of Output, Inflation and Federal funds Rate from 2008Q3 till 2012Q3. The first two columns on the left reproduce the results reported in Figure 12 for comparison. Column 3 (rightmost) reports results from the model with a more persistent liquidity demand shock. The shock is calibrated such that convenience yield rises by $180 \mathrm{bps}$ on impact. The nominal interest rate hits the ZLB under the Taylor rule and stays there for 12 quarters. Output drops by $7.30 \%$, and Inflation drops by $1.58 \%$. Contrast this with the data where output drops by $8.6 \%$ and Inflation drops by $2 \%$. Thus, the liquidity demand shock can explain $84 \%$ of the drop in output and $79 \%$ of the observed drop in inflation. Figure 18 plots consumption, and investment under a more persistent shock. In the data, consumption and capital investment drop by $4.34 \%$ and $27 \%$ respectively. In the model with more persistent liquidity demand shock, the drop in consumption and capital investment are $2.88 \%$ and $18.40 \%$ respectively. Thus, the liquidity demand shock can explain $66 \%$ of the observed drop in consumption and $68 \%$ of the observed drop in investment. Importantly, the model produces a faster recovery in investment as observed in the data, while consumption recovers sluggishly. As noted in the main text, the model generates counterfactually high responsiveness of R\&D investment. This persistent liquidity demand shock reduces long-run output by $2.50 \%$, through a slowdown in endogenous productivity growth. 
Figure 17: Response of Output, Inflation, and the Nominal Interest Rate to the Liquidity Shock

Data
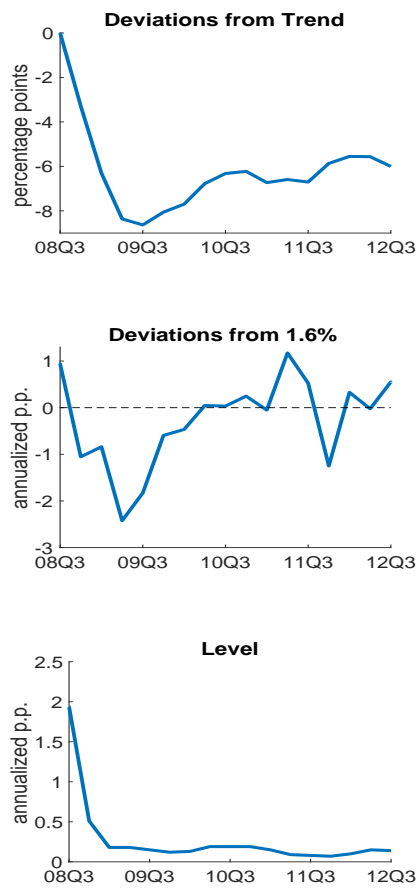

Model with persis $=0.938$

Model with persis $=0.955$

Output

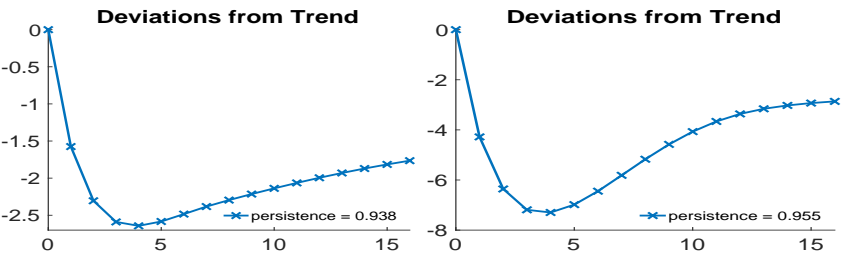

Inflation
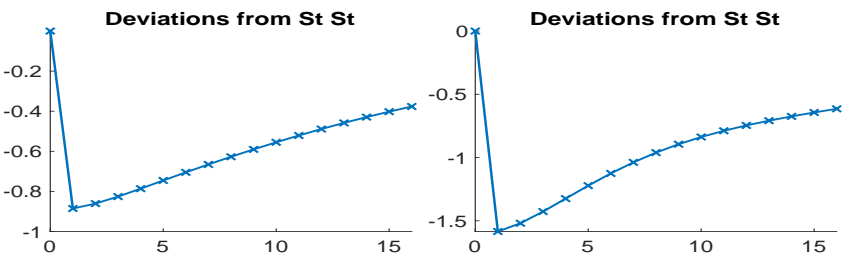

Federal Funds Rate

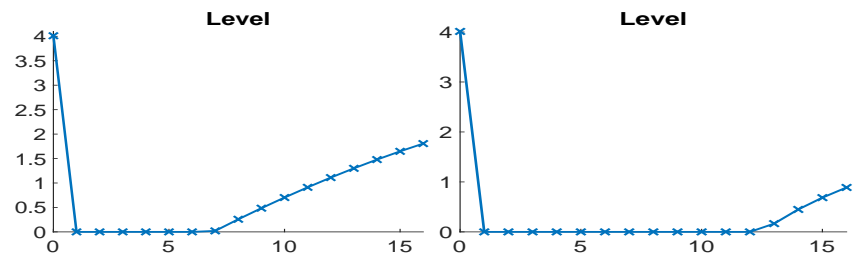

Notes: The figure compares the evolution of output, inflation, and the nominal interest rate in the data (left column) and in the two variants of the model in response to the calibrated liquidity shock (right columns). The first two columns plot the data and model with exogenous patent loss as in Figure 12. Column 3 plots these variables in response to a more persistent liquidity demand shock. The data start in 2008Q3. Both data and model are plotted for 16 quarters. Output in the data (top-left) is the sum of consumption and investment, in percentage log-deviations from a linear trend estimated from 2000Q1 to 2007Q4, and is normalized to zero in 2008Q3. Inflation in the data (middle-left) is the annualized quarterly inflation rate of the GDP deflator minus $1.6 \%$. Value of $1.6 \%$ is chosen for the model to hit a steady state nominal interest rate of $4 \%$. The interest rate in the data (bottom-left) is the annualized effective Federal Funds Rate. Output in the model (top-right) is the log-deviation from steady state in percentage points. Inflation in the model (middle-right) is expressed in annualized percentage points. The interest rate in the model (bottom-right) is the annualized level of the nominal interest rate in percentage points (the horizontal line is its steady state value). 
Figure 18: Response of Consumption, Investment, R\&D Investment, and Convenience Yield to the Liquidity Shock with 12 quarters expected ZLB duration

Data

Model

\section{Consumption}
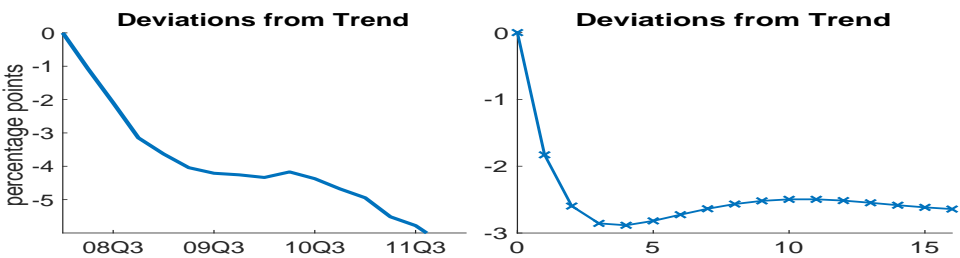

Convenience Yield
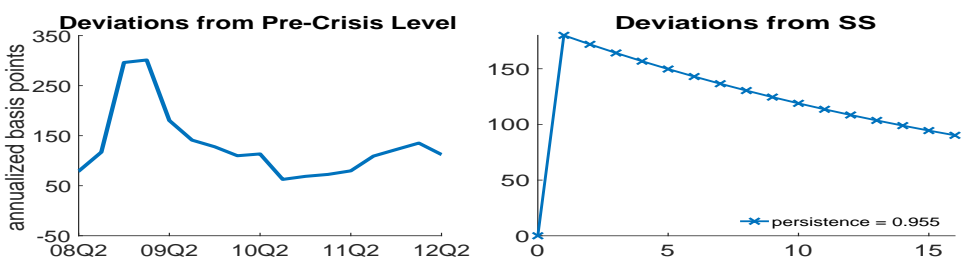

Data

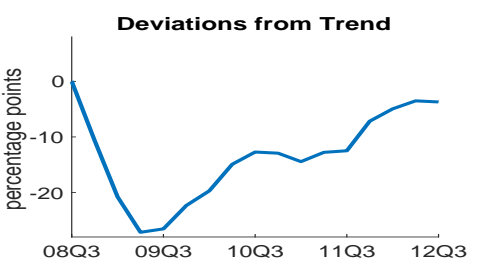

R\&D Investment

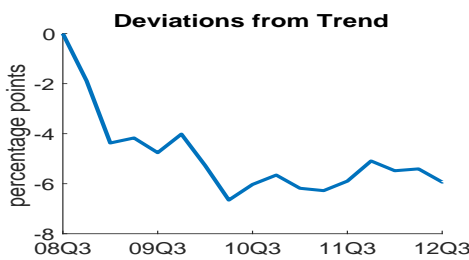

Model

Investment

Note: The figure compares the evolution of consumption, investment, R\&D investment, and convenience yield in the data (left column) and in the model in response to the calibrated liquidity shock (right column). Column 1 plots the data counterpart of these variables as reported in Figure 13. Column 2 plots the model evolution under a more persistent liquidity demand shock. The ZLB binds for 12 quarters. The data start in 2008Q3. Both data and model are plotted for 16 quarters. Consumption in the data (top-left) is total consumption minus durable consumption. Investment in the data (top-middle-left) is investment plus durable consumption minus Intellectual Property Investment. R\&D Investment in the data (bottom-middle-left) is the Intellectual Property Investment. These three variables are expressed in percentage log-deviations from a linear trend estimated from 2000Q1 to 2007Q4, and are normalized to zero in 2008Q3. The convenience yield in the data (bottom-left) is in annualized basis points (produced by (Del Negro et al., 2017)). Consumption (top-right), investment (top-middle-right), and R\&D investment (bottom-middle-right) in the model are log-deviations from steady state in percentage points. The convenience yield in the model (bottom-right) is the annualized absolute deviation from steady state expressed in basis points. 